\title{
CRIME AND INDIVIDUAL AND NEIGHBOURHOOD SOCIODEMOGRAPHIC CHARACTERISTICS IN THE CITY OF TORONTO
}

\author{
BY: GABBY LEE
}

BA Geographic Analysis, Ryerson University, 2016

\author{
A MRP presented to Ryerson University \\ in partial fulfillment \\ of the requirements for the degree of \\ Master of Spatial Analysis \\ in the program of \\ Spatial Analysis
}

Toronto, Ontario, Canada, 2017

(C)Gabby Lee, 2017 


\begin{abstract}
:
The overall objective of this study is to determine what neighbourhood and offender-related demographic characteristics impact crime rates in the City of Toronto. By doing so, quantitative and qualitative approaches were implemented in this study. This study includes both property and violent crime datasets from 2014-2016 and census related information from the 2011 Canadian Census. The advancing techniques of Geographical Information System (GIS) has been explored and applied to achieve a thorough understanding of crime occurrences and patterns in the city. Hotspot and Kernel Density mapping were applied to analyze the spatial distribution of crime occurrences and account for spatial autocorrelation. Findings revealed that property and violent crimes across the three years of study showed similar distribution of significant hotspots in the core, Northwest, and East end of the city. An Ordinary Least Square (OLS) regression was conducted to examine the ways in which individual and neighbourhood demographic characteristics predict the effects of crime occurrences. The OLS model was a good predictor for offender-related demographics as opposed to neighbourhood level demographics at the 0.05 significant level. These findings revealed that social disadvantaged neighbourhood characteristics such as low income, unemployment, low education, female lone parent were poor predictors of property crimes but good predictors for violent crimes. However, individual characteristics were
\end{abstract}




\section{Author's Declaration for Electronic Submission of an MRP}

I hereby declare that I am the sole author of this thesis. This is a true copy of the thesis, including any required final revisions, as accepted by my examiners.

I authorize Ryerson University to lend this thesis to other institutions or individuals for the purpose of scholarly research.

I further authorize Ryerson University to reproduce this thesis by photocopying or by other means, in total or in part, at the request of other institutions or individuals for the purpose of scholarly research.

I understand that my thesis may be made electronically available to the public. 


\section{Acknowledgement}

I would like to thank my supervisor Lu Wang for her guidance and support that was provided throughout this MRP. I would also like to thank my co-supervisor Ian Williams and his team in the Business Intelligence \& Analytics unit at Toronto Police Service for their support and valuable insights. Lastly, I want to thank my friends and family for their continuous support throughout my academic career. 


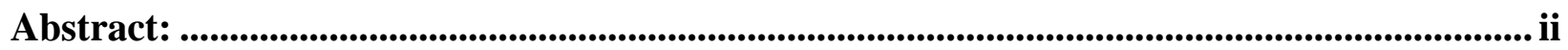

Author's Declaration for Electronic Submission of an MRP ..................................................... iii

Acknowledgement ................................................................................................................................................. iv

TABLE OF CONTENTS …............................................................................................................ $\mathrm{v}$

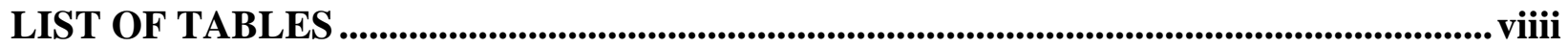

LIST OF FIGURES ....................................................................................................iiii

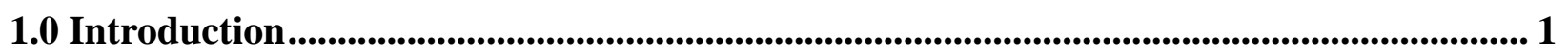

1.1 Study Area

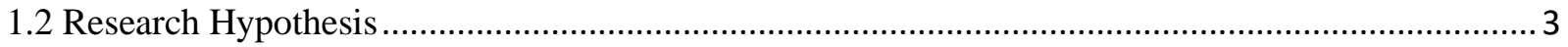

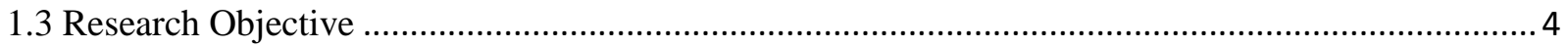

2.0 Literature Review .......................................................................................................................... 6

2.1 Theories and Factors Influencing Crime.....................................................................................

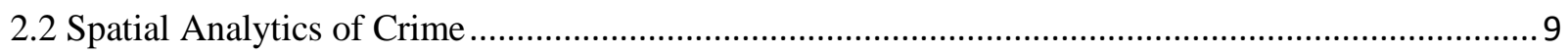

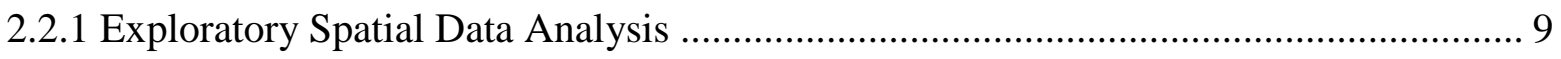

2.2.2 Thematic Mapping and Kernel Density ........................................................................ 10

2.2.3 Hotspot Mapping in Spatial Statistics .......................................................................... 11

2.3 Quantitative Approaches to Crime Analysis ..............................................................................11

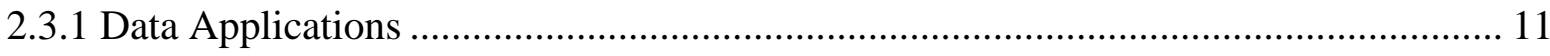

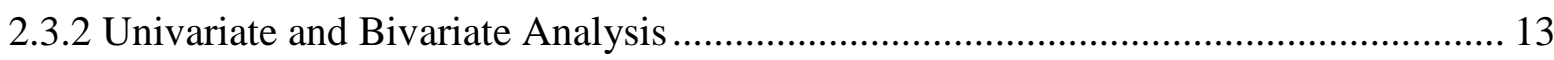

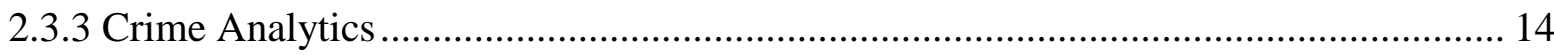

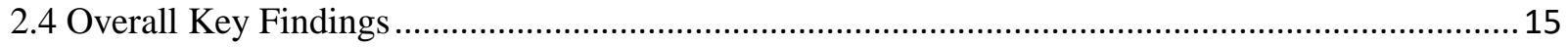

3.0 Data and Methodology .............................................................................................................. 17

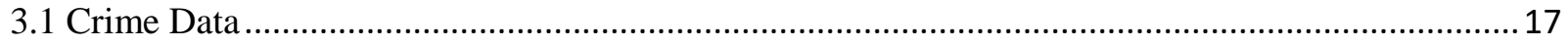

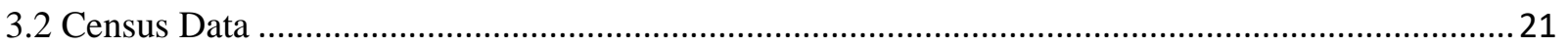

3.3 Crime Rates and Distance Calculation......................................................................................2

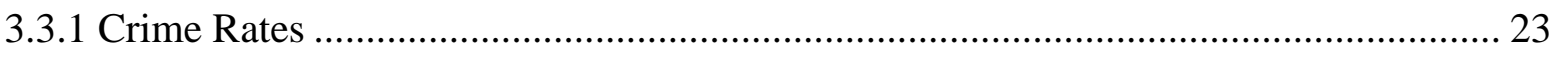

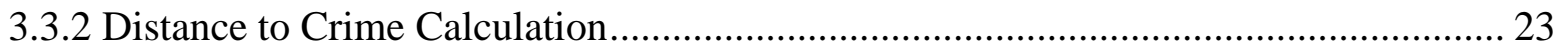

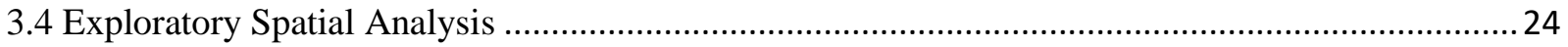

3.4.1 Thematic Display and Heat Mapping ......................................................................... 24

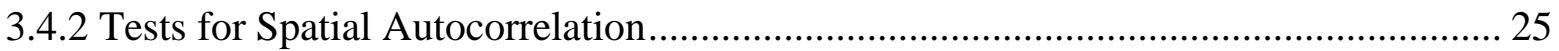


3.4.3 Local Indicator of Spatial Association ............................................................... 26

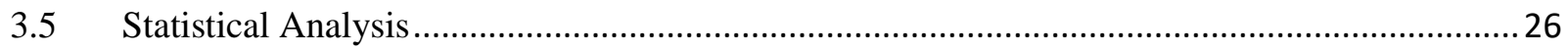

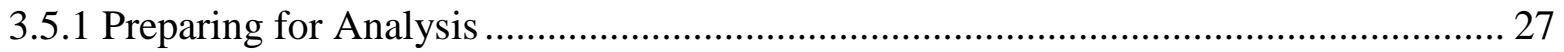

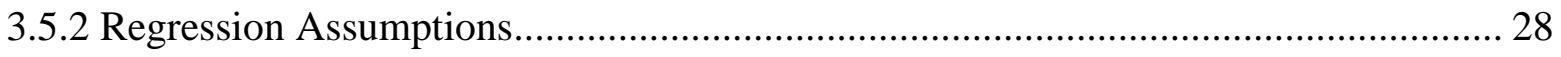

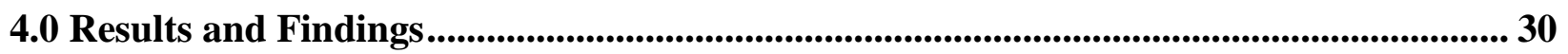

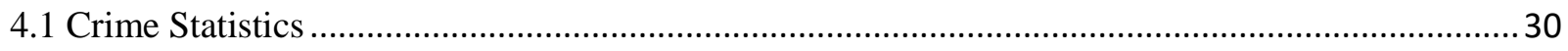

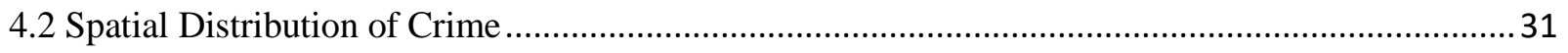

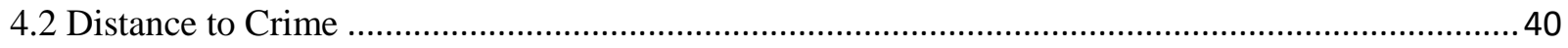

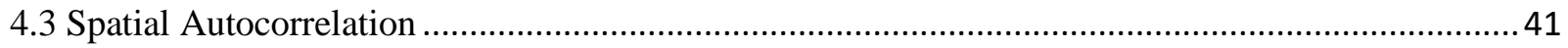

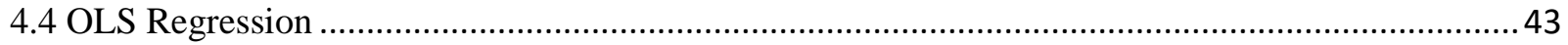

4.4.1 OLS Regression on Neighbourhood Characteristics .......................................... 43

4.4.2 OLS Regression for Individual and Neighbourhood Characteristics ........................ 45

5.0 Discussion, Limitations, and Future Research .......................................................50

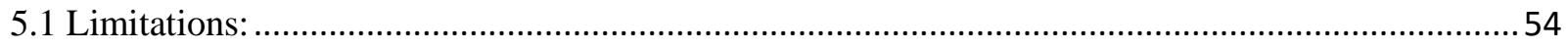

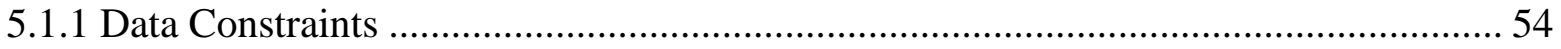

5.1.2 Modifiable Areal Unit Problem .................................................................................. 55

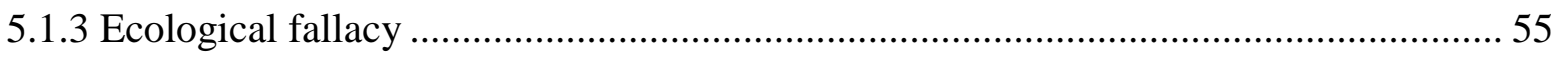

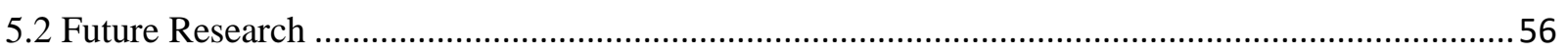

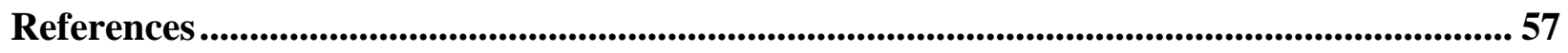

Appendix A

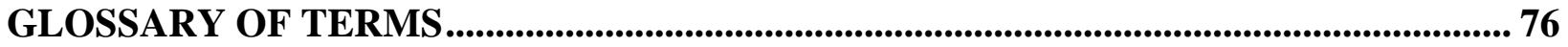




\section{LIST OF TABLES}

Table 3.1. Major Crime Indicators and Demographic factors of Offenders Charged

Table 3.2. Justification for Selected Census Variables

Table 4.1. Total Number of Property and Violent Crimes, 2014-2016

Table 4.2. Number of Property and Violent Crimes Committed by Offenders Charged 2014-2016

Table 4.3. Number of Offenders Charged that reside in the City of Toronto, 2014-2016

Table 4.4. Demographic Characteristics of Property and Violent Crime Offenders, 2014-2016

Table 4.5. Distance to Crime Statistics

Table 4.6. Spatial Autocorrelation of Property and Violent Crimes, 2014-2016

Table 4.7. Linearity Relationship of Property and Violent Crimes

Table 4.8. Normality and Significance for Logged Violent Crime Rate, 2014-2016

Table 4.9. Bivariate Correlation of Neighbourhood Independent Variables

Table 4.10.OLS Regression Coefficients and Multicollinearity Diagnostic for Logged Violent Crimes, 2014-2016

Table 4.11. Skewness and Kurtosis Statistics After Transformation

Table 4.12. Bivariate Correlation of Logged Property Crime Rates and Independent Variables

Table 4.13. Bivariate Correlation of Logged Violent Crime Rates and Independent Variables

Table 4.14. OLS Regression Coefficients for Logged Property Crime Rates, 2014-2016

Table 4.15. OLS Regression Coefficients for Logged Violent Crimes, 2014-2016 


\section{LIST OF FIGURES}

Figure 4.1. Property crimes per 100,000 persons by Neighbourhood, 2014

Figure 4.2. Property crimes per 100,000 persons by Neighbourhood, 2015

Figure 4.3. Property crimes per 100,000 persons by Neighbourhood, 2016

Figure 4.4. Violent crimes per 100,000 persons by Neighbourhood, 2014

Figure 4.5. Violent crimes per 100,000 persons by Neighbourhood, 2015

Figure 4.6. Violent crimes per 100,000 persons by Neighbourhood, 2016

Figure 4.7. Kernel Density of Residential Locations of Offenders Charged with a Property Offence, 2014-2016

Figure 4.8. Kernel Density of Residential Locations of Offenders Charged with a Violent Offence, 2014-2016

Figure 4.9. Distribution of Property Crimes and Percentage of Census Predictors

Figure 4.10. Distribution of Violent Crimes and Percentage of Census Predictors

Figure 4.11. LISA Statistics Map for Property Crimes, 2014-2016

Figure 4.12. LISA Statistics Map for Violent Crimes, 2014-2016 


\subsection{Introduction}

Crime is important to study and monitor to help identify trends and relationships to patterns and activities pertaining to crime (Wheeler, 2016). These values have been adapted from police organizations nationally to develop core strategies to policing and further develop a reliable relationship with the public community (Braga, 2016). Thus, it is important to recognize that factors influencing crime is not solely internal but external as well. Factors commonly recognized in crime analysis were demographic characteristics because it has been shown to impact the involvement of crime and serve as an antecedent to crime (Arnio \& Baumer, 2012). More importantly, when studying the distribution of crime patterns and demographic characteristics, studies have shown that crime is not random within cities but rather concentrated within specific neighbourhoods (Charron, 2011; Lersch \& Hart, 2011). Existing literature have examined the association between crime and sociodemographic characteristics and found that neighbourhoods with high crime rates also had higher levels of economic disadvantages, higher proportions of young people, and greater residential instability (Thompson \& Gartner, 2014). This is why it is important to continue studying the spatial demographic patterns between neighbourhoods and crime occurrences as population changes continuously. Braithwaite (1975) found that population growth and the increase in urban density has resulted in higher crime occurrences due to an increase in opportunities and reduction in social cohesion.

This research takes a spatial and statistical approach to explore the relationship between the spatial patterns of crime occurrences and the economic, social, and demographic factors that influence both property and violent crimes. The Annual Statistical Report (2012) defines an offence that includes a threat of application with force to a person which includes homicide, attempted murder, sexual assault, non-sexual assault, other sexual offences, abduction, and robbery. A property crime is defined as an unlawful act committed to obtain or interfere with the use of property but does not include a threat/use of violence against an individual; these include the attempt and act of a motor vehicle theft, other theft, break and enter, stolen property, mischief and fraud (Annual Statistical Report, 2012). Demographics pertaining to the offender and neighbourhood characteristics was included. For full definition of terms used in this study, refer to the Glossary of Terms. Spatial analytical methods within a Geographic Information System (GIS) was applied in this study to illustrate patterns, trends, hotspots and density of crime occurrences. Statistical techniques were applied to further predict for selected demographic 
characteristics that effect the rate of property and violent crimes. Crime patterns were important to study to better develop crime reduction strategies, allocate policing resources, and maximize safety within a community (Johnson et al, 2014). This study also supports scholarly research in crime applications, crime analysis strategies, and theoretical frameworks revolving around the field of criminology.

\subsection{Study Area}

This study focuses on crime patterns within the City of Toronto, Ontario which is the largest city in Canada with a total population of 2,731,571 as of 2016 (Statistic Canada, 2016). However, due to unreadily available census data for 2016, attributes from the 2011 census data was used. In 1998, the municipal government restructured Toronto to combine seven large municipalities and to further improve the municipal and provincial responsibilities (City of Toronto, n.d.). The City of Toronto is located Northwest of Lake Ontario and consists of four city-wide ward boundaries which are: Etobicoke-York, North York, Toronto East York, and Scarborough. The City of Toronto is projected to rise to 3.64 million by 2041 following rapid growth since the mid-1970s (City of Toronto, n.d). The current highest number of persons fall between the age group of 25 to 29 years of age, compared to the younger group between 20-24 in the 1970s (Ostler 2014). Age groups have shifted over time within the city's structure. There were currently more people over the age of 65 than there were people under the age of 15 in Toronto. From the previous 2011 census, the number of older adults in Toronto continues to rise (City of Toronto, n.d.).

In addition to Toronto's high population density, it is perhaps one of the most multicultural and diverse cities in the world. Over 140 languages and dialects were spoken here, and just over 30 per cent of Toronto residents speak a language other than English or French at home (City of Toronto, n.d.). Additionally, some of the most affluent areas were located in the downtown core; these areas have a lower recent immigrant population (Kern, 2005). Areas outside of the downtown core also known as the inner suburbs have become the destination for immigrant settlements (Siemiatrycki \& Isin, 1997). The number of Toronto families living in poverty has also increased by $36.1 \%$, the number of individuals living in poverty has increased by $5.3 \%$ and waiting lists for affordable housing has swelled to over 150,000, with average waittimes reaching an all-time high of eight years (Hudson \& Graefe, 2011). 
This study focused on the analysis of crime at a neighbourhood level. Stein et al (2015) recognizes that crime is suitable to study within pockets of neighbourhoods because people were mostly influenced by their immediate surroundings rather than at a larger scale; this highlights the role of opportunities in criminal activities. In the City of Toronto, there are currently 140 neighbourhood profiles with an average of about 4,000 persons (City of Toronto, n.d.). Boundaries were created to be as versatile as possible for any user and were not intended to make judgements (City of Toronto, n.d).

\subsection{Research Hypothesis}

Existing literature from similar studies provided rationale for developing three of the following hypotheses for this study:

Hypothesis 1: property and violent crimes tended to cluster in the same neighbourhoods over time and space across the three years of analysis

Hypothesis 2: low-income neighbourhoods in the City of Toronto experienced higher levels of crime activities for both violent and property offences

Hypothesis 3: demographic factors such as female, married or common-law, and seniors are expected to have a weaker effect on crime rates

The first hypothesis refers to the spatial stability of crime occurring in certain neighbourhoods over time. A study conducted in Glasglow, Scotland found that neighbourhood and crime activity trends/patterns tend to influence and recommence individuals to offend (Livingston et al, 2014). In other words, a neighbourhood that is prevalent for criminal activities were attractive locations for crimes to occur and likely to follow the same patterns throughout the years. Building upon the impacts suggested from Social Disorganization theory, neighbourhoods that were continuously categorized as disadvantaged in terms of poverty, ethnic, and instability remain highly concentrated with crime. Additionally, Friedson \& Sharkey (2015) goes on to say that high crime occurrences tend to be geographically concentrated in small number of city blocks and neighbourhoods in the core. The concentration of crime tends to occur at certain neighbourhoods and is highly stable over long periods of time (Braga \& Clarke, 2014). Johnson \& Bowers (2008) argued that necessary procedures such as redesigning the physical environment or implementing proper crime reduction strategies is needed to change the stability of crime hotspots reoccurring in the same neighbourhoods. Therefore, it can be hypothesized that 
crime patterns were consistent in terms of spatial trends for the three years (2014 to 2016) of analysis.

The second hypothesis is built upon the Social Disorganization theory that links elevated levels of crime to neighbourhoods with low socioeconomic status, residential instability, family disruption, ethnic heterogeneity, and routines/behaviours (Vilalta \& Muggah, 2016). A study conducted by Krivo et al (2015) found that crime rates were higher amongst low-income neighbourhoods in eighty-six of the largest cities in the United States. The study associates lowincome with all crime activities, regardless if the incident was a violent or property crime. With similar context, it can be hypothesized that low-income neighbourhoods in the City of Toronto experience higher levels of crime activities for both violent and property offences.

The last hypothesis was generated from reoccurring studies that have found correlation between certain gender, marital status, and age cohort that induces lower and higher crime rates. Loinaz (2014) found a comparable difference between male and female offenders in which females tend to commit less crime when compared to males. A study conducted in China analyzed the activities of female offenders since the 1980s and acknowledged that although female offending has increased, it continues to be less occurring when compared to male offenders (Shen \& Winlow, 2014). Additionally, Van Mastrigt \& Farrington (2009) looked at offenders in North England and found that offending and co-offending significantly decreased as age increased. Multiple studies also found that married persons were less likely to commit crime when compared to single persons (Barnes et al, 2014; Jung et al, 2015).

\subsection{Research Objective}

There were many existing studies and evidence that associates crime with social, geographical, economical, political, and environmental factors (Charron, 2011; Fitzgerald et al, 2004; Kuo \& Sullivan, 2001). However, because there were multiple circumstances and opportunities that influence an offender to commit an offence, it becomes difficult to solely pinpoint one attribute influencing crime. Every case and scenario is different, but there were factors that were persistent and continuous in terms of trends and patterns the exist amongst this specific context of crime. With Toronto's growing population it is important to investigate the spatial relationship between socioeconomic characteristics in relation to crime to further understand the structural features of each neighbourhood. 
This research seeks to address two main objectives:

1) To determine the clustering of crime occurrences and hotspots in the City of Toronto; and

2) To explore the types of individual and neighbourhood socioeconomic characteristics that impact property and violent crime rates

This study uses an exploratory and quantitative analysis that includes both spatial and statistical approaches to address the above objectives. The first objective was addressed by analyzing hotspots and density of crime occurrences for each categorized crime events (violent and property). This determined the relationship between the concentrations of crime occurrences to the different levels of socioeconomic factors within a neighbourhood. The second objective was addressed by determining the types of predictor variables that influence crime rates by applying an OLS Regression. This objective was first completed by applying the neighbourhood predictors against the crime rate. A second model was then applied by including both individual and neighbourhood predictors against the crime rates in the regression. These outcomes were to align with theories as proposed by Social Disorganization that crime tends to concentrate in areas that have high proportion of low-income, lower education, marginalized and disadvantaged neighbourhoods. 


\subsection{Literature Review}

There were many existing theories and applications that have been adapted over the years when conducting crime analysis. Applying geographical techniques has enabled researchers to examine the association between crime and social, economic, and physical characteristics. The use of geographical information system continues to evolve as more alluding approaches were used to identify the relationship between crime and space. Crime activities were said to be unevenly distributed over space; the occurrence of crime is concentrated in certain places and relate to a variety of socio-economic and crime opportunity factors (Wang et al, 2013). A review of literature has been examined to conceptualize the underlining nature of criminal activities in relation to socio-economic influences. This literature is broken down in to its categories to define and emphasize the key features within this research. The four categories addressed are theories and factors influencing crime, spatial analytics of crime, qualitative approaches to crime analysis, and a final summary of literature.

\subsection{Theories and Factors Influencing Crime}

Many theories explaining the causation of crime in the early twentieth century has shifted away from biological and psychological causes of human behaviours but rather more towards social environmental explanations (Zembroski, 2011). Historical explanations that are classified as structuralist reflect the factors in the social, economic, and political environments as a way to explain crime and delinquency by emphasizing objectivity over subjectivity (Fitzgerald, 2011). That is, social structures and society has evolved over the years to further cause a shift in crime patterns. Fitzgerald (2011) goes on to state that the industrialization era caused more property crimes to occur and as neighbourhoods became more heterogeneous, there was an increase in the perception of crime.

Police officers are the primary law enforcers that are exposed to and are familiar with crimes and apprehensions. From a generalized theory, interviews were conducted amongst police officers to determine factors influencing crime. The overall consensus was that street crimes are affected by weather, crimes against property by economic conditions, crimes against person(s) by racial and class composition, delinquency by family/peer group controls (Allen \& Jacques, 2013). In addition to these subjective opinions, there are existing theories that build upon this foundation. Social Bond and Control theory suggests three major factors that contribute to criminality, which are, self-control, parental management, and opportunities for deviance 
(Lindberg et al, 2017). This theory focuses on the internal impacts influencing criminal activities such as poor childhood development and lack of supportive resources. As a result, the external factors influencing crime can be linked to Rational Choice theory which considers a cost-tobenefit analysis where benefits are greater than costs in the line of action (Pratt, 2008). That is, if an individual sees that there are greater benefits in a robbery occurrence, this would impact their decision in committing a criminal act. If the perceived benefits of the crime outweigh the costs, committing the crime is a rational choice (Deller \& Deller, 2010).

Another theory that developed during the transition is Social Disorganisation theory which focuses on socio-economic dimensions such as economic disadvantages and ethnic heterogeneity (Osgood \& Anderson, 2004). It is used in crime analysis to understand the influences of social cohesion/social capital to understand crime rates at a neighbourhood level (Kawachi et al, 1999). If social norms, networks, and integration decline and the lack of social control impacts criminal activities, this bond weakens and crime increases (Deller \& Deller, 2010). Some theorists even affiliate Social Learning theories to further reinforce this theorem. Social Learning theory states that individuals are attracted to crime because they associate themselves with others who teach, praise, or are in favour of crime (Agnew, 2016). Similarly, Social Contagion Theory proposes that the behaviour in one person is influenced by another within the human social network (Christakis \& Fowler, 2013). Thus, it can be said that social cohesion and economic disadvantages are pulling factors whereas the pushing factors are the influencers the offender is associated with.

The theories mentioned about serve as explanatory concepts that evaluate factors influencing criminal activities. Routine Activity Theory is unlike the previous theories mentioned as it suggests that crime occurs when there is a convergence between space and time of three important elements: a motivated offender, a suitable target, and lack of capable guardian (Breetzke \& Cohn, 2013). A motivated offender is an individual that is attracted to or drawn to certain social/environmental temptations but are not necessarily actively looking to commit an offence (Musataine \& Teksbury, 2009). A suitable target is defined as someone who is vulnerable or perceived as attractive or rewarding to an offender (Popp, 2012). A capable guardian can include any individual that can influence or prevent an individual from committing a potential criminal act; this guardian can be any individual including an acquaintance, family member, etc (Hollis-Peel, 2011). This theory ties in Social Disorganisation, Social Learning, and 
Social Bond \& Control theory to explain for the factors manipulating the offender and further increasing the risk of criminal activities. Essentially, this approach emphasizes the idea that certain types of crime occur at different circumstances rather than understanding the characteristics influencing crime; where previous theories have argued (Argun \& Daglar, 2016) This theory is built upon the foundation that suggests crime increases as opportunities increase from time and space for an offender.

Coherently, Lifestyle Theory suggests that crime occurrences are related to demographic variables because these characteristics are related to the offender's lifestyle (Soo Chon, 2017). Some of the important sociodemographic variables to consider include: gender, age, social class, marital and employment status (Soo Chon, 2017). Lifestyle Theory is also behavioural in terms of the daily activities that the offenders are involved in such as their work, school, housing conditions, and leisure activities (Maxfield, 1987).

Understanding the variation and spatial patterns of crime can be constructive to identify areas with relative deprivation, low socioeconomic status and lack of opportunities (Braga \& Clarke, 2014). These factors are generalizations and are popular amongst many researches; however, there are other factors that may influence crime in certain neighbourhoods. More importantly, many studies have identified "that the concentration of crime at particular places is highly stable over long periods of time" (Weisburd et al, 2004). In addition to this theorem, Walters (2015) used recidivism to predict future criminal behaviours from past criminal behaviours and argues that socioeconomic status and social behaviours such as age, gender, race, pre-adult antisocial behaviour, family structure and intellectual functioning attribute to risk factors amongst offenders. If criminal activities are likely associated with disadvantaged neighbourhoods or issues pertaining to poverty and exclusion, then analyzing the sociodemographic variations within an area explain for those causes. In a study conducted by Seddon (2006), he argues that drugs and crime tend to blight the poorest communities and neighbourhoods but also acknowledges that drug related crimes could occur at all social levels; but more relatively among areas already suffering from multiple socio-economic difficulties.

Since the nineteenth and early twentieth century, researchers believed that criminals exhibited genetic strains and biological features that impacted their decision to commit a crime (Roth, 2010). However, this has evolved overtime to suggest that common theories such as the ones mentioned above are causing crime in certain neighbourhoods. Needless to say, crime is 
concentrated in certain areas. This is supported by Braga \& Clarke (2014) which stated that criminal opportunities are high depending on the facilities such as bars, site features such as attractiveness, offender mobility such as accessibility to many targets, and target selection such as rationality to commit the offence. These theories exhibit certain characteristics, dynamics, and situations that suggest the effects of crime to concentrate in particular neighbourhoods (Braga \& Clarke, 2014).

\subsection{Spatial Analytics of Crime}

Some of the familiar challenges that are faced with crime mapping are the confidential or private policies that are disclosed when applying crime data. Kounadi \& Leitner (2015) uses the term geoprivacy to define the privacy of personal information while maintaining two main aspects - protecting private information regarding location and developing location protection methodologies to avoid information disclosure. It is then essential for the purpose of this research to be subsequent in the methodologies applied for integrity purposes. However, mapping is a constructive method to visually represent crime data. Below are some of the crime mapping benefits that Ratcliffe (2002) suggests:

1. Crime maps that are accessible to the public increase community knowledge and further increase community co-operation

2. Crime maps can assist in community policing and problem solving

3. Crime maps can increase public awareness about neighbourhood characteristics

4. Quality data provisions can help prevent its figures from being misinterpreted

\subsubsection{Exploratory Spatial Data Analysis}

Nonetheless, mapping can provide illustrations on patterns of crime occurrences and demographics at a geographical unit of study. The term exploratory spatial data analysis (ESDA) is commonly used in the field of GIS and have been defined as "a phase of analysis in which spatial patterns and structures are revealed, hypotheses proposed, and models suggested" (Wilson \& Greenlee, 2016). Messner et al (2013) also address in their study that ESDA can identify spatial dependence, spatial heterogeneity, spatial autocorrelation and to determine significant clustering. These terms are related and associated with ESDA because they can determine at what degree are points similar and dissimilar; clustered or dispersed. Analyzing the existence of spatial dependence improves the predictive performance of the multiple linear regression model (Lopes et al, 2014). Spatial dependence and spatial autocorrelation are 
intertwined as they measure the correlation and direction of associated values. A positive spatial autocorrelation exists when similar values occur near one another and a negative spatial autocorrelation exists when there are dissimilar values around each other (Shen, 1994). Essentially, spatial dependence can be explained by spatial autocorrelation using the spatial statistics Moran's I whereas spatial heterogeneity refers to spatial differences (Zhang et al, 2011). Spatial analytical techniques such as thematic mapping and different forms of hotspot analysis was appropriate to investigate the spatial relationship of crime occurrences across the City of Toronto.

\subsubsection{Thematic Mapping and Kernel Density}

One of the more generic forms of mapping is thematic mapping and is used to show the spatial variation and patterns of occurrences from a ranking system. This type of analysis stems upon a classification method where the colour gradient diminishes as the value lowers. Prior to more advanced statistical hotspot mapping, thematic mapping is beneficial to get a general scope of the high and low distributions of events across the study area (Smith, 2016). There are several types of classifications to display the level of intensity and these are: natural breaks, quantiles, equal intervals, and standard deviation (Murray et al, 2001). Each method represents data differently and is subjective to the choice of the researcher. Crime occurrences are provided in raw counts and can obscure the spatial patterns when population varies in size (Erdogan et al, 2013). Therefore, it is also important to consider a proper approach to maintain raw count data to avoid misrepresentation of data. Standardization from aggregated crime occurrences by neighbourhoods overcome this issue through comparable results by a rate of total population (Boscoe \& Pickle, 2003). A study conducted by Quick \& Law (2013) looked at drug offence rates per 1,000 in the City of Toronto and found that there were high clustering in the downtown core, west side and smaller clusters on the east side.

Similarly, a kernel density analysis generalizes discrete data values so that the data is represented on a continuous surface area (Hart \& Zandbergen, 2014). This method takes point distributions and generates a density value based on a colour gradient (Nakaya \& Yano, 2010). This tool is flexible in terms of setting parameters which include grid cell size and bandwidth but there is no specified rule under an circumstance (Chainley et al, 2008). Kernel density analysis has been highly executed in crime analysis to locate the concentration of crime occurrences. In his work, Gerber (2014) found that crimes often occur in the vicinity of past crimes which makes 
a tool such as kernel density a valuable crime prediction tool. Thematic mapping and kernel density mapping are merely used to show the intensity of crime occurrences but are limiting because it does not provide further explanation to the occurrences. However, it remains a popular and beneficial tool amongst researchers to access a visually impactful representation of data variations.

\subsubsection{Hotspot Mapping in Spatial Statistics}

There are many techniques available to identify the location of hotspots, however, the following techniques discussed are commonly used in crime analysis. One of the techniques is known as the Moran's I Statistics. There are global and local methods, however, local methods are more advantageous because it identifies the specific location of clusters and measures significance against the null hypothesis for all apparent clusters (Quick \& Law, 2013). The Local Moran's I statistics is used to test for spatial autocorrelation and indicates whether or not there is evidence of clusters or dispersion in the aggregated area (Wilson \& Greenlee, 2016). This statistic is associated with the local indicator of spatial association, also known as LISA statistics. The LISA statistics falls into four distinct categories: high-high, low-low, high-low, and low-high. High-high includes a location with a above average value in and within its surrounding, low-low includes a location with a below average value in an within its surrounding, high-low when a location is above average but surrounded by below average values, and low-high when a location is below average but surrounding by high average values (Flores \& Villarreal, 2015). In his study, Andresen (2015) looked at the clustering of crime in Vancouver by implementing the local Moran's I statistics and found that much of the clustering was insignificant but found that hotspots were present in poorer areas with lower income. Similarly, Cheong (2012) using local Moran's I to examine physical disorder of an area (poorly maintained houses, trash) in relation to violent crimes in Lansing, Michigan and found that the State Capitol and southwestern region had high significant hotspots.

\subsection{Quantitative Approaches to Crime Analysis}

\subsubsection{Data Applications}

Crime data can be complex and ambiguous, however, many existing literatures choose to categorize crime between violent and property. These two primary categories allow unique opportunities for analysis and comparisons (Diefenbach \& West, 2001). A study conducted by Brantingham (2016) found that crime is not uniformly distributed across space. Additionally, 
Schreck et al (2009) examined the different spatial distributions between violent and property crimes and found that there is a distinct difference in neighbourhood characteristics relative to the type of crime. This further renders the decision in this study to explore the two crime types separately. These type of neighbourhood characteristics are associated to the theories and factors influencing crime as mentioned above and are worth exploring in this study.

In terms of analysis, there are several important socioeconomic characteristics that were frequently used and deemed relevant to determine the association with crime rates. These factors generally include age, gender, marital status, education, low-income status, employment rates, family structure, and ethnicity (Cook et al, 2014). Different age cohorts are relatively apparent in the study of crime due to distinguishing social features amongst age groups. It is suggested that the 'old' are seen as weak, vulnerable, fearful and the 'young' are viewed as strong, fearless, and more likely constructed as the perpetrator rather than the victim (Tulloch, 2000). A study that examined crime rates based on age groups found that the age range 18-29 committed more crimes when compared to older age groups (Mundia et al, 2016). Gender is amongst one of the popular variables assessed in crime. Many researchers have conducted studies to address the gender ratio problem or the gender generalization issue (Kruttschnitt, 2013) This idea is built upon the fact that there is a large difference in crime rates between men and women where women are less likely to commit crime than men (Steffensmeier \& Allan, 2002). In addition to crime involvement, Fox et al (2009) found that not only are women less likely to commit crime but they are also more likely to be victimized when compared to men. Marital status is also a variable that is highly studied in crime; many research have concluded that married persons are less likely to commit crime when compared to non-married persons (Barnes et al, 2014). In contrast, Jung et al (2015) found that being married was significantly related to both property and violent crimes. Both studies applied statistical techniques and found contradicting findings which makes it a variable worth exploring in this study.

The factors above are some of the most common individual demographic characteristics that are studied, however, social disorganization theory suggests that external ecological factors are associated with crime rates in a neighbourhood. Some of the important ecological factors that are commonly associated with crime rates include low education, low income, unemployment, and lone parent female. In correlation, many researchers have linked the relationship between the level of education to high crime rates. That is, higher education yields social benefits and further 
reduces crime (Machin et al. 2011). Economic prosperity was amongst one of many factors that motivated offenders to commit crime (Vandeviver et al, 2015). Essentially, higher educated individuals are more likely to earn more than individuals with lower education (Groot \& Van Den Brink, 2010). In his study, Veselak (2015) associates high school diploma and no education to higher crime rates. As previously mentioned, income is a factor that is also highly associated with crime rates. Hipp \& Yates (2011) found that crime increases exponentially in neighbourhoods with higher poverty rates. Depending on the study region, there are different thresholds that measure poverty. Analyzing the impact of poverty against crime rates can indicate various results across different time and space. A study conducted by Papaioannou (2017) found that applying ordinary least square regression was bias and underestimated the relationship of poverty on crime rates.

Unemployment rate also coincides with the social disorganization theory and is a factor that many researchers have demonstrated as a positive association to crime. Unemployment is worth exploring in this context because property crimes are highly economically driven as opposed to violent crimes where it is rarely economically motivated (Nordin \& Almen, 2017). Lone parents are amongst the social groups that are most susceptible to debt (Hinton-Smith, 2016). More specifically, lone mothers are viewed as disadvantaged in terms of having lack of adequate social and economic resources (Russell et al, 2008).

In their study, Moore et al (2016) uses three different levels of measure (individual, family, and neighbourhood) to analyze neurocognitive performance using census and crime data. Similarly, the dataset were provided in counts, hence it was necessary to convert the selected variables in to percentages by diving it by the neighbourhood level to remain consistent and suitable for statistical applications.

\subsubsection{Univariate and Bivariate Analysis}

There are several common quantitative methods that currently exist in research that relate to crime and sociodemographic principles. Prior to exploring different techniques and methods applied, it is important to understand the types of datasets associated in the analysis. In their study, Lipsky (2012) examined racial and ethnic disparities of perpetrators and incident characteristics by applying a mixed method approach that highlights the importance of applying a univariate and bivariate analysis. A univariate analysis is beneficial to understand the general statistics of the data and is commonly applied prior to advanced statistical modelling. The 
univariate analysis is independent and measures the statistical uniqueness of a single variable (Lie \& Zhu, 2017). In conjunction, a bivariate analysis is used to determine the correlation between two variables. The bivariate analysis is important to determine the significant correlation amongst variables to determine the level of association for a model (Jung et al, 2015). A Pearson's correlation can aid in determining the association amongst variables based on significance and strength. This correlation is used to quantify the linear relationship between two variables and takes any values in between -1 and 1 . A negative value explains for a negative association where a value nearest zero indicates a weak relationship and vice versa (Giroldini et al, 2016). Pearson's correlation is applied after testing for normality and before a regression analysis for the purpose of testing for multicollinearity and strength between selected variables (Laerd Statistics, n.d.). Additionally, Fornango (2010) ran a correlation between demographic factors and violent crimes and found that variables such as poverty, female lone parents, unemployed males were positively correlated.

\subsubsection{Crime Analytics}

Applying appropriate methods and techniques to crime studies provides a better understanding in the interactions that reflect true clustering and effects on crime patterns. Integrating sociodemographic characteristics are amongst the most popular methods used to determine frequencies and relationships in crime occurrences (Wallace et al, 2006; Savoie, 2008; Charron, 2011). As previously mentioned, there are many theories that explain and provide reasons that influence an individual to commit a criminal act. Many research implement a variety of methods to truly capture critical findings such as applying surveys, analyzing historical research, or deploying fieldwork investigations. However, perhaps the most popular analytical technique would be applying a regression model. Regression models are used to predict and explain for a set of variables or measures that influence criminal activities. Ideally, it takes a set of predictor variables and determines if there are any significant relationship to the dependent variable. For example, the effects of low income on crime rates.

There are many regression models that have been used on count data in crime analysis, however, OLS regression is amongst one of the commonly used models (Atkins \& Gallop, 2007). Other popular crime models that integrate regression when handling count data are the Poisson regression and Logistic Regression. Although there have been many criticisms on the applications of OLS regression, the method continues to be used and validated amongst many 
researchers. Sturman (1999) analyzed count data using various regression models and found that OLS regression with and without logged transformation did not produce more false conclusions when compared to the Poisson, Tobit, and Negative Binomial regressions. Often, crime count data are represented as rates along with a logged transformation to reduce bias in the analysis and minimize outliers (Andresen, 2012). In an OLS regression, log transformation is applied to the dependent variable to normalize the residuals and further correct for linearity (Atkins \& Gallop, 2007). In a study conducted by Entorf \& Sieger (2014), they found that unemployment rate was

insignificant in the OLS regression. They also found that the mean and median were impacted by skewed crime distributions, additionally there were insignificant results for assault when OLS regression was applied.

A more complex approach to regression analysis would be applying individual and neighbourhood characteristic in the model. That is, both individual and neighbourhood sociodemographic characteristics serve as the predictor and crime rates are the dependent variables. A study conducted by Scarborough et al (2008) looked at the relationship between individual and neighbourhood demographic characteristics to predict the fear of crime. Their method included an OLS regression on individual demographics alone and then an inclusive model with both individual and neighbourhood characteristics. Additionally, multiple levels of analysis can also be integrated in a regression model. Porter et al (2011) uses individual, community and county level characteristics to predict neighbourhood fear of crime. Essentially, regression models are valuable and fundamental to determine factors causing crime occurrences. The flexibility in measurement, factors, and unit of analysis is what makes it a popular method used by many researchers to this day.

\subsection{Overall Key Findings}

There are many published literatures on the analysis of sociodemographic characteristics and property or violent crimes. The array of literature available has opened up different geographical and social factors that can be explained for crime occurrences in urban and rural settings. In relation to social disorganization theory, certain sociodemographic characteristics have been common predictors for both violent and property crimes, such as low income, low education, and low education attainment (Kitchen, n.d.). Additionally, many research has found that certain characteristics such as age, gender, and marital status have been significant to crime involvement (Bunch et al, 2015). These are important characteristics that are commonly found in 
studies from the United States and Canada. However, there are limited number of research in Canada that integrates ethnicity as a predictor factor. Ethnicity is perhaps one of the most signified and used variable to explain for crime in the United States (Cook et al, 2014; Hollis, 2016; Lyons, 2008). Crime studies in the United States and Canada differentiate in this aspect, however, Canadian literature continues to progress and this further poses the need to expand and broaden the techniques used in this field. 


\subsection{Data and Methodology}

The data in this study is critical for the purpose of analyzing spatial clusters, distributions, statistical significance, and relationships amongst variables. The datasets that were used in this study were obtained from Toronto Police Service and Statistics Canada. Data and information from Toronto Police Service provides information on the location and select demographic characteristics of offenders charged by property and violent crimes. Data from Statistics Canada provides information about general demographics, social, and economic characteristics of the population residing in the City of Toronto.

\subsection{Crime Data}

All crime data was provided by Toronto Police Service from the Business Intelligence \& Analytics unit. The datasets were retrieved from an internal database known as Versadex, which is a records management software. Two major datasets was evaluated in this study. The first being the overall major crime indicators which has provided the analysis with the overall spatial distribution of property and violent crime occurrences by neighbourhood. The second dataset was the sociodemographic characteristics of offenders charged including their postal code location and the level of offence committed. It is important to note that the dataset provided contains confidential information that is not to be distributed publicly. In accordance with the Municipal Freedom of Information and Protection of Privacy Act which abide to the fact that, "local government institutions shall protect the privacy of an individual's personal information existing in government records" (IPC, 2014). This study has taken the necessary measures to protect the privacy of individuals involved in a crime occurrence. Therefore, all personal identifiers such as name and street addresses were not included in this study and general information has been aggregated to a neighbourhood level to deter and maintain the individual's privacy. Additionally, demographic variables that were deemed relevant to the study but were excluded from analysis because sensitivity include, ethnicity and immigration. Due to the offset of these locations, the reported findings do not guarantee the accuracy and exact location of an occurrence. Additionally, these datasets does not account for those individuals who choose to have their information masked and hidden.

One of the major crime dataset includes detailed information about the offenders who have been charged with an offence under one of the major crime indicators. Refer to Table 3.1 for information that was included in this analysis. This data only includes offenders who have 
been charged over the three years from 2014 to 2016 and excludes information about suspects or person of interest due to the lack of documented information. The coordinates of the residential location of offenders was deliberately offset to the nearest postal code location to protect the privacy of the individuals involved in an occurrence. However, this dataset is critical in this study as it provides the location of residence and offence location, demographic characteristics pertaining to the offender, and the type of crimes committed. To abide with the Municipal Freedom of Information and Protection of Privacy Act, this dataset did not apply postal code level data for spatial analysis but merely for the purpose of measuring distance to a level of crime and type of major crime indicator. However, to leverage this data, the aggregation of coordinates to neighbourhood was implemented to analyze the spatial distribution of offenders in the city. This further enabled a thorough comparison between the spatial distribution of census demographics with demographic characteristics of offenders charged. It is important to note that an offender can have multiple charges laid against them for multiple offences, thus the word offence and occurrences are used interchangeably. For example, an offender could have committed a violent offence and a property offence which was counted as two different occurrences. The following offender characteristics include age, sex, and marital status.

The major crime indicators contain six of the following categories: assault, auto theft, break and enter, robbery, sexual assault and theft over \$5000. A major crime indicator is also associated with a detailed description of an offence which can be found in Appendix A. For the purpose of remaining consistent with existing literature, the major crime indicators were aggregated in to two categories in this study. The first being property crimes and the second being violent crimes. Property crimes included Auto Theft, Break and Enter, and Theft Over. Violent Crimes included Assault, Robbery, and Sexual Assault. Murder were excluded from the dataset because of drastically lower number of occurrences compared to the other major crime indicators. Murders accounted for less than 1\% of all crimes for each year from 2014 to 2016. Therefore, it was determined that the low number of occurrences was not enough to impact the analysis and interpret accurate results. Additionally, property crimes and violent crimes have been separated from previous literatures due to differences in patterns that were worth exploring. Studies have found that these differences include seasonality, travel distance, and predictor models (Cohn \& breetzke, 2017; Ackerman \& Rossmo, 2015; Fitzgerald et al, 2004). This further rendered the decision in this study to explore the two crime types separately. 
The data also provides the categorization under the Canadian Centre for Justice Statistics which aids in determining whether or not an offence was a violation of a property or violent level crime. This dataset also provides two different geographic locations, one for the residential location of offenders charged and the other for the location in which the offence occurred at. In this case, coordinates were spatially joined to the neighbourhood boundary for analysis. 
Table 3.1. Major Crime Indicators and Demographic factors of Offenders Charged

\begin{tabular}{|c|c|c|c|c|c|}
\hline $\begin{array}{l}\text { Variable } \\
\text { Type }\end{array}$ & Data Type & Categories & Description & Justification & Source \\
\hline Unique ID & Numeric & N/A & $\begin{array}{l}\text { Common ID that is } \\
\text { congruent with the } \\
\text { type of event that the } \\
\text { offender charged } \\
\text { committed }\end{array}$ & N/A & N/A \\
\hline Age & Categorical & $\begin{array}{l}17 \text { and } \\
\text { Under } \\
18-34 \\
35-54 \\
55+\end{array}$ & $\begin{array}{l}\text { The age range that } \\
\text { the offender charged } \\
\text { falls under }\end{array}$ & $\begin{array}{l}\text { Different groupings of age } \\
\text { cohorts can help distinguish } \\
\text { and capture offending } \\
\text { patterns such as categories of } \\
\text { offenders (youth, senior, } \\
\text { adult) by type of crime }\end{array}$ & \multirow[t]{3}{*}{$\begin{array}{l}\text { (Arnio \& Baumer, } \\
\text { 2012); } \\
\text { (South \& Messner, } \\
\text { 2000); (Kando, } \\
\text { 2015); (Barnes et al, } \\
\text { 2014); }\end{array}$} \\
\hline Sex & Categorical & $\begin{array}{l}\text { Male } \\
\text { Female }\end{array}$ & $\begin{array}{l}\text { The gender of the } \\
\text { offender charged }\end{array}$ & $\begin{array}{l}\text { Evaluate the } \\
\text { disproportionality of crime } \\
\text { activities regarding the } \\
\text { severity of crime. } \\
\text { Gender differences or gender } \\
\text { inequalities in crime patterns }\end{array}$ & \\
\hline $\begin{array}{l}\text { Marital } \\
\text { Status }\end{array}$ & Categorical & $\begin{array}{l}\text { Single } \\
\text { (Divorced, } \\
\text { Separated, } \\
\text { Widowed, } \\
\text { Single) } \\
\text { Couple } \\
\text { (Common- } \\
\text { Law, } \\
\text { Married) }\end{array}$ & $\begin{array}{l}\text { The marital status of } \\
\text { the offender charged }\end{array}$ & $\begin{array}{l}\text { Marital status effects the } \\
\text { social behaviours of an } \\
\text { individual and influence } \\
\text { desistance from criminal } \\
\text { activities }\end{array}$ & \\
\hline Year & Categorical & $2014-2016$ & $\begin{array}{l}\text { Year the offender } \\
\text { was charged }\end{array}$ & N/A & N/A \\
\hline Postal Code & Geographical & N/A & $\begin{array}{l}\text { The postal code that } \\
\text { the offender resides } \\
\text { in }\end{array}$ & N/A & N/A \\
\hline $\begin{array}{l}\text { Residential } \\
\mathrm{X} \\
\text { Coordinate } \\
\end{array}$ & Geographic & N/A & $\begin{array}{l}\text { X coordinate of the } \\
\text { offender's residential } \\
\text { postal code location }\end{array}$ & N/A & N/A \\
\hline $\begin{array}{l}\text { Residential } \\
\text { Y } \\
\text { Coordinate }\end{array}$ & Geographic & N/A & $\begin{array}{l}\text { Y coordinate of the } \\
\text { offender's residential } \\
\text { postal code location }\end{array}$ & N/A & N/A \\
\hline Offence & Categorical & $\begin{array}{l}\text { Refer to } \\
\text { Appendix A }\end{array}$ & $\begin{array}{l}\text { The offence that the } \\
\text { offender was } \\
\text { charged with under } \\
\text { the Criminal Code }\end{array}$ & N/A & N/A \\
\hline $\begin{array}{l}\text { MCI } \\
\text { Category }\end{array}$ & Categorical & $\begin{array}{l}\text { Assault } \\
\text { Auto Theft } \\
\text { Break and } \\
\text { Enter } \\
\text { Robbery } \\
\text { Sexual } \\
\text { Assault } \\
\text { Theft Over }\end{array}$ & $\begin{array}{l}\text { Offence that } \\
\text { occurred that falls } \\
\text { under the six major } \\
\text { crime indicators }\end{array}$ & N/A & N/A \\
\hline $\begin{array}{l}\text { Offence } \\
\text { Location X } \\
\text { Coordinate }\end{array}$ & Geographic & N/A & $\begin{array}{l}\text { X coordinate of the } \\
\text { postal code location } \\
\text { where the offence } \\
\text { occurred }\end{array}$ & N/A & N/A \\
\hline $\begin{array}{l}\text { Offence } \\
\text { Location Y } \\
\text { Coordinate }\end{array}$ & Geographic & N/A & $\begin{array}{l}\text { Y coordinate of the } \\
\text { postal code location } \\
\text { where the offence } \\
\text { occurred }\end{array}$ & N/A & N/A \\
\hline
\end{tabular}




\subsection{Census Data}

Census data provides a wide range of information pertaining to population demographics from a variety of themes and topics including social and economic factors. In 2011, the mandatory long form census was replaced with the National Household Survey (NHS) which was a voluntary survey in which a portion of the population participated in the questionnaire (NHS Profile, 2011). Therefore, this study utilized the 2011 CensusPlus which is an enhanced dataset that accounts for the variation that resulted from the NHS. The 2011 CensusPlus was transfixed by Environics Analytics and was retrieved through Simplymap. This data required aggregation from a census tract level to neighbourhood level. To achieve this, the City of Toronto neighbourhood boundary shapefile was retrieved from the City of Toronto Open Data Catalogue. Using ArcGIS Desktop, the area geometry for both the census and neighbourhood shapefile was calculated and the Union tool was applied to calculate all the census tracts that fell within a neighbourhood. Considering that the areas from both boundaries are different, it was important to calculate the proportion of census variables from a census tract level to the neighbourhood level. To do this, the formula below was used.

Equation 3.1. Crime Rate Equation

Variable Count $=$ Area Geometry of Census Tract $*$ Total Population $/$ Area Geometry of Neighbourhood

The Dissolve tool was then implemented to assign all the census tracts in to a neighbourhood and the offender characteristics shapefile was joined for the regression analysis.

Based upon the various theories found in literature, crime tends to cluster around communities that are marginalized and deemed socially disadvantaged from factors including structural, economic, and social characteristics within a neighbourhood. Variables that were retrieved from the 2011 CensusPlus are shown below with a brief description describing the importance of each characteristic. 
Table 3.2. Justification for Selected Census Variables

\begin{tabular}{|c|c|c|c|}
\hline Topic & Variable Selected & Description & Source \\
\hline Education & $\begin{array}{l}\text { Proportion of } \\
\text { population } 15 \text { years } \\
\text { or over with a high } \\
\text { school diploma or } \\
\text { less (no certificate, } \\
\text { diploma or degree }\end{array}$ & $\begin{array}{l}\text { Education is one of the most evaluated characteristics used } \\
\text { in literature to explain for crime activities. } \\
\text { As School attainment increases, the likelihood of an } \\
\text { individual participating in criminal activities decreases. } \\
\text { A study looked at the relationship between education and } \\
\text { crime and found that over half of the US population of } \\
\text { inmates did not have a high school degree. } \\
\text { Education is also associated with other attributes such as } \\
\text { social well-being, income, and employment. Therefore, } \\
\text { lower education impacts the above attributes and further } \\
\text { contribute to the explanation of crime. }\end{array}$ & $\begin{array}{l}\text { Lochner \& Moretti } \\
\text { (2004); Fella \& } \\
\text { Gallipoli (2014) }\end{array}$ \\
\hline Income & $\begin{array}{l}\text { Proportion of } \\
\text { population with a } \\
\text { low household } \\
\text { income }\end{array}$ & $\begin{array}{l}\text { Obtained from the City of Toronto low income cut-offs } \\
\text { (LICO) for urban areas with population over 500,000. } \\
\text { LICO is essentially an income threshold where families } \\
\text { spend a large portion ( } 20 \% \text { more) of their income on food, } \\
\text { shelter and necessities. } \\
\text { Low income reflects crime activities within a } \\
\text { neighbourhood because of certain economic and social } \\
\text { challenges that are faced included limited amount of } \\
\text { opportunities, lower level of support which includes health } \\
\text { and stability } \\
\text { Poorer conditions also results in under-resourced } \\
\text { neighbourhoods which include the exposure to higher } \\
\text { noise levels, poor quality housing, and community } \\
\text { violence }\end{array}$ & $\begin{array}{l}\text { Profile of Low } \\
\text { Income (2011); } \\
\text { DeGuzman et al } \\
\text { (2013); Pitner et al } \\
\text { (2013); Kilewer } \\
\text { (2013) }\end{array}$ \\
\hline $\begin{array}{l}\text { Labour Force } \\
\text { Activity }\end{array}$ & $\begin{array}{l}\text { The unemployment } \\
\text { rate of population } 15 \\
\text { years and older in } \\
\text { the labour force }\end{array}$ & $\begin{array}{l}\text { Many research has adopted the idea that unemployment } \\
\text { rate correlates with crime, particularly property offences. } \\
\text { It also reflects the economic conditions which further } \\
\text { effects motivational and opportunity factors in crime. } \\
\text { Unemployment rate also results in fewer opportunities and } \\
\text { an indication of lower self-support. }\end{array}$ & Andreson (2012) \\
\hline Family Structure & $\begin{array}{l}\text { Proportion of lone } \\
\text { female parents living } \\
\text { in a private } \\
\text { household }\end{array}$ & $\begin{array}{l}\text { Lone parents, particularly female parents are more } \\
\text { susceptible to crime activities because of unfavourable } \\
\text { conditions such as vulnerability, low income, } \\
\text { unemployment and dependency on social welfare. } \\
\text { Lone parent females are at higher risk of criminal } \\
\text { behaviours involving victimisation and aggressive } \\
\text { behavioural problems. } \\
\text { This further goes on to say that because lone-motherhood } \\
\text { can be difficult there is a tendency to attract crime } \\
\text { activities because of a decrease in the lack of guardianship }\end{array}$ & $\begin{array}{l}\text { Neises \& } \\
\text { Gruneberg (2005); } \\
\text { Jablonska \& } \\
\text { Lindberg (2007) }\end{array}$ \\
\hline Population & $\begin{array}{l}\text { Proportion of male } \\
\text { aged } 15-24\end{array}$ & $\begin{array}{l}\text { Males aged } 15-24 \text { have been known to be the highest risk } \\
\text { age group to commit an offence. } \\
\text { Studies have looked at this particular age group and found } \\
\text { a correlation to high crime rates. }\end{array}$ & $\begin{array}{l}\text { Fitzgerald et al } \\
\text { (2004); Larson \& } \\
\text { Garrett (1996) }\end{array}$ \\
\hline
\end{tabular}




\subsection{Crime Rates and Distance Calculation}

\subsubsection{Crime Rates}

The first part of the analysis was to calculate the number of occurrences that took place from 2014 to 2016 in each neighbourhood. This task was completed using ArcGIS to assign each XY coordinate to a neighbourhood. This resulted in a total count of occurrences that fell within each neighbourhood geographical area and was then filtered by property and violent crimes. In this case, there were a total of 33,848 property crimes and 68,525 violent crimes across the three years. For offenders charged, there was a total of 3,419 property offences laid and 21,999 violent offences laid from 2014 to 2016.

While this study focuses on the most recent crime occurrences from year 2014 to 2016, the most recent Canadian Census data is available for 2011. Therefore, rates and percentages were calculated using the 2011 population in the city.

The norm to analyzing crime rates in Canada has always been reported as a rate per 100,000 . This method has been adopted for many years and is critical to understanding the distribution of crime in the city without reporting disproportional values (Keighley, 2017). This also enables a systematic comparison between violent and property crimes across the city. The crime rates were calculated by dividing the number of occurrences in count to the 2011 City of Toronto population and then multiplying by 100,000 . This was used to analyze the spatial patterns across the city. However, for the OLS regression the crime rate values were multiplied by 10,000 .

\subsubsection{Distance to Crime Calculation}

Each offender's distance to crime was calculated in Alteryx using the XY coordinates of the offender's postal code location to the offence location. The distance tool was applied to calculate the shortest route between the two points. Presumably, the shortest distance is assumed amongst many studies to reduce the cost of travelling and at the same time, maximize the benefits of the criminal act (Ackerman \& Rossmo, 2015; Drawve et al, 2015; Hodgkinsoi \& Tilley, 2007). The outputs were in kilometres and were classified amongst property and violent crimes to determine the difference and motivations amongst both groups. 


\subsection{Exploratory Spatial Analysis}

The exploratory portion of this study allows for a visual investigation of the distribution of crime patterns across the city. Inferences can be made about the clustering of crime occurrences across the city to further identify areas that have higher or lower rates of crime. The fundamental use of GIS is a favourable tool used to explore different techniques to analyzing spatial crime patterns. This study utilizes generic techniques such as thematic mapping and further develops towards testing for spatial clustering using spatial statistics. This first method utilized ArcGIS for Desktop and results were interpreted to achieve the first objective, that is, to determine the clustering of crime occurrences and hotspots in the City of Toronto. Hotspot mapping is one of the most ubiquitous techniques used to identify areas that have higher frequencies of crime to compare and contrast between areas with lower crime frequencies. This technique aids to bridge the gap between crime occurrences and possible predictors of crime. Many researchers have adopted the idea that the location of crime occurrences could be explained for many socioeconomic factors impacted in the area (Wang et al, 2013). The methods used below are merely a visual representation of spatial clustering and does not show statistical robustness of the maps produced.

\subsubsection{Thematic Display and Heat Mapping}

Perhaps one of the more sought out techniques used in crime analysis are density and heat mapping. A choropleth map is used to visually display the intensity of crime occurrences; it goes on to provide a general idea of high and low comparisons throughout the neighbourhoods. ArcGIS for Desktop has the necessary tools to implement user-friendly thematic mapping with various options for the user to apply various techniques. The major crime indicator dataset from 2014 to 2016 was used to create thematic maps to show the intensity of crime patterns. The dataset was parted in to the three given years and further divided by property and violent crimes. These points were spatially joined to the neighbourhood level. From there, the crime rate calculation per 100,000 persons was applied and displayed using natural breaks with the default of five classes. The percentage of census predictors were summed and normalized by total population for each neighbourhood to show meaningful values. These settings gave the best representation of crime and socioeconomic variation across the city. There are many different depictions of classes that are available to show spatial variation in thematic mapping such as natural breaks, equal interval, defined interval, quantile, geometrical interval, and standard 
deviation. However, although these classes display different spatial variations, there is almost no rule to using a specific class. That is, the selection of classes has no particular rationale behind them but are there for the purpose of exploring alternative approaches and showing differences (Murray et al, 2001). For that reason, the default of natural breaks classification was applied using five classes to show the increase in intensity as the colour gradient got darker.

A second form of intensity mapping that shows strength of clusters through a gradient scale is kernel density mapping. This type of mapping is popular amongst researcher as it allows the reader to get a general consensus of areas with high and low density of crime occurrences. Although thematic maps can show the range of frequencies of crime occurrences within a neighbourhood, it does not show where the clustering is occurring outside of a given boundary. The kernel density method requires a set radius and grid cell size but these parameters are flexible for the researcher and can be adjusted based on what the researcher wants to perceive (Chainey et al, 2008). Using ArcGIS, the kernel density tool was applied to create a map showing the smoothness of offenders residential locations across the city. In this case, the point data of postal codes of offenders have been geolocated and aggregated to the City of Toronto boundary where a bandwidth of $1 \mathrm{~km}$ was applied across the continuous surface. Other bandwidths were tested and found that a bandwidth of $1 \mathrm{~km}$ or less showed small local variation and a bandwidth of $1 \mathrm{~km}$ or more showed larger variations, thus rendering the disproportionality in its representation.

\subsubsection{Tests for Spatial Autocorrelation}

Although the above methods provide the spatial association of single crime occurrences, it does not take in to consideration its surrounding events. Spatial autocorrelation accounts for this gap where it determines similarity of one object to another. The Moran's I index was applied in this analysis to identify clusters of violent and property crimes with similar or dissimilar values. This tool is highly used in research and it works by comparing values to neighbouring averages to identify where spatial autocorrelation is occurring in the region (Cheong, 2012). The Moran's I statistics is shown below: 
Equation 3.2. Moran's I Equation

$$
I_{i}=\frac{x_{i}-\bar{X}}{S_{i}^{2}} \sum_{j=1, j \neq i}^{n} w_{i, j}\left(x_{j}-\bar{X}\right)
$$

Using ArcGIS, the Moran's I index was calculated for the offenders charged with a property or violent crime datasets from 2014 to 2016. The Moran's I index falls between positive one and negative one; values that fall positively show clustering and values that fall negatively show dispersion. The Moran's I value is also associated with a p-value and z-score to indicate whether or not it is statistically significant in the model.

\subsubsection{Local Indicator of Spatial Association}

Coherently, to visually present the spatial association with the Moran's I values, the Cluster and Outlier Analysis also known as Local Indicator of Spatial Association (LISA) was applied to show the visual distribution of features that are similar or dissimilar. This method can show areas with spatial autocorrelation by taking a set of weighted features to identify hot and cold spots and spatial outliers (ArcMap, n.d.). Similar to the thematic mapping, the location of property and violent crimes from 2014 to 2016 were spatially joined to the neighbourhood level. From there, the cluster and outlier analysis tool was applied to measure statistically significant clustering and outliers at the $95 \%$ confidence level. A statistically significant positive cluster with a high positive z-score indicates that the surrounding features are similar regardless if they are clustered with high (high-high) or low (low-low) values. A statistically significant negative cluster with a low negative z-score indicates that the surrounding features are dissimilar regardless if the neighbouring features are high to low (high-low) or low to high (low-high) values.

\subsection{Statistical Analysis}

The exploratory portion of this study has merely given a general perception of the distribution of crime across the city. However, to explore various types of individual and neighbourhood socioeconomic characteristics that impact property and violent crime rates, a statistical approach was applied. Both OLS Regression and Logistic Regression were run on the crime dataset to determine the best model. Logistic Regression requires a dichotomous dependent variable. In this case, the analysis was conducted at the individual level where all 
violent crime occurrences were coded as ' 0 ' and all property crime occurrences were coded as ' 1 '. However, this model was problematic due to significant differences in the number of property and violent cases. This goes on to say that having a large variation in the number of cases can lead to poor classification and failure to converge between the dependent and predictors (Pallant, 2005). The uneven split in the number of cases can lead to biases and failure in the model. In their study, Cronley et al (2015) used Logistic regression models to predict property and violent crimes in adulthood and found that the matched number of cases model was a better fit. However, a model with matched number of cases would exclude a large number of deleted cases and result in findings that are biased or misleading. This also produced a negative effect on the classification accuracy (Saerens, 2002). As an alternative, the OLS regression model is often used by many researchers to determine the statistical relationship between the dependent and independent variable(s). Essentially, the selected independent variables serve as predictors whereas the dependent variable is the criterion variable. For this study, a OLS regression model was used to determine the statistical association between crime rates and sociodemographic characteristics. To assure that the analysis is a good fit a number of assumptions must be met to limit bias and to avoid misleading findings. These assumptions include checking for linearity, normality, multicollinearity, and homoscedasticity.

\subsubsection{Preparing for Analysis}

Prior to checking the assumptions of OLS regression, the data needed to be cleaned in order to select the appropriate representation for each variable. The datasets included for the regression model contained both individual and neighbourhood characteristics which was aggregated to the neighbourhood level. These included sociodemographic characteristics retrieved from the 2011 CensusPlus and demographic characteristics of offenders charged with a violent or property criminal offence from 2014 to 2016 . The variables that were available for the offenders charged dataset included age, sex, and marital sex. Therefore, in order to maximize the opportunities and coincide with the social disorganisation theory, neighbourhood census characteristics were included as an extension for the missing characteristics (or as influential variables). The census variables that were deemed important and included in this analysis were population with no education (no certificate, diploma, degree), unemployment rate, lone parent females, and male aged 15 to 24 . The proportion of each characteristics was calculated and included in the model. Similarly, regarding the offenders charged dataset, the data types were 
categorical. The dataset was best represented as a percentage for each variable to provide meaningful interpretations.

\subsubsection{Regression Assumptions}

In order to analyze the relationship at which property and violent crimes can be explained by the selected socioeconomic and demographic factors, regression was applied. To run a proper analysis using OLS regression, the dependent variable has to be continuous and the independent variables have to be either continuous or categorical. In this case, the dependent variable are crime rates per 10,000 for both property and violent crimes. The independent variables are all continuous and are represented as percentages. In addition to this, outliers and bar charts were assessed through descriptive statistics to minimize distortion in the model. It is also important to test all the assumptions of OLS regression in order to maximize its finding and avoid presenting incorrect results. All assumptions were validated using SPSS Statistics.

The first assumption looks at linearity and normality between the dependent variables and the independent variables. There are several different ways to test for this assumption but scatterplots were generated to validate this assumption. The importance of a plots analysis is to assess the relationship of the dependent variable to each independent variable. These plots show the independent variables on the $\mathrm{x}$ axis and the dependent variables on the $\mathrm{y}$ axis. For any plot that did not show a linear relationship, transformation was applied. Additionally, in adjacent to linearity it is also important to test for normality. That is, a perfect normal distribution exhibits a mean of 0 and a standard deviation of 1 . Testing for linearity was important to further account for non normally distributed variables. To test for normality, the skewness and kurtosis statistics was generated for all variables. Skewness measures for symmetry where a value of 0 displays a normal distribution and a value greater than or less than 1 indicates skewness in the dataset. Kurtosis measures for peakedness where a value of 0 displays a normal distribution and values greater than or less than 2 indicates the presence of kurtosis in the data. For variables that were not normally distributed, transformation was applied.

The second assumption addresses multicollinearity in a linear regression. Multicollinearity refers to the correlation between two independent variables. That is, if the correlation between a set of independent variables are high, then it becomes difficult to determine which variable is impacting the dependent variable at what degree. Multicollinearity is tested through a Pearson's correlation diagnostic where independent variables that are highly 
correlated have a correlation value of .90 or higher, this means the assumption of multicollinearity is violated. The Pearson's correlation value is also associated with the direction of the relationship to indicate whether it is positive or negative. A second diagnostic to test for multicollinearity is to evaluate the tolerance and variance inflation factor (VIF) value. A tolerance value below .200 and a VIF value exceeding 10.00 would indicate multicollinearity. Any violation of multicollinearity results in a poor and misleading model.

The third assumption addresses homoscedasticity, that is, the variance values should be similar throughout the line of best fit. To test for homoscedasticity, a plot graph was generated where the $\mathrm{y}$ axis contained the unstandardized residuals and the $\mathrm{x}$ axis contained the unstandardized predicted values. The results indicate whether or not heteroskedasticity is present. This means that the plot widens or fan outwards as the independent variable increases. The goal is to have homoscedasticity to show that the variability in the dependent variable is equal across the independent variables.

After testing for all the assumptions, the OLS regression model was implemented through SPSS Statistics for both property and violent crimes from 2014 to 2016 . The independent predictor variables included a regression analysis on the neighbourhood demographics alone and then a separate analysis was conducted on both individual and neighbourhood characteristics. The regression coefficients were evaluated at the 0.05 significance level which is equivalent at the $95 \%$ confidence level. Various regression methods were also attempted such as Enter, Stepwise, Backward Elimination, and Forward Selection. The final regression models used the Enter method by default which inputs all the independent predictors all at once in no sequential order. 


\subsection{Results and Findings}

This section presents the findings from the spatial and statistical methods applied in this study. Inferences are made solely based on the representation and outcome of the analysis deployed and do not reflect the opinions of Toronto Police Service.

\subsection{Crime Statistics}

Table 4.1 shows the number and percentage change of total crime occurrences for both property and violent crimes. In 2014 there were a total of 33,707 crime occurrences that were reported where 11,766 were property crimes and 21,941 were violent crimes. There are significantly more violent crimes reported when compared to property crimes and this trend remains consistent throughout the three years of analysis. The interesting findings is that property crimes decreased as the year increased. From 2014 to 2015 there was a $-3.1 \%$ change in property crime occurrences and from 2015 to 2016 there was a greater decrease at $-6.9 \%$ change. In contrast, violent crimes experienced an increase from 2014 to 2015 with an increase of $2.1 \%$ and a slight decrease from 2015 to 2016 at $-0.6 \%$.

Table 4.1. Total Number of Property and Violent Crimes, 2014-2016

\begin{tabular}{|l|l|l|l|l|l|}
\hline & $\mathbf{2 0 1 4}$ & \% Change 2014-2015 & $\mathbf{2 0 1 5}$ & \% Change 2015-2016 & $\mathbf{2 0 1 6}$ \\
\hline Property Crimes & 11,766 & $-3.1 \%$ & 11,412 & $-6.9 \%$ & 10,670 \\
\hline Violent Crimes & 21,941 & $4.7 \%$ & 23,032 & $2.2 \%$ & 23,552 \\
\hline Total Crimes & 33,707 & $2.1 \%$ & 34,444 & $-0.6 \%$ & 34,222 \\
\hline
\end{tabular}

Table 4.2 shows the number and the percentage change of offences that were laid against the offender who was charged. In 2014 there were a total of 12,068 crime occurrences in which 2,148 were property crimes and 9,920 were violent crimes. There are significantly more violent crimes reported when compared to property crimes and this trend remains consistent throughout the three years of analysis. The interesting findings is that property crimes decreased as the year increased. From 2014 to 2015 there was a $-15.9 \%$ change in property crime occurrences and from 2015 to 2016 there was a change of $-3.3 \%$. In contrast, violent crimes experienced an increase from 2014 to 2015 with an increase of 2.3\% and a slight decrease from 2015 to 2016 at $2.5 \%$. Overall, the total number of crimes decreased with each year. 
Table 4.2. Number of Property and Violent Crimes Committed by Offenders Charged 2014-2016

\begin{tabular}{|l|l|l|l|l|l|}
\hline & $\mathbf{2 0 1 4}$ & \% Change 2014-2015 & $\mathbf{2 0 1 5}$ & \% Change 2015-2016 & $\mathbf{2 0 1 6}$ \\
\hline Property Crimes & 2,148 & $-15.9 \%$ & 1,852 & $-3.3 \%$ & 1,792 \\
\hline Violent Crimes & 9,920 & $2.3 \%$ & 10,155 & $-2.4 \%$ & 9,917 \\
\hline Total Crimes & 12,068 & $-0.5 \%$ & 12,007 & $-2.5 \%$ & 11,709 \\
\hline
\end{tabular}

In addition to the number of offences reported, Table 4.3 shows the number and percentage of documented offenders who were charged under the Canadian Criminal Code. In 2014 , there were a total of 8,666 offenders charged with an offence where 1,334 were property offence related and 7,332 were violent offence related. Again, there were significantly more violent offences when compared to property offences throughout the three years of analysis. From 2014 to 2015 there was a $-18.8 \%$ change in property charged offences and from 2015 to 2016 there was a $-16.7 \%$ change, a difference of $2.1 \%$. Violent charged offences increased from 2014 to 2015 at $1.5 \%$ and decreased from 2015 to 2016 at $-3.2 \%$. Overall, the total number of criminal offenders decreased throughout the three years and significantly more from 2015 to 2016 at $-4.8 \%$.

Table 4.3. Number of Offenders Charged, 2014-2016

\begin{tabular}{|l|l|l|l|l|l|}
\hline & $\mathbf{2 0 1 4}$ & \% Change 2014-2015 & $\mathbf{2 0 1 5}$ & \% Change 2015-2016 & $\mathbf{2 0 1 6}$ \\
\hline Property Crime Offenders & 1,334 & $-18.8 \%$ & 1,123 & $-16.7 \%$ & 962 \\
\hline Violent Crime Offenders & 7,332 & $1.5 \%$ & 7,450 & $-3.2 \%$ & 7,217 \\
\hline Total Criminal Offenders & 8,666 & $-1.1 \%$ & 8,573 & $-4.8 \%$ & 8,179 \\
\hline
\end{tabular}

\subsection{Spatial Distribution of Crime}

The following figures corresponds with Table 4.1 which show the total number of crime occurrences in the city within 140 neighbourhoods for both property and violent crimes. These maps depict the standardized counts of property and violent crimes by population per 100,000 persons. It is important to note that not all offences were geocoded due to missing coordinates or invalid coordinates that were displaced outside of the City of Toronto boundary.

As shown in Figure 4.1, there is a high concentration of property crimes in the core, Northeast end, and small pockets in the East end of the city. There are lower concentration of property crimes at the center and lower West end of the city. These trends remained consistent through 2015 and 2016 as shown in Figures 4.2 and 4.3. However, remembering that the number 
of property crimes decreased as the years increased, therefore some neighbourhoods in the East end diminished in concentration in 2016.

In comparison, violent crimes showed similar trends in terms of the spatial concentration of crimes per 100,000. That is, there are higher concentrations of violent crimes in the core, Northwest, and small pockets in the East end of the city. Lower concentrations are seen in the center, North, and Southwest regions. In this case, violent crimes showed an increase as the years increased, therefore, Figures 4.6 showed slightly more darker regions in the East end when compared to Figures 4.4 and 4.5. 


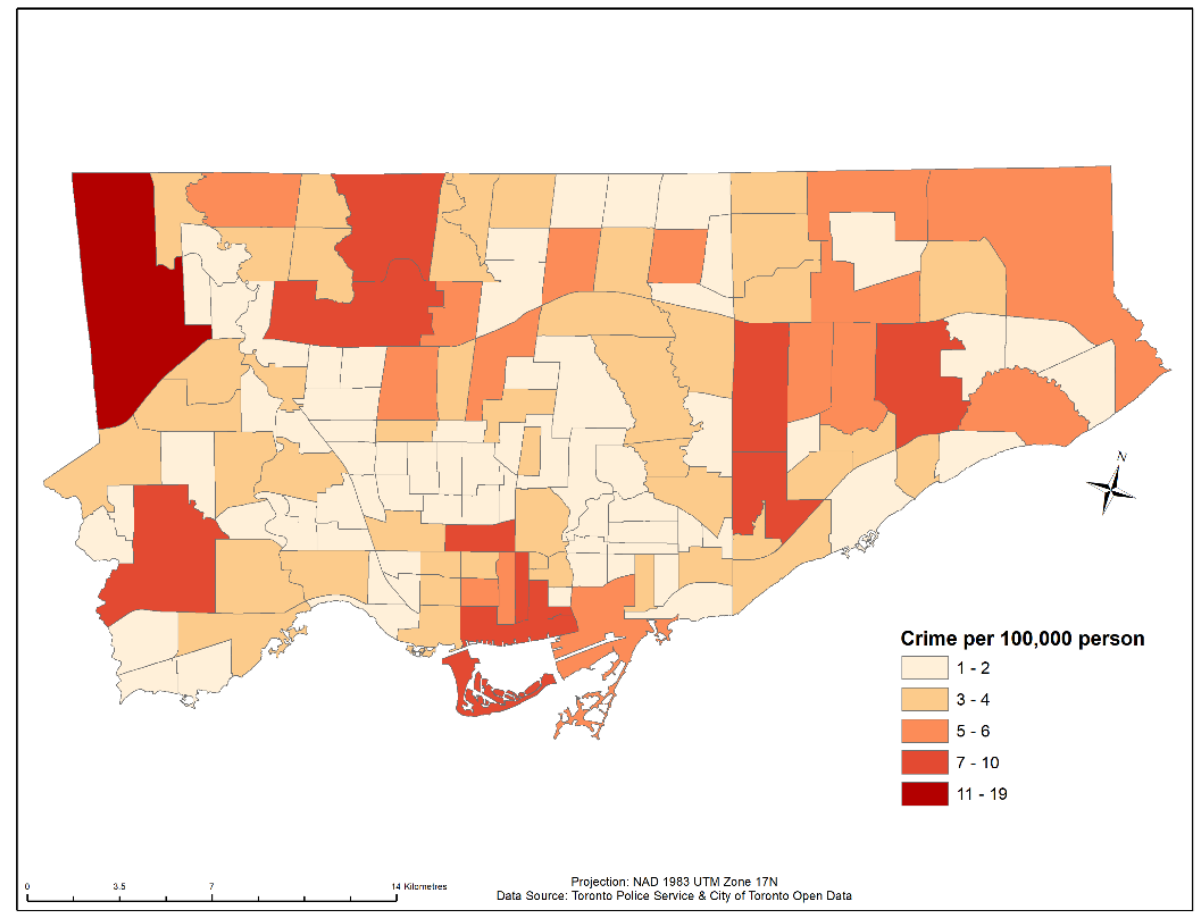

Figure 4.1. Property crimes per 100,000 persons by Neighbourhood, 2014

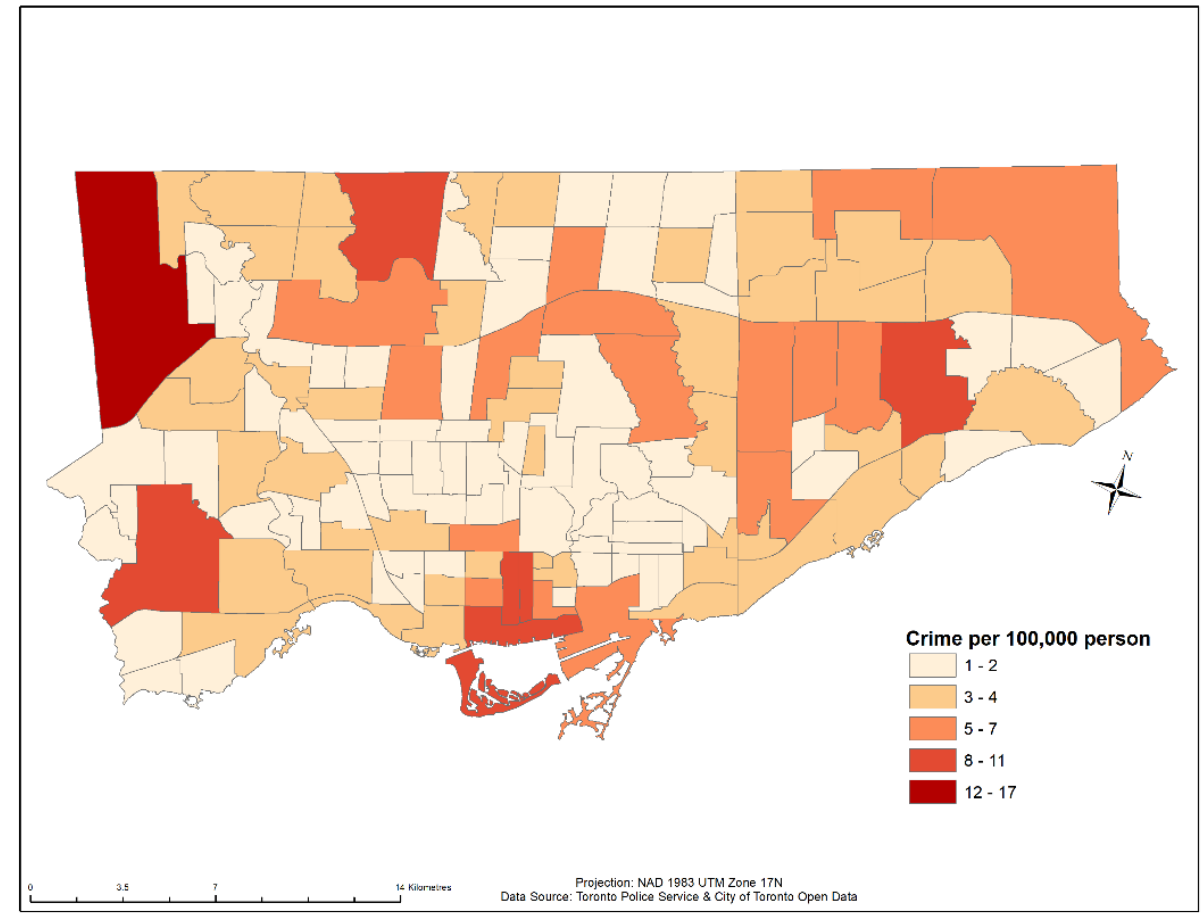

Figure 4.2. Property crimes per 100,000 persons by Neighbourhood, 2015 


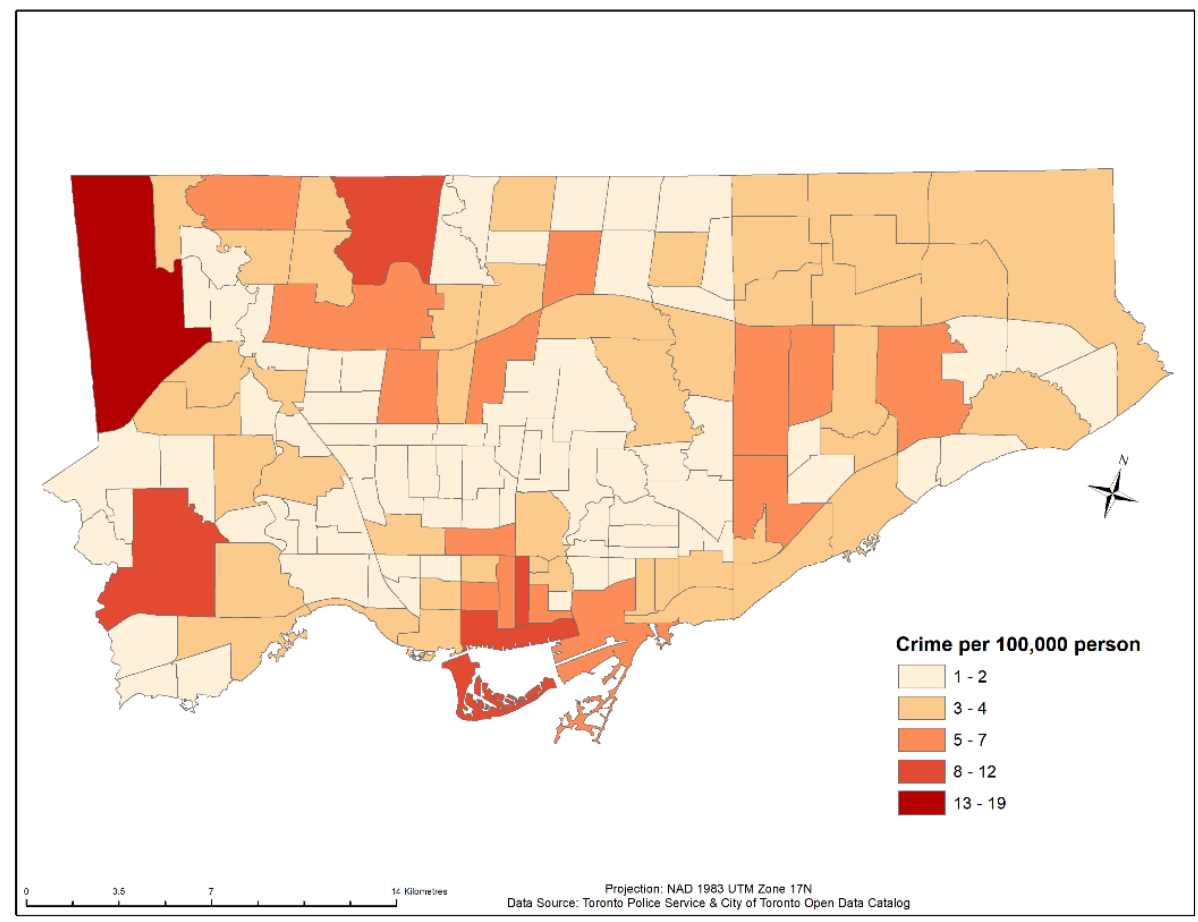

Figure 4.3. Property crimes per 100,000 persons by Neighbourhood, 2016

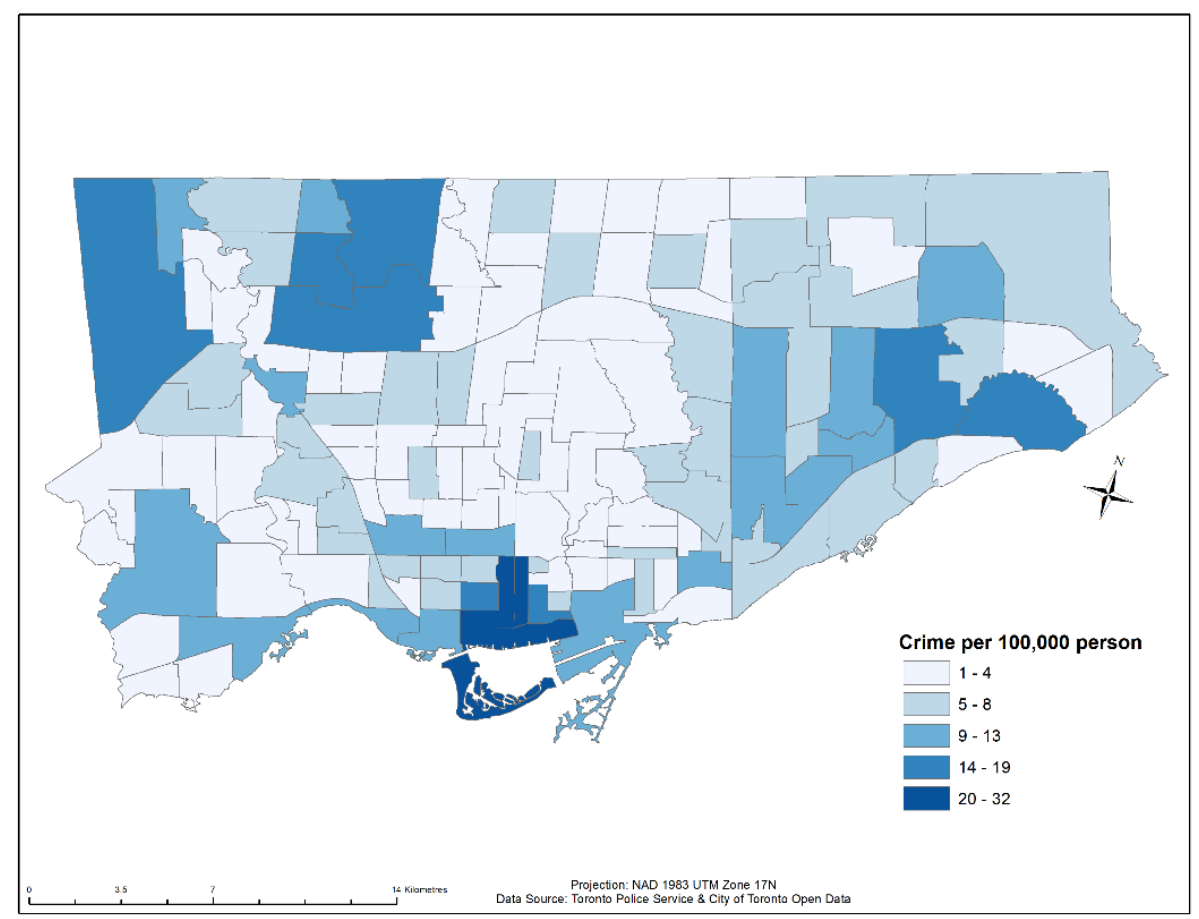

Figure 4.4. Violent crimes per 100,000 persons by Neighbourhood, 2014 


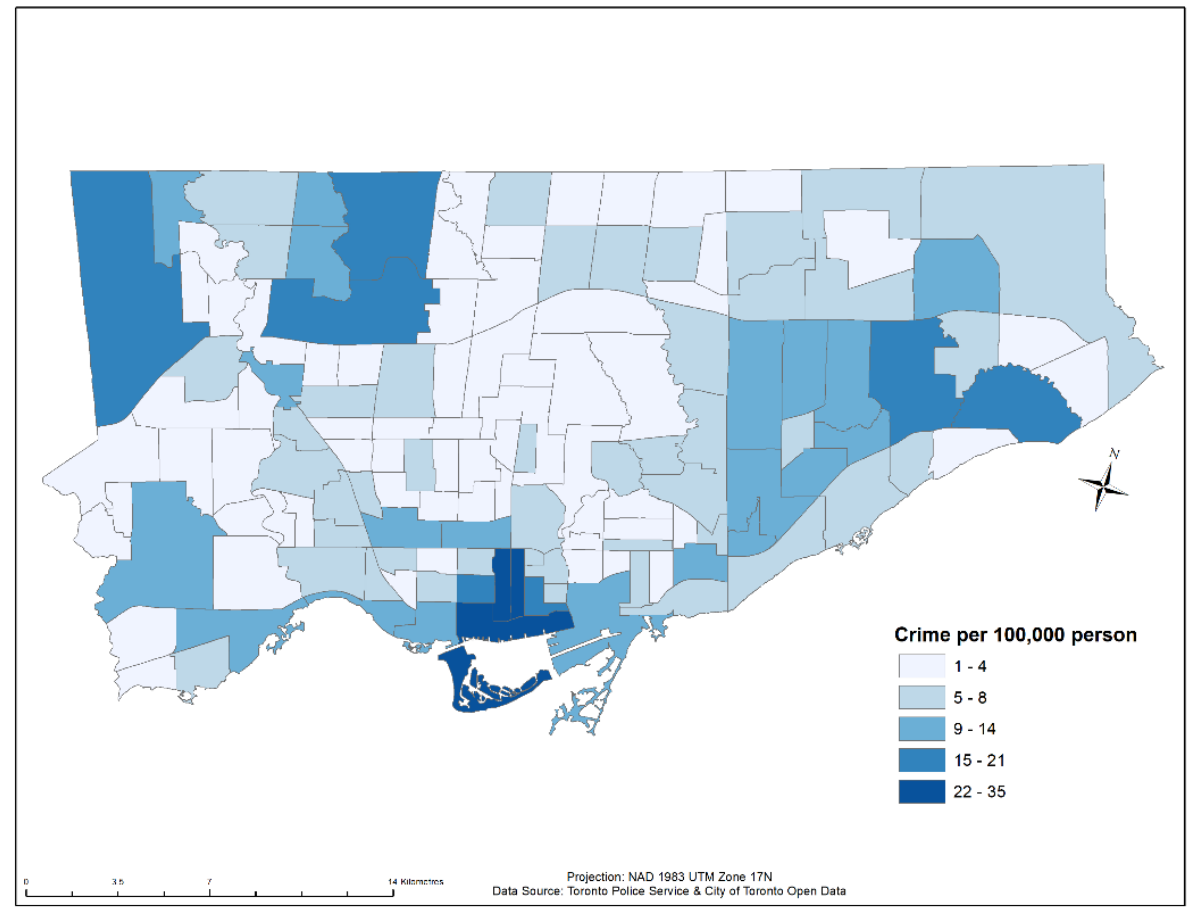

Figure 4.5. Violent crimes per 100,000 persons by Neighbourhood, 2015

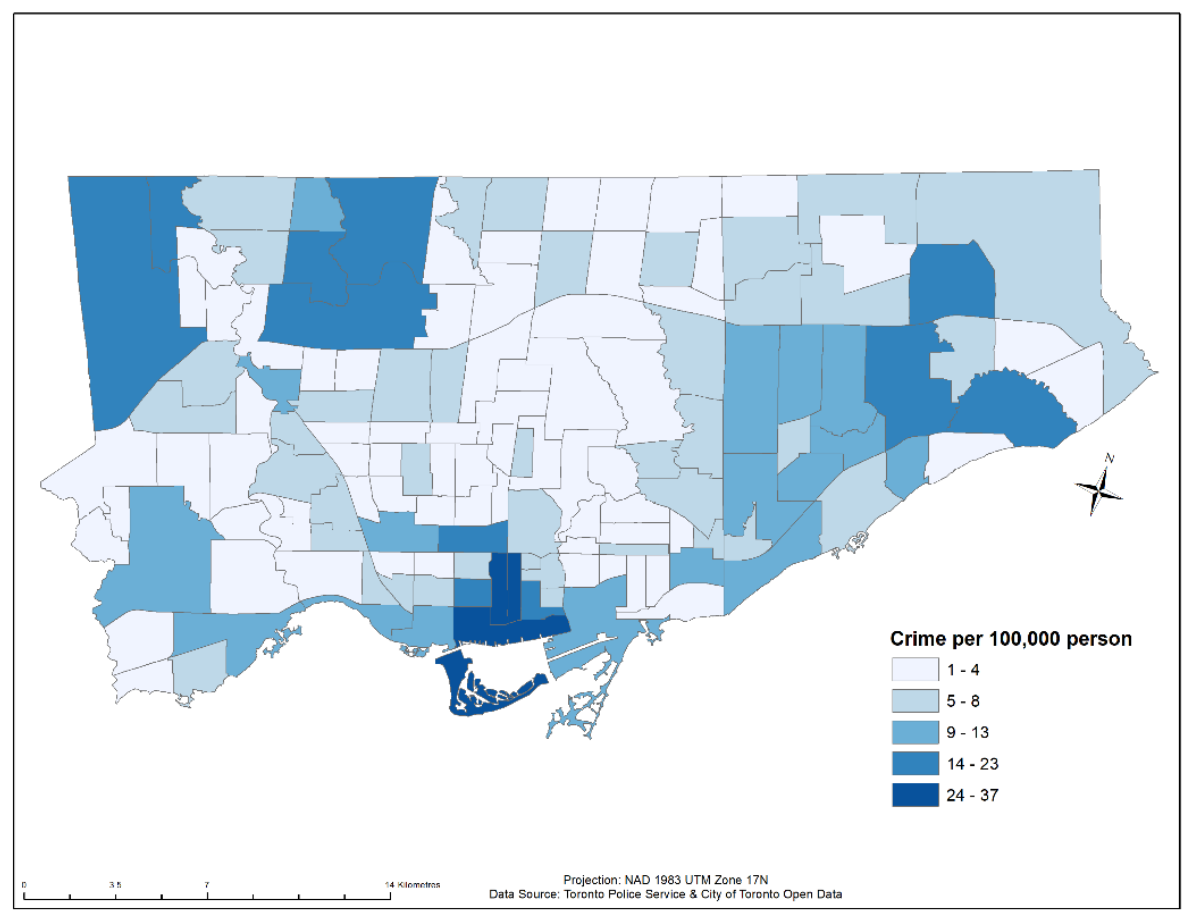

Figure 4.6. Violent crimes per 100,000 persons by Neighbourhood, 2016 
In addition to analyzing the crime occurrences in the city, the major focal point of this study was to assess the characteristics of offenders charged. Thus, it was an important criteria to analyze the spatial clustering of the residential location of offenders charged. Kernel density was applied to this analysis as it preserves the privacy of disclosing actual locations of offenders charged. As previously stated, analyzing three years separately was almost meaningless due to similar patterns. Figures 4.7 and 4.8 showed the clustering of offenders charged with either a property or violent offence from 2014 to 2016.

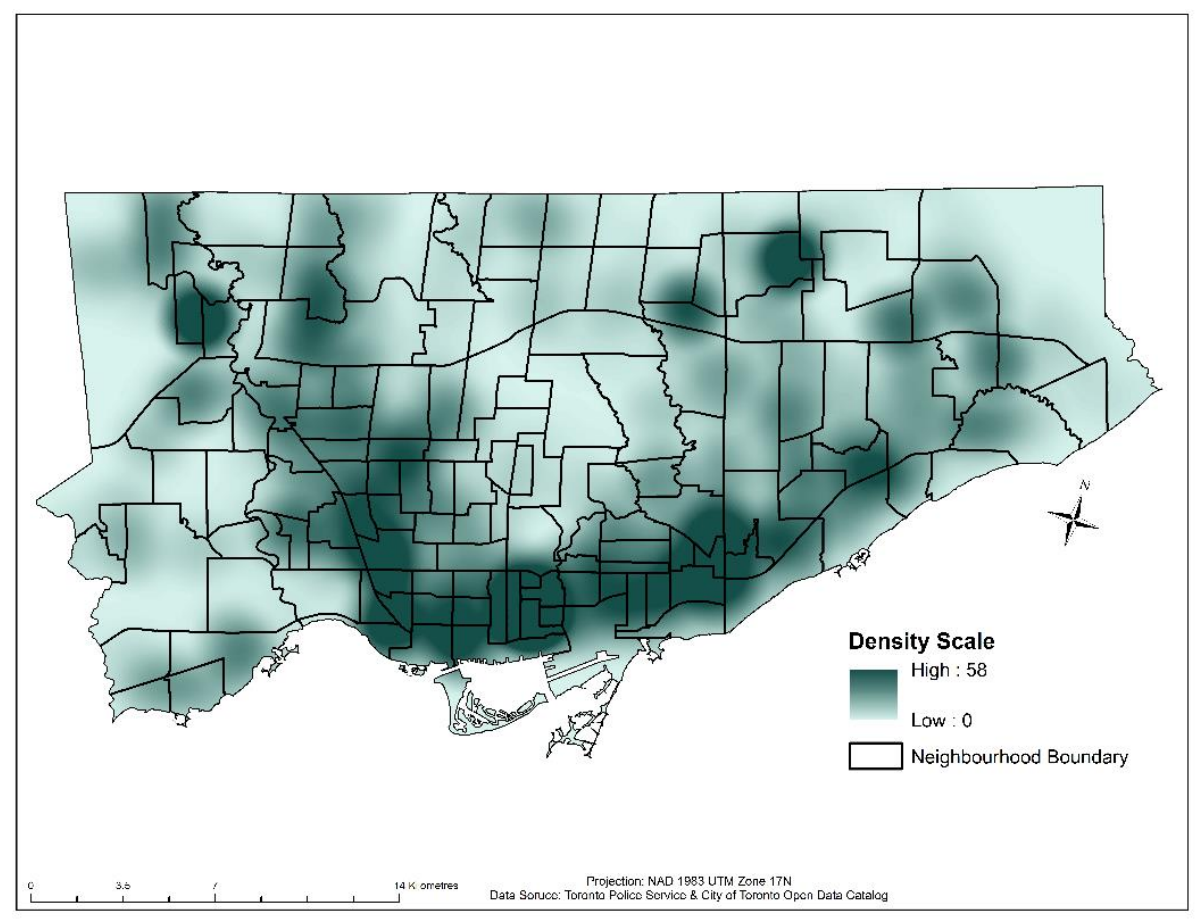

Figure 4.7. Kernel Density of Residential Locations of Offenders Charged with a Property Offence, 2014-2016 


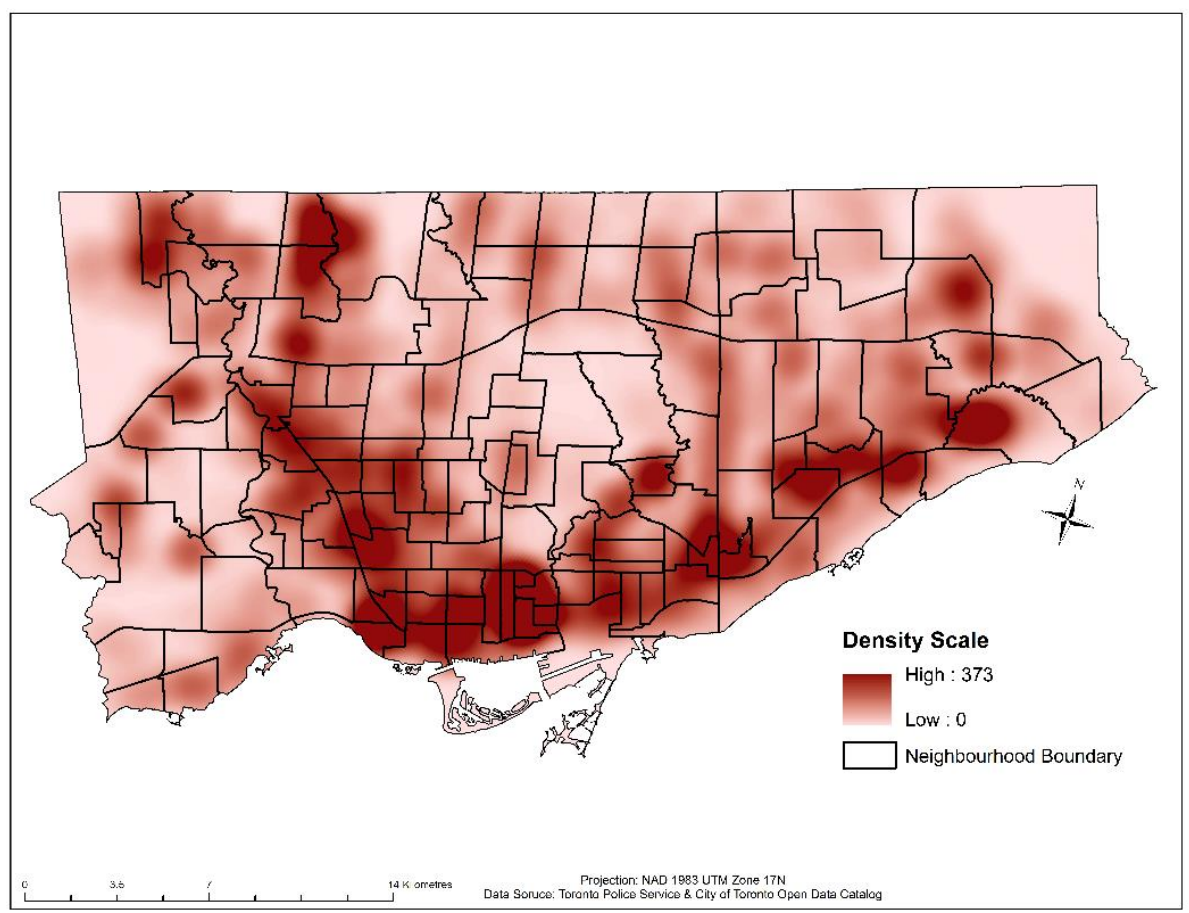

Figure 4.8. Kernel Density of Residential Locations of Offenders Charged with a Violent Offence, 2014-2016

In correspondence to Figures 4.7 and 4.8, Table 4.4 showed the general statistics of offenders charged with a property or violent crime from 2014 to 2016 . Some facts was drawn from these statistics based on the three characteristics that were provided from Toronto Police Service. For the age characteristic, the age group 18-34 was the highest for both property and violent offences. Gender showed that male offenders were drastically higher when compared to female offenders. Lastly, marital status revealed that offenders who were single was at a larger percentage than those who had a partner. For property offences, the difference between single and coupled offenders was larger than those who committed a violent offence. 
Table 4.4. Demographic Characteristics of Property and Violent Crime Offenders, 2014-2016

\begin{tabular}{|c|c|c|}
\hline & $\begin{array}{l}\text { Property Crime Offences \% } \\
(n=3,419)\end{array}$ & $\begin{array}{l}\text { Violent Crime Offences \% } \\
(n=21,999)\end{array}$ \\
\hline \multicolumn{3}{|l|}{ Age Characteristics (\%) } \\
\hline 17 Under & 9 & 8 \\
\hline $18-34$ & 50 & 51 \\
\hline $35-54$ & 36 & 32 \\
\hline 55 Plus & 5 & 8 \\
\hline \multicolumn{3}{|l|}{ Gender Characteristic (\%) } \\
\hline Male & 89 & 83 \\
\hline Female & 11 & 16 \\
\hline \multicolumn{3}{|l|}{ Marital Status Characteristic (\%) } \\
\hline $\begin{array}{r}\text { Single (Single, Divorced, Separated, } \\
\text { Widowed) }\end{array}$ & 59 & 37 \\
\hline Couples (Common-Law, Married) & 9 & 17 \\
\hline
\end{tabular}

Lastly, to compare the distribution of property and violent crimes against the selected census variables, two bivariate maps were created. The census predictors are represented as percentages and includes the following characteristics: no education, low income, unemployment, female lone parents, and male aged 15-24. Converting the predictor variables to percentages provides a meaningful and easier interpretation, it is also commonly used in many crime analysis studies (Broidy et al, 2006; Charron, 2011; Fitzgerald et al, 2004). The standardized variables also enables comparison between neighbourhoods. The crime occurrences are represented as proportional symbols to distinguish areas with high, medium, and low occurrences. Figure 4.9 depicts the distribution of property crime offenders charged against the crime predictors. As shown, areas with higher percentages of crime predictors tend to have higher number of property crime occurrences. However, there are certain areas located on the Northwest end that have high predictors of crime with low number of occurrences. Areas with lower number of crime occurrences mostly show lower percentage of crime predictors. However, 
one of the neighbourhoods in the downtown core show low number of crime predictors but high number of crime occurrences. This finding is similar to that of Charron (2011) who found that city core of Toronto was a hotspot for crime occurrences under all circumstances.

Figure 4.10 illustrate the distribution of violent rime offenders charged against the crime predictors. Similarly, areas with higher percentages of crime predictors tend to have higher number of violent crime occurrences. There are also regions in the Northwest end that have high percentage of crime predictors against lower number of violent crime occurrences. Evidently, the one neighbourhood in the downtown core also has high violent crime occurrences with a low percentage of crime predictors. Some researchers suggest that the downtown region has high density of bars which results in a higher attraction of crime in the area (Treno et al, 2007).

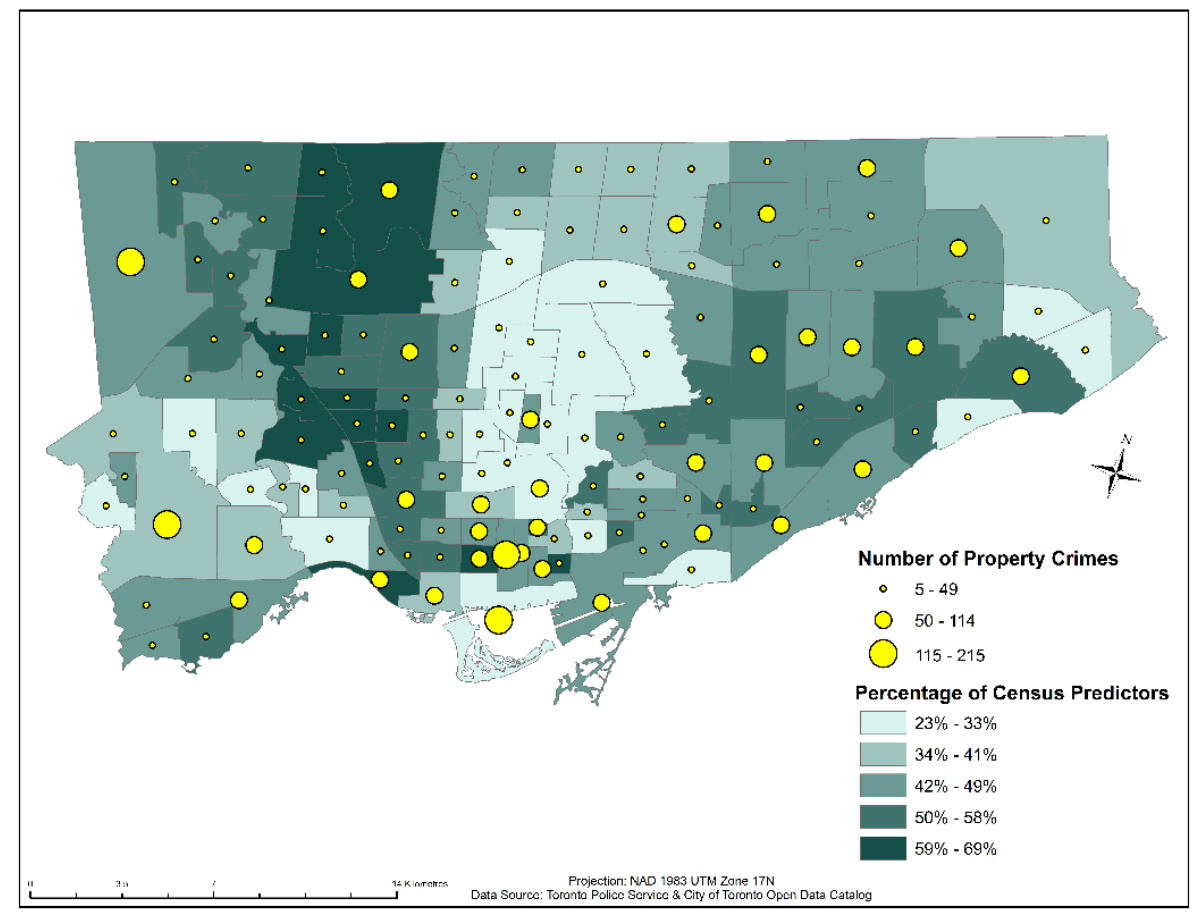

Figure 4.9. Distribution of Property Crimes and Percentage of Census Predictors 


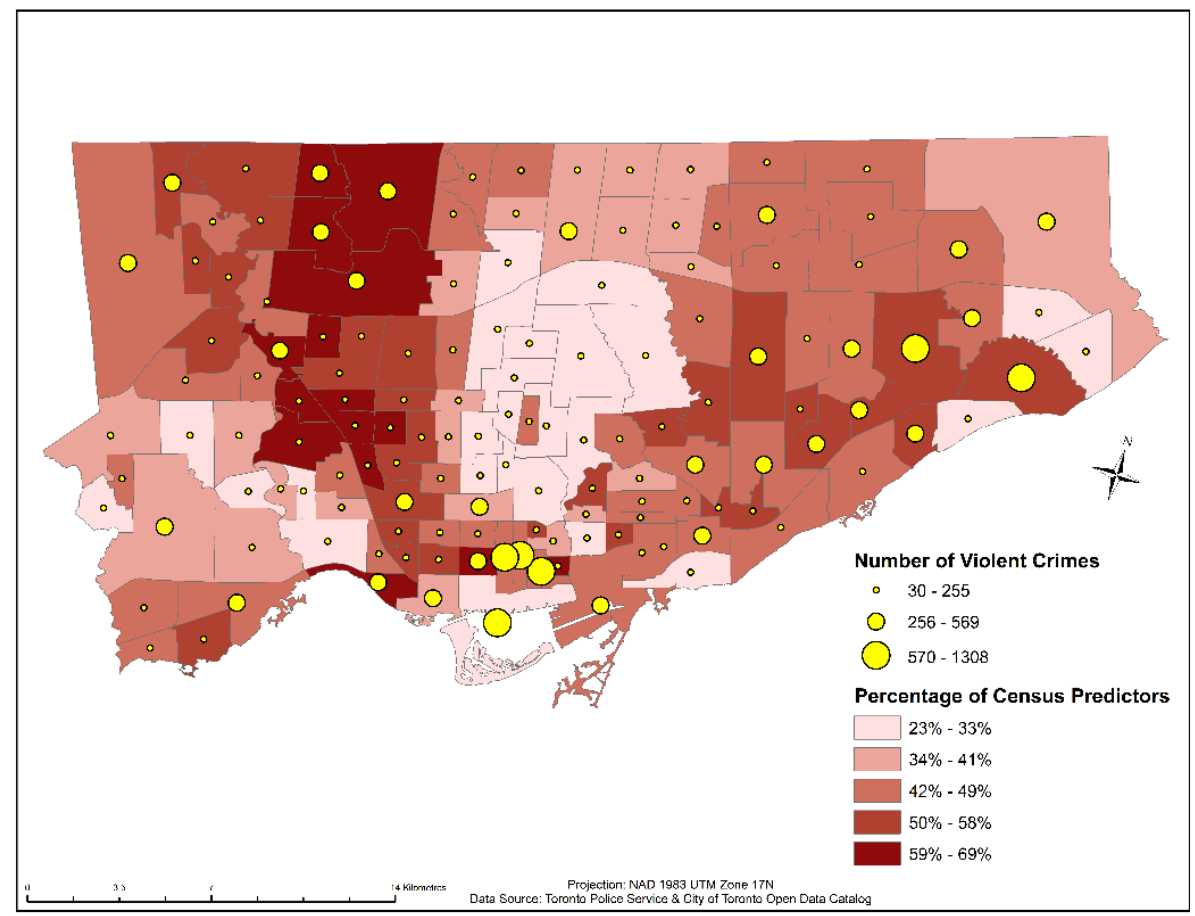

Figure 4.10. Distribution of Violent Crimes and Percentage of Census Predictors

\subsection{Distance to Crime}

The distance to crime measurement provided the shortest distance travelled by the offender within the City of Toronto. The average distances were calculated for both property and violent crime offenders. Table 4.5 outlines the values for each crime. In comparison, it was evident that there were differences between the two groups. The average distance for violent crime offenders was $4.9 \mathrm{~km}$ whereas the average distance for property crime offenders was $7.6 \mathrm{~km}$. Additionally, the longest distance travelled was a property offender at $49.2 \mathrm{~km}$. The longest distance travelled for a violent crime offender was at $36.6 \mathrm{~km}$. This was substantially shorter than the property crime offender. The overall findings in this section showed that property crime offenders tend to travel longer distances to commit an offence compared to violent crime offenders. This component could further explain for the spatial distribution of property crimes clustering not only in the city core but also in neighbourhoods West, North and East of the city. 
Table 4.5. Distance to Crime Statistics

\begin{tabular}{|l|r|r|}
\hline & Property Crimes & Violent Crimes \\
\hline $\mathbf{n}$ & 3759 & 21954 \\
\hline Average (km) & 7.6 & 4.9 \\
\hline Median (km) & 4.2 & 1.3 \\
\hline Minimum (km) & 0 & 0 \\
\hline Maximum (km) & 49.2 & 36.6 \\
\hline
\end{tabular}

\subsection{Spatial Autocorrelation}

Prior to running a regression analysis, it was important to test the dataset for spatial autocorrelation. The spatial autocorrelation tool in ArcGIS took the location and values of both property and violent crimes from 2014 to 2016 and evaluated the spatial patterns. The Moran's I value is associated with a $\mathrm{z}$-score and p-value. These values were important to determine the significance and direction of the dataset. Referring to Table 4.6, both datasets showed a statistically significant association and a positive z-score. Therefore, the null hypothesis can be rejected that there was no spatial independence in these datasets but rather a more spatially clustered spatial distribution.

Table 4.6. Spatial Autocorrelation of Property and Violent Crimes, 2014-2016

\begin{tabular}{|l|l|l|l|}
\hline & Moran's I & Z-Score & P-Value \\
\hline Property Crime & 0.268870 & 6.958907 & $0.00^{*}$ \\
\hline Violent Crime & 0.396187 & 10.230426 & $0.00^{*}$ \\
\hline
\end{tabular}

*Significant at the 0.05 level $\mathrm{n}=140$

To visually display the distribution of significant and insignificant spatial autocorrelation, the Cluster and Outlier tool also known as LISA was applied. Figures 4.11 and 4.12 show the relatively high and low significance for both property and violent crime rates. Neighbourhoods that showed positive spatial autocorrelation are in dark red and dark blue. Neighbourhoods that showed negative spatial autocorrelation are in light red and light blue. 


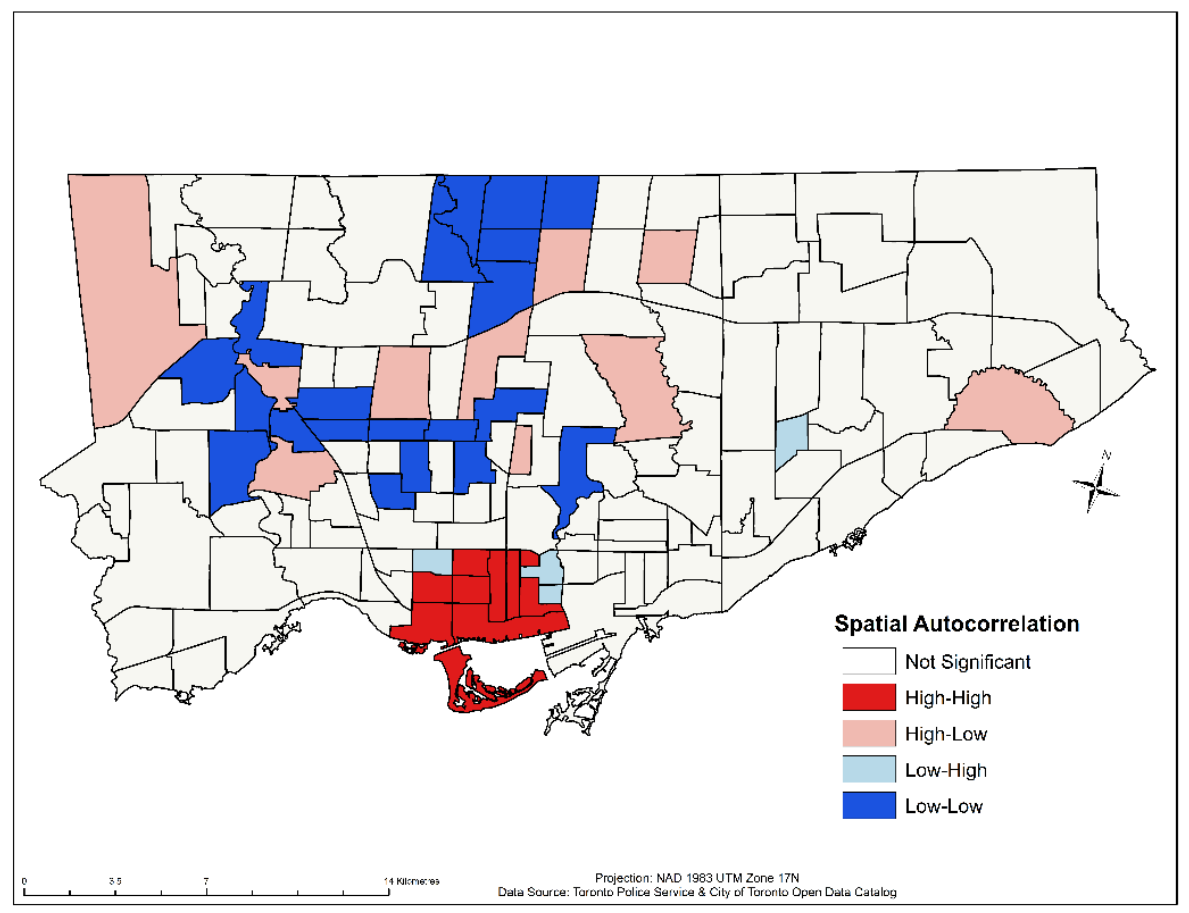

Figure 4.11. LISA Statistics Map for Property Crimes, 2014-2016

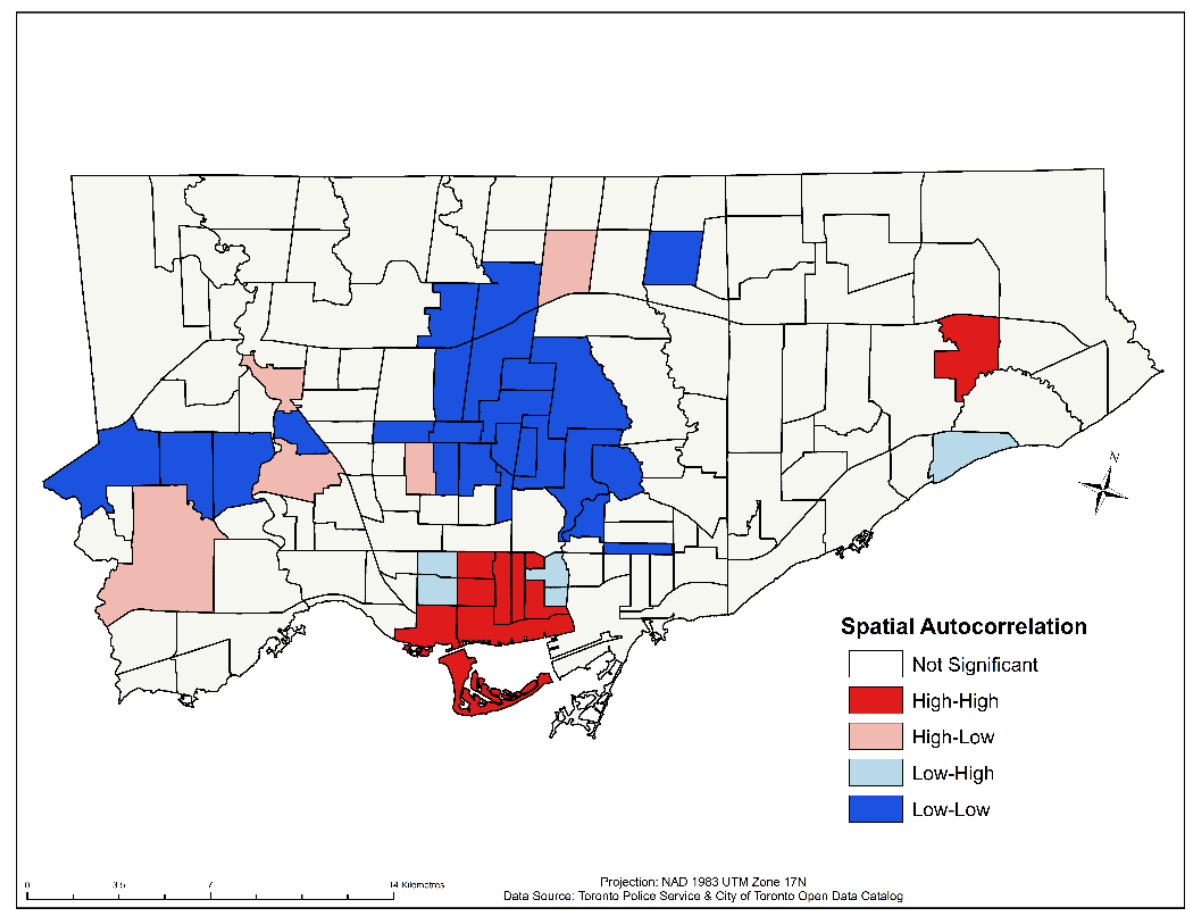

Figure 4.12. LISA Statistics Map for Violent Crimes, 2014-2016 


\subsection{OLS Regression}

\subsubsection{OLS Regression on Neighbourhood Characteristics}

Now the analysis required the regression to meet all assumptions as mentioned in section 3.5. First, a test to show the linear strength between the neighbourhood characteristics and crimes rates were evaluated. The results were fairly poor for property crimes but were moderate for violent crimes. Transformation was applied in order to fix the variables, however, the model continued to be weak. As shown in Table 4.7 the $\mathrm{R}^{2}$ values for property crime rates were low whereas the $\mathrm{R}^{2}$ values for violent crime rates were moderate. For property crime rates, each characteristic showed weak linearity in which the $\mathrm{R}^{2}$ value was close to zero, indicating a weak model and further concluding that the model should be abandoned.

Table 4.7. Linearity Relationship of Property and Violent Crimes

\begin{tabular}{|l|r|r|}
\hline $\begin{array}{l}\text { Neighbourhood } \\
\text { Characteristics }\end{array}$ & $\begin{array}{l}\text { Property Crime Rate per 10,000 } \\
\left(\mathbf{R}^{\mathbf{2}}\right)\end{array}$ & $\begin{array}{l}\text { Violent Crime Rate per 10,000 } \\
\left(\mathbf{R}^{2}\right)\end{array}$ \\
\hline \% No Education & 0.007 & 0.104 \\
\hline \% Low Income & 0.045 & 0.404 \\
\hline \% Unemployed & 0.006 & 0.219 \\
\hline \% Female Lone Parent & 0.020 & 0.108 \\
\hline \% Male Aged 15-24 & 0.000 & 0.034 \\
\hline Total Combined Characteristics & 0.115 & 0.492 \\
\hline $\mathrm{n}=140$ & &
\end{tabular}

To continue with the model for logged violent crime rates, normality was tested by evaluating skewness and kurtosis values along with the significance associated with the independent variables on the dependent. As shown in Table 4.8, normality was not an issue as skewness values did not exceed $+/-1$ and kurtosis values did not exceed $+/-2$. Additionally, each variable showed a positive significant correlation between logged violent crime rates at the $95 \%$ confident level $(\mathrm{p}<0.05)$. A significant relationship indicated that the predictors did provide explanation to violent crimes. 
Table 4.8. Normality and Significance for Logged Violent Crime Rate, 2014-2016

\begin{tabular}{|l|l|l|l|}
\hline Independent Variables & Skewness & Kurtosis & Significance \\
\hline \% No Education & 0.439 & -0.307 & Positive \\
\hline \% Low Income & 0.522 & 0.980 & Positive \\
\hline \% Unemployed & 0.336 & -0.146 & Positive \\
\hline \% Female Lone Parent & 0.823 & 1.079 & Positive \\
\hline \% Male Aged 15-24 & 0.408 & 0.789 & Positive \\
\hline
\end{tabular}

$\mathrm{n}=140$

After addressing linearity and normality, multicollinearity was tested using Pearson's

Correlation. The correlation matrix in Table 4.9 identified no multicollinearity in the model. This was further validated in the next model using tolerance and VIF values.

Table 4.9. Bivariate Correlation of Neighbourhood Independent Variables

\begin{tabular}{|l|l|l|l|l|l|}
\hline & No Education & Low Income & Unemployment & Female Lone Parent & Male Aged 15-24 \\
\hline No Education & & & & & \\
\hline Low Income & .162 & & & & \\
\hline Unemployment & $.389^{* *}$ & $.443^{* *}$ & & & \\
\hline Female Lone Parent & $.707^{* *}$ & $.282^{* *}$ & $.507^{* *}$ & & \\
\hline Male Aged 15-24 & $.234^{* *}$ & -.076 & $.443^{* *}$ & $.278^{* *}$ & \\
\hline
\end{tabular}
$\mathrm{N}=140$

Table 4.10 shows the results of the regression along with the multicollinearity diagnostic. When addressing multicollinearity, it is important that tolerance values are not less than .200 and VIF are not above 10.00. In this case, all independent variables did not violate this assumption, therefore, there is no multicollinearity that exists in this model. Applying the Enter method, the $\mathrm{R}^{2}$ for this model is 0.492 which translates to the model explaining for $49.2 \%$ of the variance in violent crime rates. In this case, both unemployment and female lone parent had an insignificant contribution to the explanation of violent crimes in this model. However, no education, low income, and males aged 15-24 were positively significant. The unstandardized B coefficient indicates the direction and units of change in the dependent variable for every independent variable.

In this case, the percentage of those with no education, low income, and males aged 1524 had a significantly positive contribution to the explanation of violent crimes in this model. As the percentage of no education $(b=.008)$, low income $(b=.030)$, and males aged 15-24 $(b=.036)$ increases, violent crimes increase. These findings were significant at the 0.05 level $(\mathrm{p}<0.05)$. 
Table 4.10.OLS Regression Coefficients and Multicollinearity Diagnostic for Logged Violent Crimes, 2014-2016

\begin{tabular}{|l|l|l|l|l|}
\hline Independent Variables & Unstandardized B Coefficient & Significance (p-value) & Tolerance & VIF \\
\hline \% No Education & 0.008 & $0.019^{*}$ & 0.496 & 2.016 \\
\hline \% Low Income & 0.030 & $0.000^{*}$ & 0.701 & 1.427 \\
\hline \% Unemployed & 0.023 & 0.293 & 0.505 & 1.980 \\
\hline \% Female Lone Parent & -0.013 & 0.415 & 0.430 & 2.324 \\
\hline \% Male Aged 15-24 & 0.036 & $0.029^{*}$ & 0.705 & 1.419 \\
\hline
\end{tabular}

* significant at the 0.05 level

$\mathrm{n}=140$

\subsubsection{OLS Regression for Individual and Neighbourhood Characteristics}

A second regression analysis was applied to include individual level characteristics and

further improve the previous models. Based on the findings from the first OLS regression model, independent variables are stronger predictors when combined for a stronger linear relationship. After accounting for linearity and applying logged transformations, the remainder of the variables were tested for normality and the results are indicated in Table 4.11.

Table 4.11. Skewness and Kurtosis Statistics After Transformation

\begin{tabular}{|l|l|l|l|}
\hline Type & Variable & Skewness & Kurtosis \\
\hline Dependent Variable & Property crime rate per 10,000 (Logged) & -0.149 & 0.206 \\
\cline { 2 - 4 } & Violent crime rate per 10,000 (Logged) & -0.009 & 0.322 \\
\hline \multirow{4}{*}{$\begin{array}{l}\text { Independent Variables (Individual } \\
\text { Characteristics) }\end{array}$} & \% 17 and Under (Logged) & -0.092 & -0.454 \\
\cline { 2 - 4 } & $\% 18-34$ & 0.092 & 0.620 \\
\cline { 2 - 4 } & \% 55 Plus (Logged) & -0.013 & 0.325 \\
\cline { 2 - 4 } & \% Male & -0.828 & 1.530 \\
\cline { 2 - 4 } & \% Female (Logged) & -0.490 & 0.054 \\
\cline { 2 - 4 } Characteristics) & \% Single & 0.347 & 0.247 \\
\cline { 2 - 4 } & \% Couple (Logged) & -0.443 & 0.122 \\
\hline Independent Variables (Neighbourhood & \% No Education & 0.439 & -0.307 \\
\cline { 2 - 4 } & \% Low Income & 0.522 & 0.980 \\
\cline { 2 - 4 } & \% Unemployment & 0.336 & -0.146 \\
\cline { 2 - 4 } & \% Female Lone Parent & 0.408 & 0.789 \\
\cline { 2 - 4 } & \% Males Aged 15-24 & 0.079 \\
\hline
\end{tabular}

To avoid the multicollinearity problem, a bivariate correlation was applied to the analysis. Additionally, a correlation analysis is used to determine the strength and direction of the relationship between property/violent crime rates and the independent predictors. Highly 
correlated variables signified that multicollinearity was present in the model. If so, the variable was removed. Table 4.12 illustrates the bivariate correlation for logged property crime rates and Table 4.13 illustrates the correlation for logged violent crime rates.

Referring to Table 4.12, independent predictor variables that showed significance to property crime rates included: 17 under, 18-34, 55 plus, female, couple, and low income. Variables that were insignificant included: male, single, no education, unemployment, lone parent, and males aged 15-24. These results showed that $\%$ female lone parent and $\%$ no education were slightly highly correlated at 0.707 and could potentially impact the model. However, there were no significant impact once the variables were removed from the model. Appendix A from Table A3 to Table A5 showed the results of the model with the variables that were removed. To further validate that multicollinearity did not severely impact the model, the tolerance and VIF value were calculated and no variables were removed from the model.

In contrast, Table 4.13 indicated signs of multicollinearity between male and females with a significant value of $(\mathrm{r}=-.976(\mathrm{p}<0.01))$. Additionally, the male variable also showed a significantly weak correlation which did not align with existing literature and studies that found the percent of male offenders increased with crime rates (Kruttschnitt, 2013; Pelfrey et al, 2016, Vikstrom et al, 2008). For those reasons, the male variable was removed. The only variable that was insignificant to violent crimes was the single variable. Additionally, \% female lone parent and $\%$ no education also correlated at 0.707 . Results did not severely impact the model once the variables were removed as shown in Appendix A from Table A6 to Table A8. Tolerance and VIF values were calculated and the two variables remained in the final model. 
Table 4.12. Bivariate Correlation of Logged Property Crime Rates and Independent Variables

\begin{tabular}{|c|c|c|c|c|c|c|c|c|c|c|c|c|c|c|}
\hline & & 1 & 2 & 3 & 4 & 5 & 6 & 7 & 8 & 9 & 10 & 11 & 12 & 13 \\
\hline 1 & Crime Rate & 1.00 & & & & & & & & & & & & \\
\hline 2 & 17 Under & $-.549^{* *}$ & 1.00 & & & & & & & & & & & \\
\hline 3 & $18-34$ & $.190^{* *}$ & .024 & 1.00 & & & & & & & & & & \\
\hline 4 & 55 Plus & $-.379^{* *}$ & $.223^{* *}$ & -.141 & 1.00 & & & & & & & & & \\
\hline 5 & Male & .084 & -.007 & .090 & -.074 & 1.00 & & & & & & & & \\
\hline 6 & Female & $-.279^{* *}$ & .154 & -.008 & $.228^{* *}$ & $-.379^{* *}$ & 1.00 & & & & & & & \\
\hline 7 & Single & -.098 & .133 & .038 & -.021 & $.168^{*}$ & .059 & 1.00 & & & & & & \\
\hline 8 & Couple & $-.412^{* *}$ & $.239^{* *}$ & .022 & $.201^{*}$ & -.070 & .099 & -.114 & 1.00 & & & & & \\
\hline 9 & No Education & -.013 & .100 & -.074 & -.078 & $-.183^{*}$ & .079 & -.158 & .118 & 1.00 & & & & \\
\hline 10 & Low Income & $.212^{*}$ & $-.227^{* *}$ & -.097 & .019 & -.164 & .144 & -.049 & $-.259^{* *}$ & .162 & 1.00 & & & \\
\hline 11 & Unemployment & .075 & -0.46 & .011 & -.128 & -.012 & -.042 & -.082 & $\begin{array}{l}.060 \\
\end{array}$ & $.389^{* * *}$ & $.443^{* * *}$ & 1.00 & & \\
\hline 12 & Lone Parent & -.140 & .158 & .047 & .003 & -.165 & .117 & -.140 & .165 & $.707^{* *}$ & $.282^{* *}$ & $.507^{* *}$ & 1.00 & \\
\hline 13 & $\begin{array}{l}\text { Males Aged } \\
15-24\end{array}$ & -.018 & -.027 & .082 & -.050 & .061 & -.110 & .117 & .028 & $.234^{* *}$ & -.076 & $.443^{* *}$ & $.278^{* *}$ & 1.00 \\
\hline
\end{tabular}

** Correlation is significant at the 0.01 level (2-tailed)

* Correlation is significant at the 0.05 level (2-tailed)

Table 4.13. Bivariate Correlation of Logged Violent Crime Rates and Independent Variables

\begin{tabular}{|c|c|c|c|c|c|c|c|c|c|c|c|c|c|c|}
\hline & & 1 & 2 & 3 & 4 & 5 & 6 & 7 & 8 & 9 & 10 & 11 & 12 & 13 \\
\hline 1 & Crime Rate & 1.00 & & & & & & & & & & & & \\
\hline 2 & 17 Under & $-.285^{* *}$ & 1.00 & & & & & & & & & & & \\
\hline 3 & $18-34$ & $.277^{* * *}$ & $-.281^{* *}$ & 1.00 & & & & & & & & & & \\
\hline 4 & 55 Plus & $-.433^{* *}$ & .002 & $-.377^{* *}$ & 1.00 & & & & & & & & & \\
\hline 5 & Male & $-.281^{* * 4}$ & $.233^{* *}$ & -.076 & .015 & 1.00 & & & & & & & & \\
\hline 6 & Female & $-.315^{* *}$ & $-.281^{* *}$ & .114 & -.047 & $-.976^{* *}$ & 1.00 & & & & & & & \\
\hline 7 & Single & $\begin{array}{l}.011 \\
-.011\end{array}$ & .158 & .060 & -.113 & .061 & -.042 & 1.00 & & & & & & \\
\hline 8 & Couple & $-.446^{* *}$ & .038 & -.077 & $.170^{*}$ & .022 & -.014 & .079 & 1.00 & & & & & \\
\hline 9 & No Education & $.323^{* *}$ & -.073 & -.027 & $-.194^{*}$ & -.155 & .161 & .028 & .158 & 1.00 & & & & \\
\hline 10 & Low Income & $.635^{* *}$ & $-.407^{* *}$ & $.222^{*}$ & $-.266^{* *}$ & $-.265^{* *}$ & $.309^{* *}$ & -.128 & $-.259^{* *}$ & .162 & 1.00 & & & \\
\hline 11 & Unemployment & $.468^{* *}$ & -.133 & $.208^{*}$ & $-.299^{* *}$ & -.061 & .100 & .080 & .125 & $.389^{* *}$ & $.443^{* *}$ & 1.00 & & \\
\hline 12 & Lone Parent & $.329^{* *}$ & -.015 & .092 & $-.243^{* *}$ & $-.226^{* *}$ & $.250^{* *}$ & -.038 & $.257^{* *}$ & $.707^{* *}$ & $.282^{* *}$ & $.507^{* *}$ & 1.00 & \\
\hline 13 & $\begin{array}{l}\text { Males Aged } \\
15-24\end{array}$ & $.184^{*}$ & .087 & $.200^{*}$ & $-.176^{*}$ & .094 & -.063 & .150 & .113 & $.234^{* *}$ & -.076 & $.443^{* * *}$ & $.278^{* *}$ & 1.00 \\
\hline
\end{tabular}

** Correlation is significant at the 0.01 level (2-tailed)

* Correlation is significant at the 0.05 level (2-tailed)

After testing the assumptions, the Enter method was applied for both regression models. Table 4.14 shows the results for logged property crimes. The $\mathrm{R}^{2}$ for this model is .509 which translates to the model explaining for $50.9 \%$ of the variance in property crime rates. In this case, the model was fairly moderate in explaining for property crimes. The variables single, no education, low income, unemployed, female lone parent, and males aged 15-24 made insignificant contributions to the model. The regression coefficients (b) indicates the level of contribution in the model.

In this case, the age cohort 17 and under made the largest contribution of explanation for property crimes $(b=-.303)$. As the age cohort 17 and under decreases, property crimes increase. Other variables that had a smaller statistically significant negative impact on the explanation of property crimes included the percentage of those 55 plus, percentage of females, and percentage 
of couples. That is, as the percentage of those aged 55 plus $(b=-.227)$, percentage of females $(b=-.146)$ and percentage of couples $(b=-.197)$ decreases, property crime rates increases. Lastly, the percentage of those between the ages 18-34 made the smallest contribution to property crimes $(b=0.003)$. As the percentage of population between the ages 18-34 increases, so does property crime rates. These findings were all significant at the .05 level $(p<0.05)$.

Table 4.14. OLS Regression Coefficients for Logged Property Crime Rates, 2014-2016

\begin{tabular}{|l|r|r|r|l|}
\hline Independent Variables & Unstandardized B Coefficient & \multicolumn{1}{l|}{ Significance (p-value) } & Tolerance & \multicolumn{1}{l|}{ VIF } \\
\hline \% 17 Under & -0.303 & $0.000^{*}$ & 0.787 & 1.271 \\
\hline \% 18-34 & 0.003 & $0.004^{*}$ & 0.929 & 1.077 \\
\hline \% 55 Plus & -0.227 & $0.001 *$ & 0.825 & 1.213 \\
\hline \% Female & -0.146 & $0.023^{*}$ & 0.875 & 1.142 \\
\hline \% Single & -0.001 & 0.329 & 0.92 & 1.087 \\
\hline \% Couple & -0.197 & $0.001 *$ & 0.817 & 1.224 \\
\hline \% No Education & 0.003 & 0.342 & 0.471 & 2.124 \\
\hline \% Low Income & 0.004 & 0.257 & 0.574 & 1.743 \\
\hline \% Unemployed & -0.003 & 0.904 & 0.485 & 2.061 \\
\hline \% Female Lone Parent & -0.016 & 0.325 & 0.388 & 2.578 \\
\hline \% Male Aged 15-24 & -0.005 & 0.752 & 0.683 & 1.464 \\
\hline
\end{tabular}

* significant at the 0.05 level $\mathrm{n}=140$

The $\mathrm{R}^{2}$ for this model is .681 which translates to the model explaining for $68.1 \%$ of the variance in violent crime rates. This model explained for more when compared to the property crime rate model. Variables that made insignificant contributions to the model included: 17 under, 18-34, single, and female lone parent. However, when compared to the property crime model, there were statistically more significant findings that contributed to the explanation of violent crimes.

In this case, the percentage of couples made the largest contribution of explanation for violent crimes $(b=-.553)$. As the percentage of couples decreases, violent crime rates increase. Other variables that had a smaller statistically significant negative impact on the contribution of violent crimes included the percentage of those 55 plus and percentage of females. That is, as the percentage of those aged 55 plus $(b=-.229)$ and percentage of females $(b=-.309)$ decreases, violent crime rates increases. Lastly, the percentage of no education, percentage of low income, percentage of unemployed, and percentage of males aged 15-24 had a statistically significant 
positive contribution to the explanation of violent crime rates. Therefore, it can be said that as the percentage of no education $(b=.006)$, low income $(b=.015)$, unemployment $(b=.045)$, and males aged 15-24 $(b=.024)$ increases, violent crime rates are to increase as well. These findings are all significant at the 0.05 level $(\mathrm{p}<0.05)$.

Table 4.15. OLS Regression Coefficients for Logged Violent Crimes, 2014-2016

\begin{tabular}{|l|r|r|r|r|}
\hline Independent Variables & Unstandardized B Coefficient & Significance (p-value) & Tolerance & VIF \\
\hline \% 17 Under & -0.057 & 0.202 & 0.679 & 1.473 \\
\hline \% 18-34 & 0.001 & 0.694 & 0.714 & 1.400 \\
\hline \% 55 Plus & -0.229 & $0.011^{*}$ & 0.715 & 1.398 \\
\hline \% Female & -0.309 & $0.014^{*}$ & 0.817 & 1.224 \\
\hline \% Single & 0.001 & 0.617 & 0.905 & 1.105 \\
\hline \% Couple & -0.553 & $0.000^{*}$ & 0.739 & 1.354 \\
\hline \% No Education & 0.006 & $0.037 *$ & 0.461 & 2.170 \\
\hline \% Low Income & 0.015 & $0.000^{*}$ & 0.479 & 2.089 \\
\hline \% Unemployed & 0.045 & $0.016^{*}$ & 0.474 & 2.108 \\
\hline \% Female Lone Parent & 0.007 & 0.592 & 0.358 & 2.790 \\
\hline \% Male Aged 15-24 & 0.024 & $0.046^{*}$ & 0.667 & 1.500 \\
\hline $\begin{array}{l}* \\
\text { significant at the 0.05 level } \\
\text { = 140 }\end{array}$ & & & &
\end{tabular}




\subsection{Discussion, Limitations, and Future Research}

The main purpose of this study was to investigate the spatial patterns of crime and determine individual and neighbourhood socioeconomic and demographic characteristics that predict for property and violent crime rates at the neighbourhood level in the City of Toronto from 2014 to 2016. Although there are many existing literatures and studies on the analysis of crime and demographic characteristics, very few incorporate the individual offender characteristics. Findings in this study coincides with other similar scholarly research that states that crime is not randomly distributed but rather concentrated in certain neighbourhoods that share similar characteristics (Charron, 2011; Lersch \& Hart, 2011). This study looked to investigate two major objectives which were to determine the clustering of crime in the city and to determine socioeconomic and demographic characteristics that predict for property and violent crimes. By doing so, spatial analytical techniques such as thematic mapping and hotspot mapping were applied to address the first objective. The second objective was addressed by applying an OLS regression to determine the selected predictors of crime.

Statistics showed that there were substantially more total number of violent crimes occurring in the city compared to property crimes from 2014 to 2016 . For each year, property crimes accounted for about $30 \%$ of occurrences and violent crimes accounted for $70 \%$. However, these findings also differentiated in terms of the number of occurrences for each given year. Property crimes showed a decrease in the total number of occurrences while violent crimes showed an increase as each year progressed. Additionally, these patterns were also similar amongst the number of committed offences by offenders charged and who reside in the city. In contrast, the number of offenders residing in the city decreased from 2015 to 2016. It is also noteworthy to mention that the rate of decrease in charges were much higher for property crimes than the number of offenders charged. From 2014 to 2015 there was a $-18.8 \%$ change and from 2015 to 2016 there was a $-16.7 \%$ change. These values were relatively higher than violent crimes which had a percentage change from 2014 to 2015 of $1.5 \%$ and $-3.2 \%$ from 2015 to 2016 . The decreased in charges for property crimes corresponded to the decrease in the number of offenders charged. However, the number of charges laid was substantially less than the number of offenders. This could be impacted by the diversion program that reduces the number of charges laid in to other programs that would assist offenders under youth related charges or mental health incidents. 
GIS techniques were utilized to determine the spatial distribution of crime occurrences in the city. These techniques also answered the first hypothesis in this study which stated that property and violent crimes tended to cluster in the same neighbourhoods over the three years of analysis. Evidently, the maps revealed a consistent concentration of property and violent crimes occurring in the core of the city from 2014 to 2016. There were also high concentrations of crime located in the Northwest and Northeast end of the city, more so for property crimes. Furthermore, because social disorganization theory suggested that crime is related to socioeconomic characteristics such as low income, unemployment, and low education attainment, the distribution of crime in this study showed clustering in areas with those corresponding characteristics (Hart \& Waller, 2013). The spatial distribution of property crimes, violent crimes, offender's residence, and distribution of socio-economic disadvantaged neighbourhoods followed a "U-shaped" pattern across the city. However, there were slight differences between the distribution of property and violent crimes. Property crimes showed more dispersion across neighbourhoods in comparison to violent crimes. Whereas for violent crimes, there were gaps that had less crime occurrences. The three years of analysis may not have been large enough to conclude with substantial findings but the spatial distinction between property and violent crimes were transparent. There were also higher proportion of crime occurrences occurring in neighbourhoods with social disadvantaged characteristics (no education, low income, unemployment, and lone parent females). As discussed, these were factors that were commonly applied in other similar studies as predictors of crime (Charron, 2011; Bunge et al, 2005; Fitzgerald et al, 2004).

This study was also unique in nature because it included individual demographic characters of offenders charged with a property or violent crime from 2014-2016. General statistics showed that in terms of age characteristics, 18-34 years of age had the highest number of offenders charged. This aligned closely with pre-existing literature that found significance in crime rates relative to those in between the age cohort 15-29 (O'Brien, 1989). In their study, Porter et al (2016) also found that the median age of inmates is 34 years of age. The lowest percentage of offenders fell in to the age cohort of 17 and under and those who are 55 years and older. Landerso et al (2017) found that crime rates start to increase from years 18-20. Seniors are also more vulnerable and susceptible to victimization rather than to commit an offence (Fitzgerald et al, 2004). 
For gender, males were dominantly higher than female offenders for both property and violent crimes. These statistics validated the gender-ratio problem as suggested by Kruttschnitt (2013). A study in Finland found that males and the age cohort from 15-30 had a high prevalence for both property and violent crimes (Elonheimo et al, 2014). This was evident from the data used in this study. Additionally, the study also found that there were higher prevalence of property crimes amongst females (Elonheimo et al, 2014). In contrast, a study conducted in Russia found that female offenders were mostly convicted of violent crimes (Kaplun, 2017). A study also looked at theories of Social Bond and Control and suggested that female offenders commited crimes mostly because of bonding and attachment to norms, families, and beliefs (Lindberg et al, 2017). With marital status, offenders who were in a common-law or was married was substantially less than those who were single. This could be explained by the financial support and stability amongst couples which could decrease the likelihood for couples to commit theft. Barnes et al (2014) states that the effect of marriage decreases the likelihood of offending and further explains that marriage changes social capital and increase in conformity when compared to unmarried persons.

Additionally, the distance to crime measurement showed that offenders of property crimes had a higher average travel distance when compared to offenders of violent crimes. The average distance for property offenders was $7.6 \mathrm{~km}$ and the average for violent offenders was $4.9 \mathrm{~km}$. The distance to crime measurement is based upon the routine activity theory that does not only state that crime is affected by socioeconomic characteristics but rather an individual's awareness space driven by a motivated offender, suitable target, and absence of a capable guardian (Drawve et al, 2017). The study conducted by Ackerman \& Rossmo (2015) found similar patterns that showed a higher average travel distance amongst property offenders when compared to violent offenders. These findings could suggest that travelling longer distances would also maximize and make it worthwhile to commit a property offence if the benefits exceed the costs. This is built upon the rational choice framework that states offenders select their targets using a spatially structured, hierarchical and sequential process (Vandeviver et al, 2015). Additionally, violent crimes clustered highly in certain neighbourhoods in this study. There were less dispersion in violent crimes which explained for the lesser travel distance when compared to property crimes. A study in Chicago also found that violence mostly occurred in neighbourhoods in which the offender resided in; requiring little to no travelling (Block et al, 2007). 
First, the OLS regression on neighbourhood characteristics only showed a $49.2 \%$ variation in explanation for violent crimes. However, the model between neighbourhood characteristics and property crimes was so weak that a regression model was not an appropriate method due to the limiting explanation in predictor variables. The bivariate correlation revealed familiar expected results that were recognized by influences suggested by social disorganization theory. With regards to the bivariate analysis of property crimes, the only variable that correlated with crime rates was low income. However, the bivariate correlation for violent crimes showed that all neighbourhood characteristics correlated with violent crime rates. Essentially, the OLS regression revealed that there was substantially a better explanation when both individual and neighbourhood characteristics were combined for both the property and violent crime models. The findings from the OLS regression models revealed that the selected individual and neighbourhood characteristics provided a better explanation for violent crimes (68.1\% variation) as opposed to property crimes (50.9\% variation). For the model regarding property crimes, the individual characteristics had a statistically significant negative association to property crime rates except for the percentage of 18-34 years of age, respectively. These patterns were similar to the violent crime model which found negative association to the selected individual characteristics and positive association to neighbourhood characteristics. These two models reaffirm the last two hypotheses that low-income neighbourhoods experience higher crime occurrences for both property and violent offences and that female, married/common law and seniors do not impact crime rates to increase.

This study also provided new information regarding the gender male and violent crimes in the City of Toronto. That is, the relationship between male and violent crime showed a significantly weaker correlation, $\mathrm{r}(138)=-.281, \mathrm{p}<0.01$. This finding is in opposition of existing studies that found an increase in crime rates amongst male offenders (South \& Messner, 2000). However, a study conducted in Winnipeg by Fitzgerald et al (2004) found that the most at-risk age cohort (15-24 years) and proportion of males in relation to crime rates were insignificant variables that predicted for property crimes but significant for violent crimes. The results of these model suggested that perhaps there are different sets of variables that better explained for both of these models. Other characteristics to take in to consideration include environment space, accessibility, crime attracting areas/facilities, and ethnicity. 


\subsection{Limitations:}

There were several limitations that coexist in this study that were unavoidable. From an exploratory and statistical stand point, the techniques applied provided empirical evidence between the relationship of crime and sociodemographic characteristics. However, it was important to recognize limiting factors that reflect the findings and ideas suggested in this study. Some limitations that were evident in this study included data constraints, modifiable areal unit problem (MAUP) and ecological fallacies.

\subsubsection{Data Constraints}

Although this study recognizes the importance of factors influencing crime as suggested by many different theories such as social disorganization theorem, such characteristics were difficult to obtain. First, the offenders charged dataset is limiting in itself due to missing information and level of sensitivity in the data. The only socioeconomic information that was available for analysis was sex, age, and marital status. Even then, such information is not mandatory for the offender to disclose. That is, under the Canadian Privacy Act an individual has the right to not disclose any personal information regardless of the circumstance. This means that it is not entirely necessary for an offender who is charged to disclose their personal information. Therefore, certain socioeconomic characteristics could be missing in that sense. Sensitive information such as ethnicity was also excluded from the analysis. Secondly, not all crimes were reported to the police. Under certain circumstances, there were many reasons as to why an individual may not report an incident to the police. Research suggests that some common factors may include public dissatisfaction with the police, police misconduct, fear and certain socioeconomic factors that may restrain the individual to report to the police (Semukhina, 2014). Therefore, the dataset that was used in this study does not assure maximum potential due to missing cases. The third concern pertains to the 2011 CensusPlus data. Due to the replacement of the required long form census with the voluntarily National Household Survey, certain statistical information was not captured accurately. Additionally, this study is based upon various years of analysis. That is, the major crime indicators and offenders charged dataset includes data from 2014 to 2016 and the Census includes data from 2011. The different years of analysis can display different sets of features and characteristics and does not account for changes that may have occurred in between the years. Essentially, current events for each year of study do not align with each other, therefore, inferences and findings were made through different circumstances. 
Although the analysis includes crime occurrences from 2014 to 2016, it does not include an extensive number of years of analysis. A thorough analysis would include many years of analysis to properly examine trends and distinctive patterns that were apparent. This would also capture different or similar changes that occur over time and enable accuracy in the analysis.

Data outside of the City of Toronto boundary were also not included in this study. This proposes a limitation due to features outside of the boundary that could potentially explain for frequency and hotspots of certain neighbourhoods that located at the perimeter of the city. For example, the census tract located in Northwest side of city was a hotspot for crime. However, this study does not capture features pertaining to crime, demographic and socioeconomic factors that were neighbouring this particular census tract. Hence, further excluding the explanation of crime occurring in this neighbourhood.

\subsubsection{Modifiable Areal Unit Problem}

The modifiable areal unit problem (MAUP) coexists in this study due to the level of aggregation from a census tract level to a neighbourhood level. MAUP recognizes the idea that information can either be overrepresented or underrepresented when data is crossed against two different levels of geographies (Hunt, 2016). In this case, census level data was aggregated from a census tract level to a neighbourhood level. This distorts the inferences made from the data because an area may not necessary reflect the same characteristics that were perceived from a smaller area unit. For example, in this study the geographical units of census tracts were smaller than neighbourhoods. Therefore, a census tract with high numbers of male population could be aggregated into a neighbourhood that shows lower numbers of male population because of the surrounding environment. This could further result in potential outliers in certain neighbourhoods. However, to minimize the amount of distortion in this study the proportion was taken by calculating the area square kilometres for both census tracts and neighbourhood.

\subsubsection{Ecological fallacy}

The presence of ecological fallacy is inevitable in this study. The assumption is made that all individuals that reside in a neighbourhood attribute to the same characteristics presented. Specifically, this applies to the individual and neighbourhood inferences that were made based on the findings from the regression model. It is not ideal to conclude that a certain gender or age group is subject to increasing crime rates. Additionally, neighbourhood characteristics were not subject to a dominant characteristic and other attributes should be taken in to consideration. 


\subsection{Future Research}

This study has taken the necessary measures to demonstrate the spatial distribution of crime and socioeconomic and demographic characteristics that influence crime rates. However, future research and new techniques and datasets can be applied to improve the analysis. This study uses the 2011 CensusPlus dataset, however, with the up and coming release of the 2016 Canadian census, opportunities for analysis will result in more accurate findings. Additionally, three years of crime data did not significantly make a difference in terms of identifying spatial patterns. Larger years of analysis may result in more robust statistical findings. Incorporating new applications and techniques can further improve the understanding of crime in the City of Toronto and to further apply the appropriate resources and strategies necessary to create a sustainable and direct approach to reducing crime in the city. However, this responsibility is not entirely held against law enforcers but rather a joint community is necessary to implement aid and crime reduction strategies amongst individuals and neighbourhoods. This joint community consists of social services from both private and public organizations, local governments and the public. It has been emphasized that it is crucial to establish local partnerships to support the government in crime prevention and community safety initiatives (Sheperdson et al, 2014). Little to no research has explored the effectiveness of partnerships and crime patterns in the city. Thus, it is important for future researchers to incorporate this component to better understand crime and propose adequate solutions and crime reduction strategies. Lastly, researchers can apply the model in this study as a backbone to predict for crime in the city. 


\section{References}

Ackerman, J. M., \& Rossmo, D. K. (2015). How far to travel? A multilevel analysis of the residence-to-crime distance. Journal of Quantitative Criminology, 31(2), 237-262.

Agnew, R. (2016). a theory of crime resistance and susceptibility. Criminology, 54(2), 181-211.

Allen, A., \& Jacques, S. (2014). Police officers' theories of crime. American Journal of Criminal Justice, 39(2), 206-227.

Andresen, M. A. (2012). Unemployment and crime: A neighborhood level panel data approach. Social Science Research, 41(6), 1615.

Andresen, M. A. (2015). Predicting local crime clusters using (multinomial) logistic regression.Cityscape, 17(3), 249.

Annual Statistical Report. (2012). Glossary of terms: Toronto police service. Toronto, ON. 2.

ArcMap. (n.d.). How cluster and outlier analysis (anselin local moran's I) works. Environmental Systems Research Institute.

Argun, U., \& Dağlar, M. (2016). Examination of routine activities theory by the property crime. International Journal of Human Sciences, 13(1), 1188-1198.

Arnio, A. N., \& Baumer, E. P. (2012). Demography, foreclosure, and crime: Assessing spatial heterogeneity in contemporary models of neighborhood crime rates. Demographic Research, 26, 449.

Atkins, D. C., \& Gallop, R. J. (2007). Rethinking how family researchers model infrequent outcomes: A tutorial on count regression and zero-inflated models. Journal of Family Psychology, 21(4), 726-735.

Badiora, A. I., Okunola, O. H., \& Ojewale, O. S. (2016). Crime statistics in a nigerian traditional city: A geographic analysis. Journal of Asian and African Studies, 51(5), 545-559.

Barnes, J. C., Golden, K., Mancini, C., Boutwell, B. B., Beaver, K. M., \& Diamond, B. (2014). Marriage and involvement in crime: A consideration of reciprocal effects in a nationally representative sample. Justice Quarterly, 31(2), 229-256.

Block, R., Galary, A., \& Brice, D. (2007). The journey to crime: Victims and offenders converge in violent index offences in chicago. Security Journal, 20(2), 123-137.

Boscoe, F. P., \& Pickle, L. W. (2003). Choosing geographic units for choropleth rate maps, with an emphasis on public health applications. Cartography and Geographic Information Science, 30(3), 237-248. 
Braga, A. A. (2016). The value of 'Pracademics' in enhancing crime analysis in police departments. Policing, 10(3), 308-314.

Braga, A. A., \& Clarke, R. V. (2014). Explaining high-risk concentrations of crime in the city: Social disorganization, crime opportunities, and important next steps. Journal of Research in Crime and Delinquency, 51(4), 480-498.

Braithwaite, J. (1975). Population growth and crime. Australian \& New Zealand Journal of Criminology, 8(1), 57-60.

Brantingham, P. J. (2016). crime diversity. Criminology, 54(4), 553-586.

Breetzke, G. D., \& Cohn, E. G. (2013). Burglary in gated communities: An empirical analysis using routine activities theory. International Criminal Justice Review, 23(1), 56-74.

Broidy, L. M., Daday, J. K., Crandall, C. S., Sklar, D. P., \& Jost, P. F. (2006). Exploring demographic, structural, and behavioral overlap among homicide offenders and victims.Homicide Studies, 10(3), 155-180.

Bunge, V. P., Johnson, H., \& Baldé, T. A. (2005). Exploring crime patterns in Canada. Canadian Centre for Justice Statistics and Time Series Research and Analysis Centre, Statistics Canada.

Chainey, S., Tompson, L., \& Uhlig, S. (2008). The utility of hotspot mapping for predicting spatial patterns of crime. Security Journal, 21(1-2), 4-28.

Chapter 25. (n.d.) Missing-data imputation.

Charron, M. (2011). Neighbourhood characteristics and the distribution of crime in toronto, Ontario: analysis on youth crime. Statistics Canada and Canadian Centre for Justice Statistics, Catalogue no. 85-561.

Cheong, J. (2012). Detecting crime hot spots using GAM and local moran's I. International Journal of Contents, 8(2), 89-96.

Christakis, N. A., \& Fowler, J. H. (2013). Social contagion theory: examining dynamic social networks and human behavior. Statistics in Medicine, 32(4), 10.1002/sim.5408.

City of Toronto. (n.d.). Neighbourhood profiles. Your City: Demographics. Retrieved on $\underline{\text { www.toronto.ca }}$

Cohn, E. G., \& Breetzke, G. D. (2017). The periodicity of violent and property crime in tshwane, south africa. International Criminal Justice Review, 27(1), 60-71.

Cook, A., Gonzalez, J. R., \& Balasubramanian, B. A. (2014). Do neighborhood demographics, crime rates, and alcohol outlet density predict incidence, severity, and outcome of hospitalization 
for traumatic injury? A cross-sectional study of dallas county, texas, 2010. Injury Epidemiology, $1(1), 1-11$.

Criminal Code. (2014). Criminal Code, R.S.C. 1985, c-46, s. 1.

Cronley, C., Jeong, S., Davis, J. B., \& Madden, E. (2015). Effects of homelessness and child maltreatment on the likelihood of engaging in property and violent crime during adulthood.Journal of Human Behavior in the Social Environment, 25(3), 192-203.

Daly, A., Dekker, T., \& Hess, S. (2016). Dummy coding vs effects coding for categorical variables: Clarifications and extensions. Journal of Choice Modelling, 21, 36-41.

DeGuzman, P. B., Merwin, E. I., \& Bourguignon, C. (2013). Population density, distance to public transportation, and health of women in Low-Income neighborhoods. Public Health Nursing, 30(6), 478-490.

Deller, S. C., \& Deller, M. A. (2010). Rural crime and social capital: RURAL CRIME AND SOCIAL CAPITAL. Growth and Change, 41(2), 221-275.

Diefenbach, D, L., \& West, M, D. (2001). Violent crime and poisson regression: a measure and a method for cultivation analysis. Journal of Broadcasting \& Electronic Media, 45(3), 434- 445.

Drawve, G., Thomas, S. A., \& Hart, T. C. (2017). Routine activity theory and the likelihood of arrest: A replication and extension with conjunctive methods. Journal of Contemporary Criminal Justice, 33(2), 121-132.

Drawve, G., Walker, J. T., \& Felson, M. (2015). Juvenile offenders: An examination of distanceto-crime and crime clusters. Cartography and Geographic Information Science, 42(2), 122-133.

Eck, J. E., \& National Institute of Justice (U.S.). (2005). Mapping crime: Understanding hot spots. (). Washington, D.C: U.S. Dept. of Justice, Office of Justice Programs, National Institute of Justice.

Elonheimo, H., Gyllenberg, D., Huttunen, J., Ristkari, T., Sillanmäki, L., \& Sourander, A. (2014). Criminal offending among males and females between ages 15 and 30 in a populationbased nationwide 1981 birth cohort: Results from the FinnCrime study. Journal of Adolescence, 37(8), 1269-1279.

Entorf, H., \& Sieger, P. (2014). Does the magnitude of the link between unemployment and crime depend on the crime level? A quantile regression approach. International Journal of Conflict and Violence, 8(2), 263.

Erdogan, S., Yalçin, M., \& Dereli, M. A. (2013). Exploratory spatial analysis of crimes against property in turkey. Crime, Law and Social Change, 59(1), 63-78. 
Fella, G., \& Gallipoli, G. (2014). Education and crime over the life cycle. The Review of Economic Studies, 81(4), 1484-1517.

Fitzgerald, C. S. (2011). Historical theories of crime and delinquency. Journal of Human Behavior in the Social Environment, 21(3), 297-311.

Fitzgerald, R., Wisener, M., \& Savoie, J. (2004). Neighbourhood characteristics and the distribution of crime in Winnipeg. Statistics Canada: Crime and Justice Research Paper Series. Canadian Centre for Justice Statistics.

Flores, M., \& Villarreal, A. (2015). Exploring the spatial diffusion of homicides in mexican municipalities through exploratory spatial data analysis. Cityscape, 17(1), 35.

Fornango, R. J. (2010). When space matters: Spatial dependence, diagnostics, and regression models. Journal of Criminal Justice Education, 21(2), 117-135.

Fox, K. A., Nobles, M. R., \& Piquero, A. R. (2009). Gender, crime victimization and fear of crime. Security Journal, 22(1), 24-39. doi:10.1057/sj.2008.13

Friedson, M., \& Sharkey, P. (2015). Violence and neighborhood disadvantage after the crime decline. The ANNALS of the American Academy of Political and Social Science, 660(1), 341358.

Gerber, M. S. (2014). Predicting crime using twitter and kernel density estimation. Decision Support Systems, 61, 115.

Giroldini, W., Pederzoli, L., Bilucaglia, M., Melloni, S., \& Tressoldi, P. (2016). A new method to detect event-related potentials based on pearson's correlation. EURASIP Journal on Bioinformatics and Systems Biology, 2016, 1.

Gottfredson, M. R., \& Hirschi, T. (2016). The criminal career perspective as an explanation of crime and a guide to crime control policy: The view from general theories of crime. Journal of Research in Crime and Delinquency, 53(3), 406-419.

Groot, W., \& Van Den Brink, H. M. (2010;2009;). The effects of education on crime. Applied Economics, 42(3), 279-289.

Grubesic, T. H., Mack, E. A., \& Kaylen, M. T. (2012). Comparative modeling approaches for understanding urban violence. Social Science Research, 41(1), 92-109.

Hart, T. C., \& Waller, J. (2013). Neighborhood boundaries and structural determinants of social disorganization: Examining the validity of commonly used measures. Western Criminology Review, 14(3), 16.

Hart, T., \& Zandbergen, P. (2014). Kernel density estimation and hotspot mapping: Examining the influence of interpolation method, grid cell size, and bandwidth on crime 
forecasting.Policing: An International Journal of Police Strategies \& Management, 37(2), 305323.

Heaton, P. (2006). Does religion really reduce crime? The Journal of Law \& Economics, 49(1), 147-172.

Hinton-Smith, T. (2016). Negotiating the risk of debt-financed higher education: The experience of lone parent students. British Educational Research Journal, 42(2), 207-222.

Hipp, J. R., \& Yates, D. K. (2011). Ghettos, thresholds, and crime: Does concentrated poverty really have an accelerating increasing effect on crime? Poverty and crime.Criminology, 49(4), 955-990.

Hodgkinsoi, S., \& Tilley, N. (2007). Travel-to-crime: Homing in on the victim. International Review of Victimology, 14(3), 281-298.

Hollis, M. E. (2016). Social demographics of crime in a military community in the united states. Crime Prevention and Community Safety, 18(2), 122-140.

Hollis-Peel, M., Reynald, D. M., Bavel, v., M.L, Elffers, H., \& Welsh, B. C. (2011).

Guardianship for crime prevention: A critical review of the literature. Crime, Law and Social Change, 56(1), 53-70.

Hudson, C., \& Graefe, P. (2011). The toronto origins of ontario's 2008 poverty reduction strategy: Mobilizing multiple channels of influence for progressive social policy change.Canadian Review of Social Policy, (65-66), 1.

Hunt, J. M. (2016). Do crime hot spots move? exploring the effects of the modifiable areal unit problem and modifiable temporal unit problem on crime hot spot stability

IPC. (2014). Ontario's municipal freedom of information and protection of privacy act: a mini guide. Information and Privacy Comissioner. Ontario, Canada.

Jablonska, B., \& Lindberg, L. (2007). Risk behaviours, victimisation and mental distress among adolescents in different family structures. Social Psychiatry and Psychiatric Epidemiology, 42(8), 656-663.

Johnson, S. D., \& Bowers, K. J. (2008). Stable and fluid hotspots of crime: differentiation and identification. Built Environment, 34(1), 32-45.

Johnson, S. D., Guerette, R. T., \& Bowers, K. (2014). Crime displacement: What we know, what we don't know, and what it means for crime reduction. Journal of Experimental Criminology, $10(4), 549$. 
Jung, H., Herrenkohl, T. I., Klika, J. B., Lee, J. O., \& Brown, E. C. (2015). Does child maltreatment predict adult crime? reexamining the question in a prospective study of gender differences, education, and marital status. Journal of Interpersonal Violence, 30(13), 2238-2257.

Kando, T. (2015). Demography is destiny: An essay on the primary correlate of violence. International Journal on World Peace, 32(2), 7.

Kaplun, O. (2017). Female criminality in russia: A research note from a penal colony.International Journal of Comparative and Applied Criminal Justice, 41(3), 231.

Kawachi, I., Kennedy, B. P., \& Wilkinson, R. G. (1999). Crime: Social disorganization and relative deprivation. Social Science \& Medicine, 48(6), 719-731.

Keighley, K. (2017). Police-reported crime statistics in Canada, 2016. Statistics Canada.

Kern, L. (2005). In place and at home in the city: Connecting privilege, safety and belonging for women in toronto. Gender, Place \& Culture, 12(3), 357-377.

Kilewer, W. (2013). the role of neighborhood collective efficacy and fear of crime in socialization of coping with violence in low-income communities. Journal of Community Psychology, 41(8), 920-930.

Kitchen, P. (n.d.). Exploring the link between crime and socio-economic status in Ottawa and Saskatoon: a small-area geographical analysis. Department of Justice Canada: Research and Statistics Division.

Kounadi, O., \& Leitner, M. (2015). Spatial information divergence: Using global and local indices to compare geographical masks applied to crime data: Calculating the spatial information divergence to compare geographical masks. Transactions in GIS, 19(5), 737-757.

Krivo, L. J., Byron, R. A., Calder, C. A., Peterson, R. D., Browning, C. R., Kwan, M., \& Lee, J. Y. (2015). Patterns of local segregation: Do they matter for neighborhood crime? Social Science Research, 54, 303-318.

Kuo, F. E., \& Sullivan, W. C. (2001). Environment and crime in the inner city: Does vegetation reduce crime? Environment and Behavior, 33(3), 343-367.

Landerso, R., Nielsen, H. S., \& Simonsen, M. (2017). School starting age and the Crime-age profile. The Economic Journal, 127(602), 1096-1118.

Larson, C. J., \& Garrett, G. R. (1996). Crime, Justice, and Society. Rowman \& Littlefield.

Law, J., Quick, M., \& Chan, P. (2016). Open area and road density as land use indicators of young offender residential locations at the small-area level: A case study in ontario, canada. Urban Studies, 53(8), 1710-1726. 
Lersch, M. K., \& Hart, C. T. (2011). Space, time, and crime. Durham, North Carolina: Caroline Academic Press.

Lindberg, M. A., Fugett, A., Adkins, A., \& Cook, K. (2017). Tests of theories of crime in female prisoners: Social bond and control, risk taking, and dynamic systems theories. International Journal of Offender Therapy and Comparative Criminology, 61(3), 282-309.

Lipsky, S., Cristofalo, M., Reed, S., Caetano, R., \& Roy-Byrne, P. (2012). Racial and ethnic disparities in police-reported intimate partner violence perpetration: A mixed methods approach. Journal of Interpersonal Violence, 27(11), 2144-2162.

Liu, F. (2011). Estimation bias in complete-case analysis in crossover studies with missing data. Communications in Statistics - Theory and Methods, 40(5), 812-827.

Liu, H., \& Zhu, X. (2017). Joint modeling of multiple crimes: A bayesian spatial approach.ISPRS International Journal of Geo-Information, 6(1), 16.

Livingston, M., Galster, G., Kearns, A., \& Bannister, J. (2014). Criminal neighbourhoods: Does the density of prior offenders in an area encourage others to commit crime?Environment and Planning A, 46(10), 2469-2488.

Lochner, L., \& Moretti, E. (2004). The effect of education on crime: Evidence from prison inmates, arrests, and self-reports. The American Economic Review, 94(1), 155-189.

Loinaz, I. (2014). Violent female offenders. Psychosocial Intervention, 23(3), 187-198. doi:10.1016/j.psi.2014.05.001

Lopes, S. B., Nair Cristina Margarido Brondino, \& Antônio Nelson Rodrigues da. (2014). GISbased analytical tools for transport planning: Spatial regression models for transportation demand forecast. ISPRS International Journal of Geo-Information, 3(2), 565-583.

Lyons, C. J. (2008). Defending turf: Racial demographics and hate crime against blacks and whites. Social Forces, 87(1), 357-385.

Machin, S., Marie, O., \& Vujić, S. (2011). the crime reducing effect of education. The Economic Journal, 121(552), 463-484.

Maxfield, M. (1987). Lifestyle and routine activity theories of crime: Empirical studies of victimization, delinquency, and offender decision-making. Journal of Quantitative Criminology, 3(4), 275-282.

Messner, S. F., Teske, R. H. C., Baller, R. D., \& Thome, H. (2013). Structural covariates of violent crime rates in germany: Exploratory spatial analyses of kreise. Justice Quarterly, 30(6), $1-27$. 
Moore, T. M., Martin, I. K., Gur, O. M., Jackson, C. T., Scott, J. C., Calkins, M. E., .. . Gur, R. C. (2016). Characterizing social environment's association with neurocognition using census and crime data linked to the philadelphia neurodevelopmental cohort. Psychological Medicine, 46(3), 599-610.

Mundia, L., Matzin, R., Mahalle, S., Hamid, M. H., \& Osman, R. S. (2016). Contributions of sociodemographic factors to criminal behavior. Psychology Research and Behavior Management, 9, 147-156.

Murray, A. T., McGuffog, I., Western, J. S., \& Mullins, P. (2001). exploratory spatial data analysis techniques for examining urban crime. The British Journal of Criminology, 41(2), 309329

Mustaine, E. E., \& Tewksbury, R. (2009). Transforming potential offenders into motivated ones: Are sex offenders tempted by alcohol and pornography? Deviant Behavior, 30(7), 561-588.

Nakaya, T., \& Yano, K. (2010). Visualising crime clusters in a space-time cube: An exploratory data-analysis approach using space-time kernel density estimation and scan statistics: Visualising crime clusters in space-time. Transactions in GIS, 14(3), 223-239.

Neises, G., \& Grüneberg, C. (2005). Socioeconomic situation and health outcomes of single parents. Journal of Public Health, 13(5), 270-278.

Nordin, M., \& Almén, D. (2017). Long-term unemployment and violent crime. Empirical Economics, 52(1), 1-29.

NHS Profile. (2011). About the data. Statistics Canada.

O'Brien, R. M. (1989). Relative cohort size and age-specific crime rates: An age-period-relativecohort-size model. Criminology, 27(1), 57-78.

Osgood D, W., \& Anderson A, L. Unstructured socializing and delinquency. Criminology (42(3): 519-549. Google Scholar.

Pallant, J. (2005). SPSS survival manual: a step by step guide to data analysis using SPSS for windows (version 12). Allen \& Unwin. Ed 2.160-170.

Papaioannou, K. J. (2017). Hunger makes a thief of any man: Poverty and crime in british colonial asia. European Review of Economic History.

Pelfrey, W. V., Keener, S., \& Perkins, M. (2016). Examining the role of demographics in campus crime alerts: Implications and recommendations. Race and Justice, , 215336871667547.

Pitner, R. O., Yu, M., \& Brown, E. (2013). Which factor has more impact? an examination of the effects of income level, perceived neighborhood disorder, and crime on community care and vigilance among low-income african american residents. Race and Social Problems, 5(1), 57-64. 
Popp, A. M. (2012). The difficulty in measuring suitable targets when modeling victimization. Violence and Victims, 27(5), 689-709.

Porter, J. R., Rader, N. E., \& Cossman, J. S. (2011). Social disorganization and neighborhood fear: Examining the intersection of individual, community, and county characteristics. American Journal of Criminal Justice, 37(2), 229-245.

Pratt, T. C. (2008). Rational choice theory, crime control policy, and criminological relevance. Criminology \& Public Policy, 7(1), 43-52.

Profile of Low Income. (2011). City of Toronto. Social Development, Finance and Administration Division. Social Policy Analysis and Research. Ontario, Canada.

Quick, M., \& Law, J. (2013). Exploring hotspots of drug offences in toronto: A comparison of four local spatial cluster detection methods. Canadian Journal of Criminology and Criminal Justice/Revue Canadienne De Criminologie Et De Justice Penale, 55(2), 215-238.

Ratcliffe, H, J. (2002). Damned if you don't, damned if you do: crime mapping and its implications in the real world. Policing and Society, Vol. 12, No. 3, pp 211-225.

Roth, R. (2010). The criminal brain: Understanding biological theories of crime. by nicole rafter (new york, new york university press, 2008) 317 pp. \$34.95 cloth \$24.00 paper. Journal of Interdisciplinary History, 41(1), 123-124.

Russell, M., Harris, B., \& Gockel, A. (2008). Canadian lone mothers describe parenting needs: European solutions explored. Canadian Social Work Review / Revue Canadienne De Service Social, 25(2), 169-185.

Saerens, M., Latinne, P., \& Decaestecker, C. (2002). Adjusting the outputs of a classifier to new a priori probabilities: A simple procedure. Neural Computation, 14(1), 21-41.

Savoie, J. (2008). Neighbourhood characteristics and the distribution of crime, edmonton, halifax and thunder bay. Statistics Canada.

Scarborough, B. K., Like-Haislip, T. Z., Novak, K. J., Lucas, W. L., \& Alarid, L. F. (2010). Assessing the relationship between individual characteristics, neighborhood context, and fear of crime. Journal of Criminal Justice, 38(4), 819-826.

Schreck, J., Jean, M., \& David S. K. (2009). On the origins of the violent neighborhood: A study of the nature and predictors of crime-type differentiation across Chicago neighborhoods. Justice Quarterly 26:771-94.

Seddon, T. (2006). DRUGS, CRIME AND SOCIAL EXCLUSION: Social context and social theory in british Drugs - Crime research. The British Journal of Criminology, 46(4), 680-703. 
Semukhina, O. (2014). Unreported crimes, public dissatisfaction of police, and observed police misconduct in the volgograd region, russia: A research note. International Journal of Comparative and Applied Criminal Justice, 38(4), 305-325.

Shen, A., \& Winlow, S. (2014). Women and crime in contemporary china: A review essay. International Journal of Comparative and Applied Criminal Justice, 38(4), 327-342.

Shen, Q. (1994). An application of GIS to the measurement of spatial autocorrelation.Computers, Environment and Urban Systems, 18(3), 167-191.

Sheperdson, P., Clancey, G., Lee, M., \& Crofts, T. (2014). Community safety and crime prevention partnerships: Challenges and opportunities. International Journal for Crime, Justice and Social Democracy, 3(1), 107-120.

Siemiatycki, M., \& Isin, E. (1997). Immigration, diversity and urban citizenship in toronto.Canadian Journal of Regional Science, 20(1-2), 73.

Smith, D. A. (2016). Online interactive thematic mapping: Applications and techniques for socio-economic research. Computers, Environment and Urban Systems, 57, 106-117.

Socia, K. M., \& Stamatel, J. P. (2012). Neighborhood characteristics and the social control of registered sex offenders. Crime \& Delinquency, 58(4), 565-587.

Soo Chon, D. (2017). Residential burglary victimization: Household- and country-level mixed modeling. International Review of Victimology, 23(1), 47-61.

South, S. J., \& Messner, S. F. (2000). Crime and demography: Multiple linkages, reciprocal relations. Annual Review of Sociology, 26(1), 83-106.

Statistics Canada. (2016). Census profile, 2016 census (Geography Products: Census Subdivision). Statistics Canada Catalogue no. 98-316-X2016001. Ottawa, Ontario, May 2017.

Steffensmeier, D., \& ALLAN, E. (2002). Gender and Crime. In J. Dressler (Ed.), Encyclopedia of Crime and Justice (2nd ed., Vol. 2, pp. 728-737). New York: Macmillan Reference USA.

Stein, E, R., Conley, J, F., \& Davis, C. (2015). The different impact of physical disorder and collective efficacy: a geographically weighted regression on violent crime. Geojournal, 81(3), 351-365.

Sturman, M. C. (1999). Multiple approaches to analyzing count data in studies of individual differences: The propensity for type I errors, illustrated with the case of absenteeism prediction. Educational and Psychological Measurement, 59(3), 414-430.

Thompson, S. K., \& Gartner, R. (2014). The spatial distribution and social context of homicide in toronto's neighborhoods. Journal of Research in Crime and Delinquency, 51(1), 88. 
Toronto Police Service. (2017). Major crime indicators and offenders charged dataset. Business Intelligence and Analytics. Toronto, ON.

Treno, Andrew J., Paul J. Gruenewald, Lilian G. Remer, Fred Johnson and Elizabeth A. Lascala. (2007). Examining multi-level relationships between bars, hostility and aggression: Social selection and social influence. Addiction. Vol. 103. p. 66-77.

Tulloch, M. (2000). The meaning of age differences in the fear of crime: Combining quantitative and qualitative approaches. The British Journal of Criminology, 40(3), 451-467.

Wallace, M., Wisener, M,. \& Collins, K. (2006). Neighbourhood characteristics and the distribution of crime in Regina. Statistics Canada.

Walters, G. D. (2015). Cognitive mediation of crime continuity: A causal mediation analysis of the past Crime-Future crime relationship. Crime \& Delinquency, 61(9), 1234-1256.

Wang, D., Ding, W., Lo, H., Stepinski, T., Salazar, J., \& Morabito, M. (2013). Crime hotspot mapping using the crime related factors - a spatial data mining approach. Applied Intelligence, 39(4), 772-781. doi:10.1007/s10489-012-0400- $\mathrm{x}$

Weisburd, D, L., Bushway, S, L., Lum, C., \& Yang, S. (2004). Trajectories of crime at places: a longitudinal study of street segments in the city of Seattle. Criminology 42:283-321.

Wheeler, A. P. (2016). Tables and graphs for monitoring temporal crime trends: Translating theory into practical crime analysis advice. International Journal of Police Science \& Management, 18(3), 159-172.

Wilson, B., \& Greenlee, A. J. (2016). The geography of opportunity: An exploratory spatial data analysis of U.S. counties. Geojournal, 81(4), 625-640.

Vandeviver, C., Van Daele, S., \& Vander Beken, T. (2015). What makes long crime trips worth undertaking? balancing costs and benefits in burglars' journey to crime. British Journal of Criminology, 55(2), 399-420.

Van Mastrigt, S. B., \& Farrington, D. P. (2009). Co-offending, age, gender and crime type: Implications for criminal justice policy. The British Journal of Criminology, 49(4), 552-573.

Veselak, K. M. (2015). The relationship between educational attainment and the type of crime committed by incarcerated offenders. Journal of Correctional Education, 66(2), 30

Vikstrom, L., Historiska, U., \& Humanistiska, F. (2008). Societal change and individual past in connection with crime: Demographic perspectives on young people arrested in northern sweden in the nineteenth century. Continuity and Change, 23(2), 331-361.

Vilalta, C., \& Muggah, R. (2016). What explains criminal violence in mexico city? A test of two theories of crime. Stability : International Journal of Security and Development, 5(1) 
Zembroski, D. (2011). Sociological theories of crime and delinquency. Journal of Human Behavior in the Social Environment, 21(3), 240-254.

Zhang, Y., Xu, J., \& Zhuang, P. (2011). The spatial relationship of tourist distribution in chinese cities. Tourism Geographies, 13(1), 75-90. 


\section{Appendix A}

Table A1. Aggregation of Property Crime Categories

\begin{tabular}{|c|c|c|}
\hline $\begin{array}{l}\text { MCI } \\
\text { Category }\end{array}$ & Type of Offence & Definition \\
\hline Auto Theft & Theft of Motor Vehicle & $\begin{array}{l}\text { Theft of a vehicle that is drawn, propelled or driven by } \\
\text { any means other than muscular power, but does not } \\
\text { include railway equipment ( } \operatorname{Sec} 333.1)\end{array}$ \\
\hline \multirow[t]{5}{*}{$\begin{array}{l}\text { Break and } \\
\text { Enter }\end{array}$} & Break \& Enter & $\begin{array}{l}\text { To break any part, internal or external; breaks and } \\
\text { enters a place (any building or structure or part of one) } \\
\text { with or without intent to commit an indictable offence } \\
\text { (Sec 348) }\end{array}$ \\
\hline & Break \& Enter - To Steal Firearm & $\begin{array}{l}\text { Break and enters a place with or without intent to steal } \\
\text { a firearm located in it ( } \mathrm{Sec} 98)\end{array}$ \\
\hline & Break \& Enter - Out & $\begin{array}{l}\text { Breaks and enters a place and commits an indictable } \\
\text { offence; breaks out of a place after (Sec 348) }\end{array}$ \\
\hline & Break \& Enter - With Intent & $\begin{array}{l}\text { Breaks and enters a place with intent to commit an } \\
\text { indictable offence (Sec 348) }\end{array}$ \\
\hline & Unlawfully in Dwelling -House & $\begin{array}{l}\text { Without lawful excuse; proof lies on that person; } \\
\text { enters or is in a dwelling-house with intent to commit } \\
\text { an indictable offence in it is guilty (Sec 349) }\end{array}$ \\
\hline \multirow[t]{5}{*}{ Theft Over } & Theft - Misappropriate Funds Over & $\begin{array}{l}\text { Every one commits theft who, having received, either } \\
\text { solely or jointly with another person, money or } \\
\text { valuable security or a power of attorney for the sale of } \\
\text { real or personal property, with a direction that the } \\
\text { money or a part of it, or the proceeds or a part of the } \\
\text { proceeds of the security or the property shall be } \\
\text { applied to a purpose or paid to a person specified in the } \\
\text { direction, fraudulently and contrary to the direction } \\
\text { applies to any other purpose or pays to any other } \\
\text { person the money or proceeds or any part of it (Sec } \\
\text { 332) }\end{array}$ \\
\hline & Theft from Mail/Bag/Key & $\begin{array}{l}\text { Steals anything sent by post, after it is deposited at a } \\
\text { post office and before it is delivered, or after it is } \\
\text { delivered but before it is in the possession of the } \\
\text { addressee or of a person who may reasonably be } \\
\text { considered to be authorized by the addressee to receive } \\
\text { mail; a bag, sack or other container or covering in } \\
\text { which mail is conveyed, whether or not it contains } \\
\text { mail; a key suited to a lock adopted for use by the } \\
\text { Canada Post Corporation (Sec 356) }\end{array}$ \\
\hline & Theft from Motor Vehicle Over & $\begin{array}{l}\text { Everyone who commits theft is, if the property stolen } \\
\text { is a motor vehicle, guilty of an offence and liable (Sec } \\
333.1 \text { ) }\end{array}$ \\
\hline & Theft of Utilities Over & \\
\hline & $\begin{array}{l}\text { Theft Over - Bicycle, Distraction, } \\
\text { Shoplifting }\end{array}$ & $\begin{array}{l}\text { Who fraudulently and without colour of right takes, or } \\
\text { fraudulently and without colour of right converts to his } \\
\text { use or the use of another person, anything, whether } \\
\text { animate or inanimate, with intent (Sec 322) }\end{array}$ \\
\hline
\end{tabular}


Table A2. Aggregation of Violent Crime Categories

\begin{tabular}{|c|c|c|}
\hline $\begin{array}{l}\text { MCI } \\
\text { Category }\end{array}$ & Type of Offence & Description \\
\hline \multirow[t]{16}{*}{ Assault } & Administering Noxious Thing & $\begin{array}{l}\text { Anyone who administered to any person or causes any } \\
\text { person to take poison or any other destructive or } \\
\text { noxious thing is guilty of an indictable offence and } \\
\text { liable (Sec 245) }\end{array}$ \\
\hline & Aggravated Assault Peace Officer & $\begin{array}{l}\text { One who wounds, maims, disfigures or endangers the } \\
\text { life of a mayor, warden, reeve, sheriff, deputy sheriff, } \\
\text { sheriff's officer, and justice of the peace (Sec 268) }\end{array}$ \\
\hline & Aggravated Assault & $\begin{array}{l}\text { One who wounds, maims, disfigures or endangers the } \\
\text { life of the complainant ( } \operatorname{Sec} 268 \text { ) }\end{array}$ \\
\hline & Air Gun or Pistol: Bodily Harm & $\begin{array}{l}\text { Discharges an air or compressed gas gun or pistol at } \\
\text { any person ( } \mathrm{Sec} 244.1)\end{array}$ \\
\hline & Assault & $\begin{array}{l}\text { Without consent of another person, applies force } \\
\text { intentionally to that other person, directly or } \\
\text { indirectly...(Sec } 265)\end{array}$ \\
\hline & $\begin{array}{l}\text { Assault - Force/Threat/Impede, } \\
\text { Resist/Prevent Seizure }\end{array}$ & $\begin{array}{l}\text { Knowingly utters, conveys or causes any person to } \\
\text { receive a threat...(Sec 264.1) }\end{array}$ \\
\hline & Assault Bodily Harm & $\begin{array}{l}\text { Carries, uses, or threatens to use a weapon or an } \\
\text { imitation thereof, or causes bodily harm to the } \\
\text { complainant (Sec 267) }\end{array}$ \\
\hline & Assault Peace Officer & $\begin{array}{l}\text { Without consent from the peace officer, applies force } \\
\text { intentionally to the life of a mayor, warden, reeve, } \\
\text { sheriff, deputy sheriff, sheriff's officer, and justice of } \\
\text { the peace (Sec 265) }\end{array}$ \\
\hline & Assault Peace Officer Weapon/CBH & $\begin{array}{l}\text { Without consent from the peace officer, applies force } \\
\text { intentionally with a weapon to the life of a mayor, } \\
\text { warden, reeve, sheriff, deputy sheriff, sheriff's officer, } \\
\text { and justice of the peace (Sec 265) }\end{array}$ \\
\hline & Assault with Weapon & $\begin{array}{l}\text { Carries, uses, or threatens to use a weapon or an } \\
\text { imitation thereof ( } \operatorname{Sec} 267)\end{array}$ \\
\hline & Criminal Negligence Bodily Harm & $\begin{array}{l}\text { One who in doing anything or in omitting to do } \\
\text { anything that it is his duty to show wanton or reckless } \\
\text { disregard for the lives or safety of other persons and } \\
\text { causes bodily harm ( } \operatorname{Sec} 221 \text { ) }\end{array}$ \\
\hline & Disarming Peace/Public Officer & $\begin{array}{l}\text { Every one commits an offence who, without the } \\
\text { consent of a peace officer, takes or attempts to take a } \\
\text { weapon that is in the possession of the peace officer } \\
\text { when the peace officer is engaged in the execution of } \\
\text { his or her duty (Sec 270.1) }\end{array}$ \\
\hline & Discharge Firearm - Recklessly & $\begin{array}{l}\text { Intentionally discharges a firearm into or at a place, } \\
\text { knowning that or being reckless as to whether another } \\
\text { person is present in the place or being reckless as to } \\
\text { the life or safety of another person ( } \operatorname{Sec} 244.2 \text { ) }\end{array}$ \\
\hline & Discharge Firearm with Intent & $\begin{array}{l}\text { Discharges a firearm at a person with intent to wound, } \\
\text { maim or disfigure, to endanger the life of or to prevent } \\
\text { the arrest or detention of any person - whether or not } \\
\text { that person is the one at whom the firearm is } \\
\text { discharged (Sec 244) }\end{array}$ \\
\hline & Pointing a Firearm & $\begin{array}{l}\text { Without lawful excuse, points a firearm at another } \\
\text { person, whether the firearm is loaded or unloaded (Sec } \\
\text { 87) }\end{array}$ \\
\hline & Traps likely cause Bodily Harm & $\begin{array}{l}\text { Sets or places a trap, device or other thing that is likely } \\
\text { to cause death or bodily harm to a parson or being in }\end{array}$ \\
\hline
\end{tabular}




\begin{tabular}{|c|c|c|}
\hline & & $\begin{array}{l}\text { occupation or possession of a place, knowingly } \\
\text { permits such a trap, device or other thing to remain in } \\
\text { that place (Sec } 247 \text { ) }\end{array}$ \\
\hline & Unlawfully causing Bodily Harm & $\begin{array}{l}\text { Unlawfully causes bodily harm to any person ( } \mathrm{Sec} \\
\text { 269) }\end{array}$ \\
\hline & Use Firearm/Imitation Offence & $\begin{array}{l}\text { Uses an imitation firearm whether or not the person } \\
\text { causes or means to cause bodily harm to any person as } \\
\text { a result ( } \operatorname{Sec} 85)\end{array}$ \\
\hline Robbery & $\begin{array}{l}\text { Robbery - Armoured Car, ATM, } \\
\text { Business, Delivery Person, Financial } \\
\text { Institute, Home Invasion, Mugging, } \\
\text { Purse Snatch, Swarming, Taxi, Vehicle } \\
\text { Jacking, With Weapon }\end{array}$ & $\begin{array}{l}\text { Steals for the purpose of extorting whatever is stolen } \\
\text { or to prevent or overcome resistance to the stealing, } \\
\text { uses violence or threats of violence to a person or } \\
\text { property; at the time of steal or immediately before or } \\
\text { after, wounds, beats, strikes, or uses any personal } \\
\text { violence to that person; assaults any person with intent } \\
\text { to steal from him; steals from any person while armed } \\
\text { with an offensive weapon or imitation thereof (Sec } \\
\text { 343) }\end{array}$ \\
\hline $\begin{array}{l}\text { Sexual } \\
\text { Assault }\end{array}$ & Anal Intercourse & $\begin{array}{l}\text { Every person who engages in an act of anal intercourse } \\
\text { (Sec 159) }\end{array}$ \\
\hline & Bestiality & $\begin{array}{l}\text { Every person who commits bestiality is guilty of an } \\
\text { indictable offence and liable to imprisonment for a } \\
\text { term not exceeding ten years or is guilty of an offence } \\
\text { punishable on summary conviction (Sec 160) }\end{array}$ \\
\hline & Corrupting Children & $\begin{array}{l}\text { Every one who, in the home of a child, participates in } \\
\text { adultery or sexual immorality or indulges in habitual } \\
\text { drunkenness or any other form of vice, and thereby } \\
\text { endangers the morals of the child or renders the home } \\
\text { an unfit place for the child to be in (Sec 172) }\end{array}$ \\
\hline & Incest & $\begin{array}{l}\text { Every one commits incest who, knowing that another } \\
\text { person is by blood relationship his or her parent, child, } \\
\text { brother, sister, grandparent or grandchild, as the case } \\
\text { may be, has sexual intercourse with that person (Sec } \\
\text { 155) }\end{array}$ \\
\hline & Invitation to Sexual Touching & $\begin{array}{l}\text { Every person who, for a sexual purpose, invites, } \\
\text { counsels or incites a person under the age of } 16 \text { years } \\
\text { to touch, directly or indirectly, with a part of the body } \\
\text { or with an object, the body of any person, including } \\
\text { the body of the person who so invites, counsels or } \\
\text { incites and the body of the person under the age of } 16 \\
\text { years (Sec 152) }\end{array}$ \\
\hline & Luring a Child via Computer & $\begin{array}{l}\text { Every person commits an offence who, by a means of } \\
\text { telecommunication, communicates with a person under } \\
\text { the age of } 18 \text { years...(Sec } 172.1)\end{array}$ \\
\hline & Sex Explicit Material to Child & $\begin{array}{l}\text { Transmits, makes available, distributes or sells } \\
\text { sexually explicit material to a person who is under the } \\
\text { age of } 18 \text { years...(Sec 171.1) }\end{array}$ \\
\hline & Sex Exploit Disabled Person & $\begin{array}{l}\text { Every person who is in a position of trust or authority } \\
\text { towards a person with a mental or physical disability } \\
\text { or who is a person with whom a person with a mental } \\
\text { or physical disability is in a relationship of dependency } \\
\text { and who, for a sexual purpose, counsels or incites that } \\
\text { person to touch, without that person's consent, his or } \\
\text { her own body, the body of the person who so counsels } \\
\text { or incites, or the body of any other person, directly or }\end{array}$ \\
\hline
\end{tabular}




\begin{tabular}{|c|c|}
\hline & $\begin{array}{l}\text { indirectly, with a part of the body or with an object } \\
\text { (Sec 153.1) }\end{array}$ \\
\hline $\begin{array}{l}\text { Sexual Assault with } \\
\text { Weapon/Threat/CBH }\end{array}$ & $\begin{array}{l}\text { Committing a sexual assault and carries, uses or } \\
\text { threatens to use a weapon or an imitation of a weapon; } \\
\text { threatens to cause bodily harm to a person other than } \\
\text { the complainant; causes bodily harm to the } \\
\text { complainant; or is a party to the offence with any other } \\
\text { person ( } \mathrm{Sec} 272 \text { ) }\end{array}$ \\
\hline Sexual Assault & $\begin{array}{l}\text { Sexual assault is guilty of an indictable offence and is } \\
\text { liable to imprisonment ( } \operatorname{Sec} 271)\end{array}$ \\
\hline Sexual Assault - Aggravated & $\begin{array}{l}\text { Every one commits an aggravated sexual assault who, } \\
\text { in committing a sexual assault, wounds, maims, } \\
\text { disfigures or endangers the life of the complainant } \\
\text { (Sec 273) }\end{array}$ \\
\hline Sexual Assault Exploitation & $\begin{array}{l}\text { Every person commits an offence who is in a position } \\
\text { of trust or authority towards a young person, who is a } \\
\text { person with whom the young person is in a } \\
\text { relationship of dependency or who is in a relationship } \\
\text { with a young person that is exploitative of the young } \\
\text { person, and who(Sec 153) }\end{array}$ \\
\hline Sexual Interference & $\begin{array}{l}\text { Every person who, for a sexual purpose, touches, } \\
\text { directly or indirectly, with a part of the body or with an } \\
\text { object, any part of the body of a person under the age } \\
\text { of } 16 \text { years (Sec } 151 \text { ) }\end{array}$ \\
\hline Voyeurism & $\begin{array}{l}\text { Every one commits an offence who, surreptitiously, } \\
\text { observes - including by mechanical or electronic } \\
\text { means - or makes a visual recording of a person who } \\
\text { is in circumstances that give rise to a reasonable } \\
\text { expectation of privacy (Sec 162) }\end{array}$ \\
\hline
\end{tabular}

Table A3. OLS Regression for Property Crimes with '\% Female Lone Parent' Removed

\begin{tabular}{|c|c|c|c|c|}
\hline Independent Variables & Unstandardized B Coefficient & Significance (p-value) & Tolerance & VIF \\
\hline$\% 17$ Under & -.312 & $.000 *$ & .807 & 1.239 \\
\hline$\% 18-34$ & .003 & $.002 *$ & .950 & 1.052 \\
\hline$\% 55$ Plus & -.230 & $.001 *$ & .827 & 1.210 \\
\hline$\%$ Female & -.149 & $.020 *$ & .877 & 1.140 \\
\hline$\%$ Single & -.001 & .349 & .921 & 1.085 \\
\hline$\%$ Couple & -.206 & $.000 *$ & .836 & 1.196 \\
\hline$\%$ No Education & .001 & .668 & .773 & 1.293 \\
\hline$\%$ Low Income & .004 & .335 & .595 & 1.680 \\
\hline$\%$ Unemployed & -.007 & .724 & .512 & 1.955 \\
\hline$\%$ Male Aged 15-24 & -.006 & .691 & 687 & 1.455 \\
\hline
\end{tabular}


Table A4. OLS Regression for Property Crimes with ‘\% No Education’ Removed

\begin{tabular}{|l|r|r|c|c|}
\hline Independent Variables & Unstandardized B Coefficient & Significance (p-value) & Tolerance & VIF \\
\hline \% 17 Under & -.303 & $.00 *^{*}$ & .787 & 1.271 \\
\hline \% 18-34 & .003 & $.002 *$ & .959 & 1.043 \\
\hline \% 55 Plus & -.235 & $.002^{*}$ & .840 & 1.191 \\
\hline \% Female & -.143 & $.025 *$ & .878 & 1.139 \\
\hline \% Single & -.001 & .290 & .926 & 1.080 \\
\hline \% Couple & -.197 & $.001 *$ & .817 & 1.224 \\
\hline \% Low Income & .004 & .286 & .577 & 1.733 \\
\hline \% Unemployed & -.002 & .940 & .486 & 2.056 \\
\hline \% Male Aged 15-24 & -.005 & .768 & .683 & 1.464 \\
\hline \% Female Lone Parent & -.006 & .616 & .637 & 1.570 \\
\hline
\end{tabular}

* Significant at $0.05(p<0.05)$

$\mathrm{N}=140$

$\mathrm{R}^{2}=0.506$

Table A5. OLS Regression for Property Crimes with ‘\%No Education’ and '\% Female Lone Parent' Removed

\begin{tabular}{|l|r|r|r|c|}
\hline Independent Variables & Unstandardized B Coefficient & Significance (p-value) & Tolerance & VIF \\
\hline \% 17 Under & -.309 & $.000 *$ & .823 & 1.215 \\
\hline \% 18-34 & .003 & $.002 *$ & .962 & 1.040 \\
\hline \% 55 Plus & -.234 & $.000 *$ & .841 & 1.189 \\
\hline \% Female & -.146 & $.021 *$ & .887 & 1.128 \\
\hline \% Single & -.001 & .313 & .939 & 1.065 \\
\hline \% Couple & -.203 & $.000 *$ & .849 & 1.177 \\
\hline \% Low Income & .004 & .320 & .597 & 1.674 \\
\hline \% Unemployed & -.005 & .798 & .546 & 1.832 \\
\hline \% Male Aged 15-24 & -.006 & .719 & .694 & 1.442 \\
\hline
\end{tabular}

* Significant at $0.05(\mathrm{p}<0.05)$

$\mathrm{N}=140$

$\mathrm{R}^{2}=0.505$ 
Table A6. OLS Regression for Violent Crimes with ‘\% Female Lone Parent’ Removed

\begin{tabular}{|l|r|r|c|c|}
\hline Independent Variables & Unstandardized B Coefficient & Significance (p-value) & Tolerance & VIF \\
\hline \% 17 Under & -.052 & .236 & .720 & 1.389 \\
\hline \% 18-34 & .001 & .657 & .720 & 1.389 \\
\hline \% 55 Plus & -.232 & $.010 *$ & .719 & 1.391 \\
\hline \% Female & .323 & $.009 *$ & .852 & 1.174 \\
\hline \% Single & .001 & .674 & .928 & 1.077 \\
\hline \% Couple & -.541 & $.000 *$ & .807 & 1.238 \\
\hline \% No Education & .007 & $.002 *$ & .773 & 1.294 \\
\hline \% Low Income & .016 & $.000 *$ & .497 & 2.010 \\
\hline \% Unemployed & .046 & $.011 *$ & .490 & 2.042 \\
\hline \% Male Aged 15-24 & .024 & .077 & .671 & 1.491 \\
\hline
\end{tabular}

* Significant at $0.05(p<0.05)$

$\mathrm{N}=140$

$\mathrm{R}^{2}=0.680$

Table A7. OLS Regression for Violent Crimes with '\% No Education' Removed

\begin{tabular}{|l|r|r|c|c|}
\hline Independent Variables & Unstandardized B Coefficient & Significance (p-value) & Tolerance & VIF \\
\hline \% 17 Under & -.076 & .090 & .707 & 1.415 \\
\hline \% 18-34 & $-8.531 \mathrm{E}-5$ & .968 & .746 & 1.340 \\
\hline \% 55 Plus & -.246 & $.007 *$ & .721 & 1.387 \\
\hline \% Female & .304 & $.017 *$ & .817 & 1.224 \\
\hline \% Single & .002 & .498 & .912 & 1.097 \\
\hline \% Couple & -.567 & $.000 *$ & .744 & 1.344 \\
\hline \% Low Income & .014 & $.000 *$ & .486 & 2.059 \\
\hline \% Unemployed & .047 & $.012 *$ & .476 & 2.101 \\
\hline \% Male Aged 15-24 & .025 & .076 & .668 & 1.498 \\
\hline \% Female Lone Parent & .026 & $.018 *$ & .601 & 1.664 \\
\hline
\end{tabular}

* Significant at $0.05(p<0.05)$

$\mathrm{N}=140$

$\mathrm{R}^{2}=0.670$ 
Table A8. OLS Regression for Violent Crimes with ‘\%No Education’ and ‘\% Female Lone Parent' Removed

\begin{tabular}{|l|r|r|c|c|}
\hline Independent Variables & Unstandardized B Coefficient & Significance (p-value) & Tolerance & VIF \\
\hline \% 17 Under & -.060 & .181 & .723 & 1.383 \\
\hline \% 18-34 & .000 & .864 & .749 & 1.336 \\
\hline \% 55 Plus & -.281 & $.002 *$ & .741 & 1.349 \\
\hline \% Female & .377 & $.003 *$ & .869 & 1.150 \\
\hline \% Single & .001 & .722 & .928 & 1.077 \\
\hline \% Couple & -.508 & $.000 *$ & .822 & 1.216 \\
\hline \% Low Income & .016 & $.000 *$ & .497 & 2.010 \\
\hline \% Unemployed & .059 & $.001 *$ & .516 & 1.937 \\
\hline \% Male Aged 15-24 & .029 & $.040 *$ & .679 & 1.473 \\
\hline
\end{tabular}

* Significant at $0.05(p<0.05)$

$\mathrm{N}=140$

$\mathrm{R}^{2}=0.655$ 


\section{GLOSSARY OF TERMS}

Assault: The direct or indirect application of force to another person, or the attempt or threat to apply force to another person, without that person's consent. This does not include domestic related occurrences. A domestic relationship is deemed to be a intimate relationship which includes common-law and by marriage (Toronto Police Service, 2016).

Auto Theft: The act of taking or another person's vehicle (not including attempts). Auto Theft figures represent the number of vehicles stolen (Toronto Police Service, 2016).

Break and Enter: The act of entering a place with the intent to commit an indictable offence therein (Toronto Police Service, 2016).

Occurrence: A written document that reflects an occurrence, unusual problem, incident, deviation from standard practice, or situation that requires follow-up action (Toronto Police Service, 2016).

Offence: is a violation against the Criminal Code of Canada or other federal statute, provincial act, or municipal by-law. Offences are counted in the year they occurred rather than the year the offence is reported to the police (Toronto Police Service, 2016).

Offenders Charged: Offenders who have been charged with an offence(s) under the Canadian Criminal Code (Toronto Police Service, 2016).

Property Crime: includes actual and attempted motor vehicle theft, other theft, actual and attempted break and enters, possession of stolen property, mischief and fraud etc. These are counted by the number of occurrences (Toronto Police Service, 2016).

Robbery: The act of taking property from another person or business by the use of force or intimidation in the presence of the victim (Toronto Police Service, 2016).

Sexual Assault: A wide range of offences fall under the Sexual Assault category, including sexual assault (s. 271), sexual assault with a weapon, threats to a third party or causing bodily harm (s. 272), aggravated sexual assault (s. 273), administering drugs for sex (s. 212), indecent assault (s. 141, 149, 148, 156) sexual interference (s. 151), invitation to sexual touching (s. 152), and sexual exploitation (s. 153). It refers to any type of sexual activity that is not consented to. Behaviours may range in severity from gestures, verbal assaults and attempts, to forced penetration, disfigurement and endangerment of life. More so than with any other type of crime, sexual assaults (including child abuse) are often reported to police long after the incident has taken place, if they are reported at all. This number represents the number of sexual assaults that 
were reported to police and that were said to have occurred during the indicated week. It should not be taken to represent all sexual assaults that actually occurred during that week. Although weekly totals may not reflect incidents that were reported later in the year, year-to-date totals reflect the most current data available as of the date indicated (Toronto Police Service, 2016).

Theft Over: The act of stealing property in excess of \$5,000 (excluding auto theft) (Toronto Police Service, 2016).

Violent Crime: Involve the use or threatened use of violence against a person, including homicide, attempted murder, nonsexual assault, sexual assault, abduction and robbery. Robbery is considered a violent crime because, unlike other theft offences, it involves the use or threat of violence. These are counted by the number of victims (Toronto Police Service, 2016). 